UNIVERSIDADE DE SÃO PAULO

FACULDADE DE ECONOMIA, ADMINISTRAÇÃO E CONTABILIDADE DEPARTAMENTO DE ADMINISTRAÇÃO PROGRAMA DE PÓS-GRADUAÇÃO EM ADMINISTRAÇÃO

CAROLINE FOSCACHES DE OLIVEIRA QUEVEDO

A lógica nas escolhas dos mecanismos de governança: a influência da identidade social 

Prof $^{\circ}$. Dr. Marco Antonio Zago

Reitor da Universidade de São Paulo

Prof ${ }^{\circ}$. Dr. Adalberto Américo Fischmann

Diretor da Faculdade de Economia, Administração e Contabilidade Prof $^{\mathrm{o}}$. Dr. Roberto Sbragia

Chefe do Departamento de Administração

Prof $^{\circ}$. Dr. Moacir de Miranda Oliveira Júnior

Coordenador do Programa de Pós-Graduação em Administração 



\section{A lógica nas escolhas dos mecanismos de governança: a influência da identidade social}

Tese apresentada ao Programa de PósGraduação em Administração do Departamento de Administração da Faculdade de Economia, Administração e Contabilidade da Universidade de São Paulo, como requisito parcial para a obtenção do título de Doutor em Ciências.

Orientadora: Prof ${ }^{a}$. Dr ${ }^{a}$. Maria Sylvia Macchione Saes

Versão corrigida

(versão original disponível na Biblioteca da Faculdade de Economia, Administração e Contabilidade)

SÃO PAULO 
Autorizo a reprodução e divulgação total ou parcial deste trabalho, por qualquer meio convencional ou eletrônico, para fins de estudo e pesquisa, desde que citada a fonte.

FICHA CATALOGRÁFICA

Elaborada pela Seção de Processamento Técnico do SBD/FEA/USP

Quevedo, Caroline Foscaches de Oliveira

A lógica nas escolhas dos mecanismos de governança: a influência da identidade social / Caroline Foscaches de Oliveira Quevedo. - São Paulo, 2016.

$139 \mathrm{p}$

Tese (Doutorado) - Universidade de São Paulo, 2017.

Orientador: Maria Sylvia Macchione Saes.

1. Custo de transação 2. Identidade social 3. Mecanismos de governança 4. Cooperativas I. Universidade de São Paulo. Faculdade de Economia, Administração e Contabilidade. II. Título.

CDD - 338.5142 


\section{AGRADECIMENTOS}

Agradeço a Deus pelo privilégio de realizar e concluir este trabalho com êxito. Pela paz que Ele me deu nos momentos difíceis e pela oportunidade que recebi d'Ele de conhecer pessoas maravilhosas durante o período do doutorado.

Agradeço ao meu marido, Filipe, pelo companheirismo, conselhos, ajudas, consolos e conforto que ele me proporcionou durante esse trabalho. Certamente, teria sido muito mais difícil sem a companhia e o apoio dele. Agradeço também aos meus pais, Manoel e Graciela, que sempre fizeram o possível para priorizar a formação dos filhos.

Agradeço à minha orientadora, $\operatorname{Prof}^{\mathrm{a}}$. Dr $^{\mathrm{a}}$. Sylvia Saes, pela sabedoria, tempo e paciência dedicados ao meu trabalho, pela forma com que lida com os seus alunos e pela sua dedicação incansável à pesquisa. Só posso admirá-la mais. Agradeço também ao apoio da FAPESP (Fundação de Amparo à Pesquisa do Estado de São Paulo) para a realização da pesquisa. Sou grata também às pessoas do assentamento visitado, que nos receberam e nos acolheram tão bem. Foi uma ótima experiência.

Por fim, agradeço aos meus amigos, Ellen, Filipe, Helton, Jemima, Maísa e Mia, os quais se tornaram minha família e fizeram com que esse período fosse muito mais leve e prazeroso. Agradeço também aos amigos do Cors e do Pensa, com os quais pude conversar e trocar experiências ao longo da pesquisa, e aos professores e amigos do projeto Casadinho.

Muito obrigada! 



\section{RESUMO}

FOSCACHES, C. A lógica nas escolhas dos mecanismos de governança: a influência da identidade social. Tese (Doutorado em Administração) Universidade de São Paulo, São Paulo, 2016.

A Economia dos Custos de Transação (ECT) é uma das abordagens da Nova Economia Institucional (NEI); a ECT é vista como uma das principais teorias referentes aos limites das firmas, discussão que começou a ser desenvolvida a partir do trabalho de Ronald Coase, de 1937. Apesar da importância e das contribuições da NEI e da ECT para o desenvolvimento da teoria das organizações, algumas críticas têm sido feitas a elas, particularmente no que diz respeito ao tratamento da questão social. Dentre as críticas, destaca-se a de Granovetter (1985), para quem a NEI reforça a visão econômica de subsocialização do indivíduo, considerando-o, assim, fora de um contexto social, isto é, o indivíduo atua de forma atomizada. Williamson (2000) cita a necessidade da NEI se atentar para o nível do enraizamento social. Na mesma linha, Van de Ven e Lifschitz (2013) criticam a pouca atenção dada pela ECT para esse contexto. Nesse sentido, um conceito que tem ganhado espaço tanto no campo social como no organizacional é o conceito de identidade social, fazendo com que alguns autores passem a considerar esse fator em suas análises, inclusive dentro da ECT. Apesar de ser possível verificar esse avanço, o mesmo ainda é incipiente. Dessa forma, este trabalho tem como objetivo aprofundar essa temática dentro da área de economia das organizações, buscando analisar qual a influência da identidade social sobre a escolha dos mecanismos de governança. Para tanto, foi realizada uma pesquisa quantitativa em um assentamento de reforma agrária. Esse objeto de pesquisa se mostrou interessante, uma vez que os produtores pertencentes a esse assentamento entregam sua produção por meio de mecanismos de governança distintos, apesar de ser possível observar semelhanças nas características transacionais do meio; além disso, no assentamento, pode-se verificar que o contexto social exerce importância para determinadas decisões. Para coletar os dados, foram realizadas entrevistas, por meio de um questionário semiestruturado, junto aos produtores. No assentamento em análise, vivem cerca de 410 famílias, sendo que a amostra foi de 109 famílias/produtores. A análise dos resultados se deu por meio de uma regressão logística. Por meio da análise, pôde-se verificar que as formas híbridas prevalecem, com destaque para os contratos relacionais junto a atravessadores. Destaca-se também o uso da forma de governança híbrida incentivada pelo grupo, no caso, via cooperativas do assentamento; foi constatado que a identidade social influencia positivamente tanto no uso 
como no favorecimento de formas cooperativas para a venda dos produtos produzidos pelos assentados, o que indica que esse aspecto influencia e deve ser levado em consideração na decisão do mecanismo de governança, especificamente em ambientes cujo aspecto social e grupal esteja enraizado no cotidiano dos indivíduos.

Palavras-chave: Economia dos Custos de Transação. Identidade Social. Mecanismos de Governança. Cooperativas. 


\begin{abstract}
FOSCACHES, C. The logic in the choice of the mechanisms of governance: the influence of social identity. Tese (Doutorado em Administração) Universidade de São Paulo, São Paulo, 2016.
\end{abstract}

Transaction Costs Economics (TCE) is an approach of the New Institutional Economics (NIE). TCE is seen as one of the most important theories regarding boundaries of firms, and discussions started with the paper from Ronald Coase, in 1937. Despite the importance and contributions of NIE and TCE to the development of the theories of firms, some have been critical of them, particularly concerning the treatment of social issues. Granovetter stands out among the critics, and according to Granovetter (1985), the NIE reinforces the economic vision of sub-socialization of the individual, considering it out of a social context, that is, that individuals act in an atomized way. Williamson (2000) mentions the necessity of paying attention to the embedded level; similarly, Van de Ven and Lifchitz (2013) criticize the little attention given to the social context by the TCE. Social identity is a concept that recognizes the social and organizational areas, and some authors consider this factor in their analysis, including the TCE. Although this is advanced, it is still developing. Thus, this project aims to deepen this theme within economics of the organization area, and tries to analyze the influence of social identity on the choice of the mechanisms of governance. To accomplish this, a quantitative research in a settlement of land reform was conducted. The objective of the research is interesting due to the producers belonging to the settlement deliver their production through different mechanisms of governance, although it is possible to note similarities in the characteristics of the transactions. Furthermore, in the settlement, it is possible to verify that social context has importance for some decisions. To collect the data, interviews were conducted through a semi-structured questionnaire. In the settlement, there are 410 families; the sample was composed of 109 families/producers and the results were found through a logistic regression. Through the analysis, it was possible to verify that hybrid forms prevail, especially relational contracts with brokers. I also highlight the use of hybrid form of governance encouraged by the group, in this case, transactions via cooperatives; it was found that social identity positively influences both the use and the fostering of cooperatives forms to the selling of products from settlers, indicating that this aspect is influential and must be considered in the decision of mechanism of governance in environments, specifically where the social and group aspects are embedded in the daily lives of individuals. 
Keywords: Transactions Costs Economics. Social Identity. Mechanisms of Governance. Cooperatives. 


\section{LISTA DE FIGURAS}

Figura 1 - Estrutura de governança e especificidade de ativos.............................................. 28

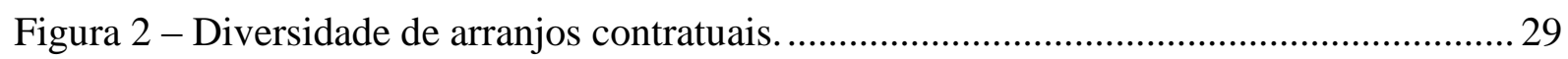

Figura 3 - Esquema de três níveis de Williamson............................................................ 32

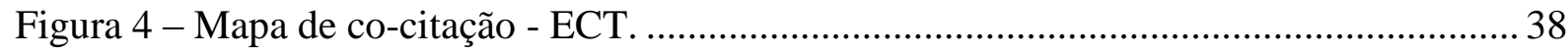

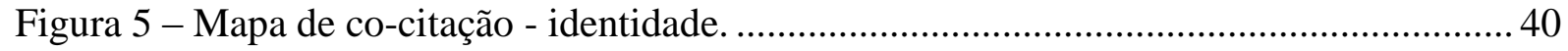

Figura 6 - Mapa de co-citação - microfundamentos.............................................................. 42

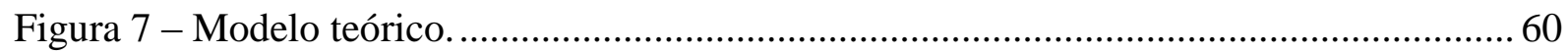

Figura 8 - Cadeia de produção dos produtos do assentamento analisado. ............................ 71

Figura 9 - Distribuição dos entrevistados nas agrovilas. .................................................... 82

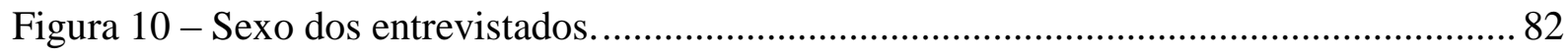

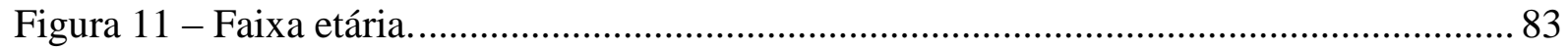

Figura 12 - Nível de escolaridade dos assentados entrevistados......................................... 83

Figura 13 - Participação no processo de ocupação do assentamento em análise. .................... 84

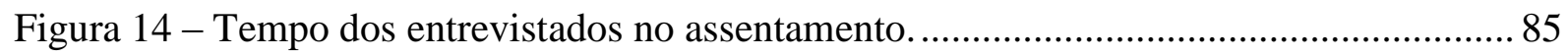

Figura 15 - Principal produto de venda dos assentados..................................................... 86

Figura 16 - Mecanismos de governança adotados......................................................... 88

Figura 17 - Estruturas conceitual e operacional da pesquisa.............................................. 90 


\section{LISTA DE QUADROS}

Quadro 1: Os 10 trabalhos mais citados na área de ECT.

Quadro 2: Os 10 trabalhos mais citados na área de identidade .............................................. 39

Quadro 3: Os 10 trabalhos mais citados na área de microfundamentos.................................. 42

Quadro 4: Autores em comum nas áreas de ECT, Identidade Social e Microfundamentos. ... 43

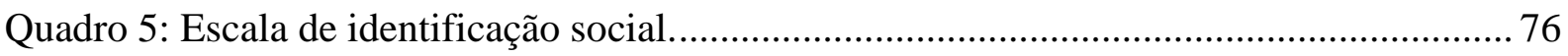

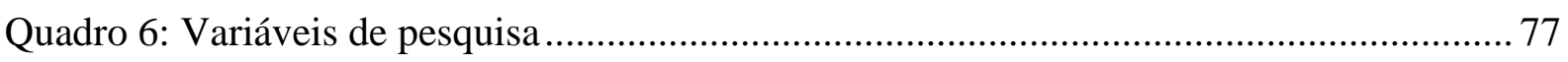

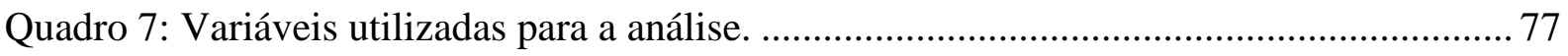

Quadro 8: Hipóteses de pesquisa e sinal esperado............................................................... 93

Quadro 9: Resultado das hipóteses de pesquisa. .................................................................. 102 


\section{LISTA DE TABELAS}

Tabela 1 - Caracterização das áreas do assentamento .......................................................... 70

Tabela 2 - Participação em cooperativas ou associações. ...................................................... 85

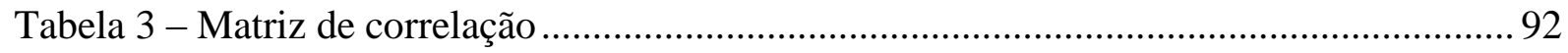

Tabela 4 - Modelo - variável dependente: mecanismo de governança.................................. 95

Tabela 5 - Modelo - variável dependente: favorecimento à cooperativa. ............................ 101 



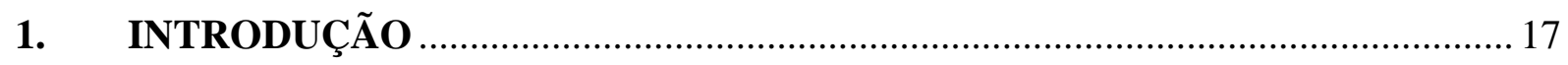

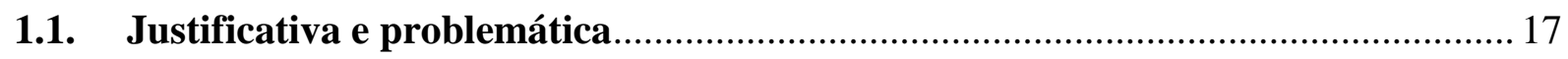

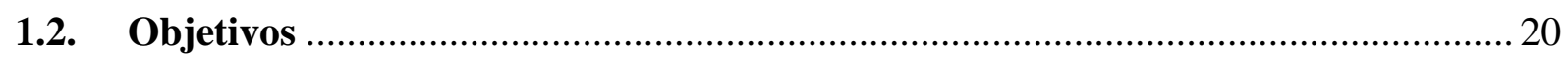

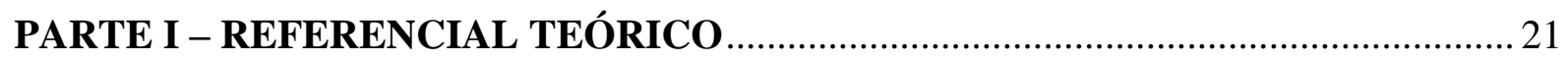

2. A NOVA ECONOMIA INSTITUCIONAL E SEUS NÍVEIS DE ANÁLISE ........ 23

2.1. A Economia dos Custos de Transação e as estruturas de governança .................... 25

3. ECONOMIA DOS CUSTOS DE TRANSAÇÃO, IDENTIDADE E MICROFOUNDATIONS: UM ESTUDO BIBLIOMÉTRICO ………………………........... 35

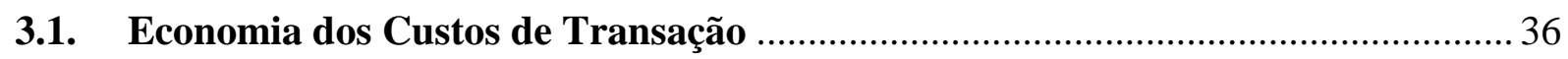

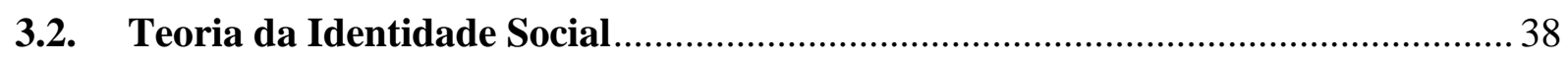

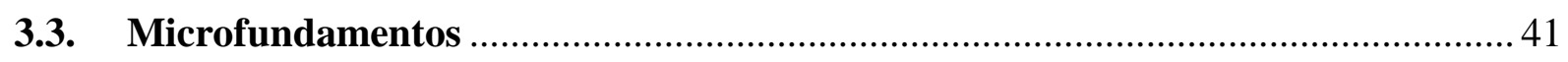

4. UMA NOVA PERSPECTIVA DOS MICROFUNDAMENTOS PARA A ECT:

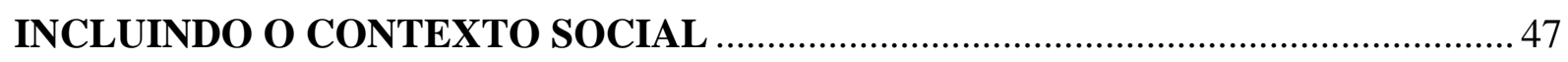

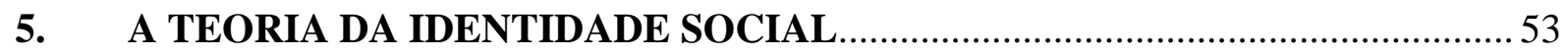

5.1. A identidade social e a Economia dos Custos de Transação ……………………......57

6. MODELO TEÓRICO E HIPÓTESES DE PESQUISA ………………………….....59

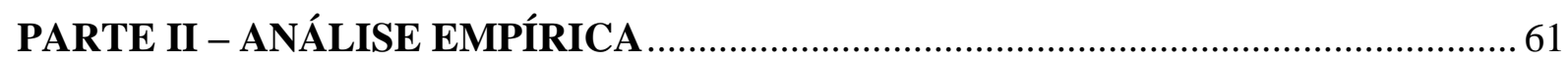

7. A REFORMA AGRÁRIA E A ORIGEM DO MOVIMENTO DOS

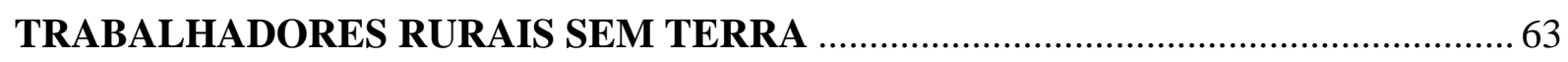

7.1. O surgimento do assentamento objeto de estudo dessa pesquisa.............................67

8. PROCEDIMENTOS METODOLÓGICOS ……………………………….........

8.1. Objetivo da pesquisa ………………………………………………………. 73

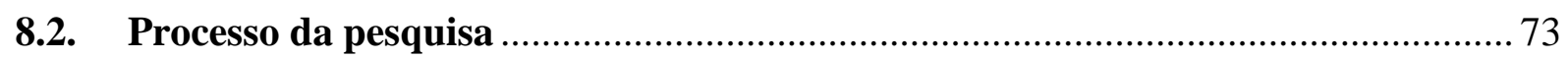

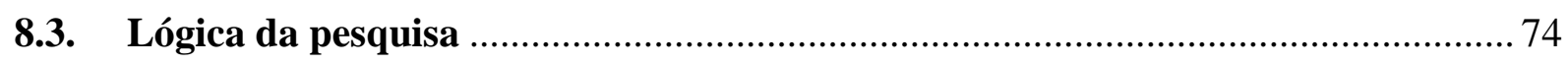

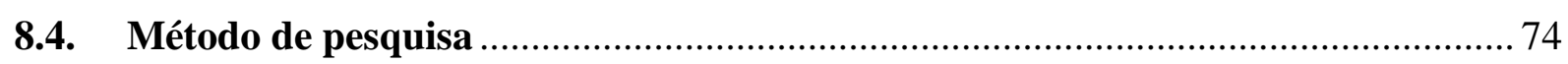

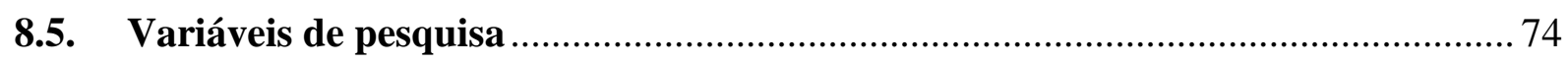

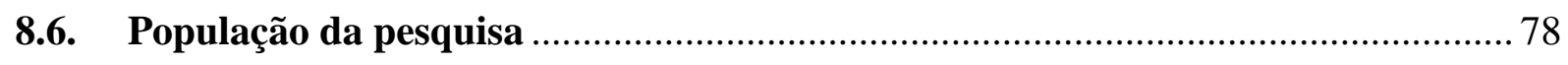

8.7. Procedimento de coleta de dados ...................................................................... 79

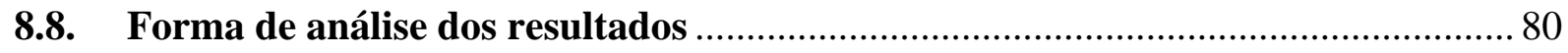


9. ANÁLISE E DISCUSSÃO DOS RESULTADOS ….......................................... 81

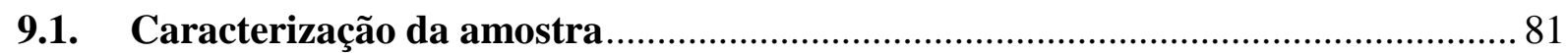

9.2. Caracterização da produção e mecanismos de governança utilizados ................... 85

9.3. Influência da identidade social sobre a escolha organizacional ............................ 89

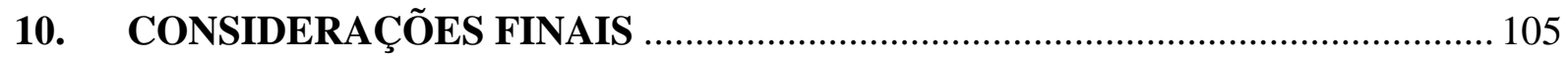

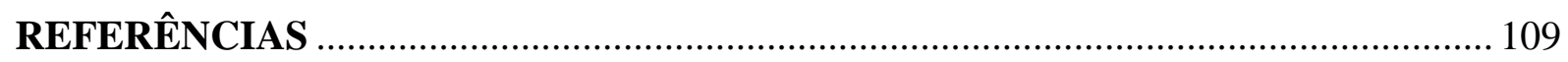

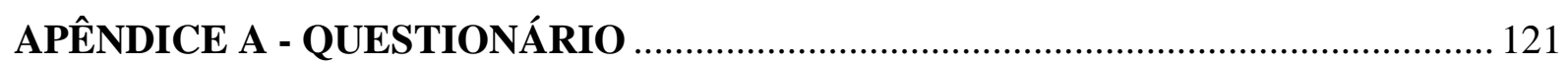

APÊNDICE B - TESTES DA REGRESSÃO LOGÍSTICA …....................................... 136

APÊNDICE C - DECLARAÇÃO DE AUTORIZAÇÃO DE PESQUISA ..................... 139 


\section{INTRODUÇÃO}

A fim de conduzir as transações, as firmas lançam mão de diferentes estruturas de governança. Uma questão presente nas análises dessas relações é explicar a lógica dessas escolhas. A escola que domina as pesquisas referentes aos limites das firmas é a Economia dos Custos de Transação (ECT), que tem Oliver Williamson como principal autor. Os questionamentos relacionados aos limites da firma, no entanto, surgiram antes, com Ronald Coase, autor responsável pela obra The Nature of the Firm, de 1937. Essa temática veio à tona novamente apenas nas décadas de 1970 e 1980, quando Oliver Williamson permitiu a operacionalização dos conceitos elaborados por Coase.

Williamson contribuiu para o avanço teórico desta questão, ao propor uma lógica econômica a redução dos custos de transação - à motivação das escolhas das formas organizacionais pelos agentes econômicos. Dessa forma, segundo a teoria, existe um alinhamento ótimo entre as características transacionais (frequência, incerteza e especificidade de ativos) e as estruturas de governança (mercado, formas híbridas e hierarquia). A redução dos custos de transação se dá via esse alinhamento.

Na visão williamsoniana, a combinação da racionalidade limitada e do oportunismo é o ponto de partida para a existência dos custos de transação (WILLIAMSON, 1985). Ou seja, a impossibilidade de prever todas as contingências futuras pode resultar em ações oportunistas, que possibilitem ganhos, o que cria o potencial de hold-up ${ }^{l}$ (KLEIN; CRAWFORD; ALCHIAN, 1978; WILLIAMSON, 1985). Na literatura, é possível encontrar diversos trabalhos que testaram a teoria proposta por Williamson (RUESTER, 2010).

\subsection{Justificativa e problemática}

\footnotetext{
${ }^{1}$ Uma situação de hold-up ocorre quando uma das partes em uma relação contratual força a renegociação, visando apropriar-se da quase renda decorrente dos investimentos específicos realizados, o que é possível em razão da incompletude contratual (KLEIN, 2000).
} 
Apesar de se caracterizar como a abordagem dominante na área da economia das organizações, a ECT tem recebido críticas decorrentes de evidências contrárias à lógica do alinhamento, dentre elas, está o fato da teoria não possuir poder explicativo para o uso simultâneo de formas de governança. Estudos têm demonstrado que as firmas podem utilizar estruturas organizacionais distintas para coordenar a mesma transação, fenômeno caracterizado como formas plurais (BRADACH; ECCLES, 1989; MÉNARD et al., 2014).

Outra crítica à teoria se refere à forma com que essa trata do aspecto social. Segundo Van De Ven e Lifschitz (2013), a ECT considera como exógenas as relações sociais presentes nas transações. Anteriormente, alguns estudos já buscaram evidenciar a importância dos aspectos sociais na determinação das relações econômicas. Sob a influência da sociologia econômica, que surge na década de 1980, destaca-se o artigo de Granovetter (1985), Action and Social Structure: the problem of embeddeness, que critica a incapacidade da ECT de endogeneizar as estruturas sociais no corpo teórico da Nova Economia Institucional. Foss (2004) critica a ECT dentro desse quadro geral, no qual a teoria não admite que questões sociais sejam conduzidas de forma diferenciada entre os agentes econômicos. Para o autor, o ambiente institucional em que os indivíduos interagem influencia não apenas as restrições objetivas, mas também como estes se enquadram na interação.

Em relação aos aspectos sociais, um conceito que vem ganhando destaque tanto no campo social como no campo econômico e organizacional é o conceito de identidade em relação ao grupo, ou identidade social. Quando se analisa a identidade social, tem-se o indivíduo como unidade de análise; mais precisamente, o sentimento de pertencimento desse indivíduo em determinado grupo. O indivíduo como unidade de análise e suas interações corresponde ao que Felin e Foss (2005) denominam de microfundamento. Entretanto, tal análise é um desafio. Segundo os autores, tomar o indivíduo como unidade fundamental pode trazer importantes contribuições para a área de estratégia, além deste ser um campo ainda pouco explorado.

O conceito de identidade foi inicialmente desenvolvido por Tajfel, na década de 1970, na área da psicologia social. Mais tarde Tajfel e Turner (1986) buscaram apresentar a teoria da identidade social, dando ênfase à teoria do comportamento intergrupo. Nesse trabalho, os autores apresentaram o conceito de grupo, bem como o de categoria social, sendo que esse último é uma ferramenta cognitiva que classifica o ambiente e direciona a ação do indivíduo. Com base nessas definições, os autores estabeleceram o conceito de identidade social, a qual é 
constituída pelos aspectos da autoimagem do indivíduo. Tais aspectos são derivados da categoria social da qual o sujeito se sente membro. De forma resumida, Ashforth e Mael (1989) definem identificação como a percepção de pertencimento a um grupo.

No campo da identidade aplicada à economia, destacam-se Akerlof e Kranton. O interesse por essa temática levou os autores a criarem o conceito economia da identidade. Para Akerlof e Kranton (2010), quando a identidade é inserida na teoria econômica, passa-se a analisar o homem em um contexto social, e não apenas o homo economicus, considerado nos modelos econômicos previamente estabelecidos. Para os autores, é preciso considerar três conceitos importantes para compreender a identidade, e são eles: norma, categoria social e utilidade da identidade. Segundo os autores, quando o indivíduo, que está inserido em uma determinada categoria social, age de forma diferente do que a norma espera para essa categoria, acredita-se que o mesmo perca utilidade da identidade. Para compensar essa perda, é preciso dar a ele outro incentivo, como o monetário, por exemplo (AKERLOF; KRANTON, 2005).

Tem-se, portanto, que a identidade social é um importante fator a ser considerado para a análise das transações, não apenas para ajudar a sanar as críticas feitas à ECT em relação à forma como o fator social é inserido na análise, mas também com vistas a aproximar ainda mais a teoria ao mundo real.

Apesar disso, pouco se tem avançado nesse sentido. De acordo com Boulu-Reshef (2013), o contexto social, o qual é pouco trabalhado na teoria da firma, pode ser mais bem desenvolvido tendo como base a literatura sobre identidade. Dessa forma, esta pesquisa busca contribuir para o preenchimento dessa lacuna. Por meio de uma busca nas bases de periódicos, foi possível observar uma pequena quantidade de trabalhos que abordaram a questão da identidade social no campo da ECT. Nessa abordagem, o conceito foi discutido por Kogut e Zander (1996); os autores buscaram explicar por que a transferência de conhecimento é mais provável dentro das firmas do que entre firmas. Para esses autores, a identidade do agente dentro do grupo é uma variável que explica esse questionamento. A relação entre identidade e ECT foi estudada também por Morita e Servátka (2013), os quais buscaram testar a relação entre identidade em relação ao grupo e a ocorrência de hold-up.

O interesse desta pesquisa segue no sentido de encontrar evidências e novos entendimentos que expliquem as decisões dos agentes na adoção de estruturas de governança, buscando incorporar 
a identidade social à análise, identificando como ela condiciona a decisão de coordenar a transação via mercado spot, formas híbridas ou integração vertical, objetivando, assim, incluir novos elementos à teoria proposta por Williamson, bem como identificar de que forma a identidade social se insere nos atributos das transações especificados pelo autor.

Dessa forma, diante do contexto apresentado, a questão da presente pesquisa fica apresentada da seguinte forma: qual a influência da identidade social sobre a escolha dos mecanismos de governança?

\subsection{Objetivos}

Este trabalho tem como objetivo geral analisar a influência da identidade social sobre a escolha dos mecanismos de governança. Especificamente, busca-se:

a) Testar a hipótese do alinhamento ótimo entre mecanismos de governança e características das transações;

b) Definir uma escala de identidade social;

c) Avaliar de que forma o mecanismo de governança é influenciado pela identidade social dos indivíduos.

Este trabalho está organizado em duas partes, além desta introdução. A Parte I trata dos aspectos teóricos necessários ao entendimento do fenômeno abordado por este trabalho. Em seguida, na Parte II, detalha-se a metodologia de pesquisa aplicada e apresentam-se os resultados empíricos encontrados. 
PARTE I - REFERENCIAL TEÓRICO

Esta seção trata dos aspectos teóricos necessários para a compreensão do fenômeno analisado neste trabalho, que tem como objetivo analisar a influência da identidade social sobre a escolha dos mecanismos de governança. Para tanto, primeiramente apresenta-se a Nova Economia Institucional e uma de suas abordagens, a Economia dos Custos de Transação, explorando-se também algumas críticas referentes a ela, dando ênfase à questão dos microfundamentos e, em particular, à teoria da identidade social, a qual tem se mostrado um campo de interesse crescente. Após esse apontamento, será apresentado um estudo bibliométrico, buscando-se analisar de que forma a Economia dos Custos de Transação, os Microfundamentos e a Identidade Social se relacionam na literatura, e quais os aspectos teóricos tratados nessa lógica. Por fim, aprofundam-se a definição dos microfundamentos e da identidade social e apresentamse o modelo teórico e as hipóteses de pesquisa. 


\section{A NOVA ECONOMIA INSTITUCIONAL E SEUS NÍVEIS DE ANÁLISE}

De acordo com Furubotn e Richter (2000), a principal mensagem passada pela Nova Economia Institucional (NEI) é a de que as instituições são importantes para o desempenho econômico. Em relação ao seu surgimento, cabe ressaltar que a mesma não despontou de forma planejada, mas sim a partir de uma tentativa de estender a aplicabilidade da teoria neoclássica (FURUBOTN; RICHTER, 2000). Ronald Coase foi um dos grandes responsáveis pelo surgimento e pelos avanços da NEI (ZYLBERSZTAJN, 2000). Para Zylbersztajn (2000), o trabalho de Ronald Coase, The Nature of the Firm, permitiu o desenvolvimento de um novo modelo para o estudo das organizações. Além de Ronald Coase, Williamson (2000) destaca outros autores como fundamentais para os avanços da NEI, dentre eles: Kenneth Arrow, Friedrich Hayek, Gunnar Myrdal, Herbert Simon, Douglas North e Armen Alchian.

A fim de tratar dos aspectos da Nova Economia Institucional, Williamson (2000) apresenta quatro níveis de análise social: i) de enraizamento social, que considera as normas, os costumes, as tradições etc; ii) nível do ambiente institucional, o qual aborda as regras formais, considerando os poderes executivos, legislativos e judiciário e, portanto, indo além do primeiro nível; iii) nível das instituições de governança, que trata da governança das relações contratuais entre os agentes e; iv) nível que aborda os incentivos de preço e quantidade. Conforme o autor, a NEI possui como foco principal os níveis ii e iii. Dessa forma, de acordo com Furubotn e Richter (2000), pode-se considerar que a NEI possui dois níveis analíticos, um macroscópico, que tem como foco o ambiente institucional, e um nível microscópico, que analisa os diferentes arranjos organizacionais.

No que diz respeito ao nível macro, Douglas North é responsável por muito dos avanços feitos. $\mathrm{O}$ autor destaca que o quadro institucional possui importância para as organizações, especialmente no que se refere ao seu desenvolvimento (NORTH, 1990), uma vez que as instituições são definidas como as "restrições concebidas pelos seres-humanos que estruturam a interação política, econômica e social" (NORTH, 1991, p. 97). Tais restrições incluem o que os indivíduos não podem fazer, bem como sob quais condições os indivíduos podem executar determinada atividade (NORTH, 1990). Dessa forma, as instituições levam a uma redução da incerteza, uma vez que provêm estrutura para o dia a dia (NORTH, 1991). Para Furubotn e Richter (2000), as instituições possuem o objetivo de dirigir os indivíduos. 
As instituições podem ser classificadas tanto como formais quanto informais. As instituições formais incluem constituições, leis e direitos de propriedade. Por outro lado, as restrições informais se referem aos costumes, tradições, códigos de conduta, entre outros. Portanto, de maneira geral, as instituições podem ser definidas como as regras do jogo da sociedade (NORTH, 1990). Helmke e Levitsky (2004, p. 727) definem as regras informais como "regras sociais compartilhadas", que geralmente estão em formato não escrito e são transmitidas sem um canal oficial.

O tempo necessário para que aconteçam mudanças pode ser rápido, quando se trata de regras formais, uma vez que tais regras dependem de decisões políticas ou sociais. Por sua vez, as restrições informais são mais difíceis de serem mudadas, pois estão internalizadas na sociedade (NORTH, 1990). Para Helmke e Levitsky (2004), no entanto, as instituições informais podem mudar de forma rápida, ao contrário do que geralmente é pensado. Ainda segundo os autores, essa mudança pode ser decorrente de alterações nas instituições formais, bem como nos valores de determinada sociedade.

North (1997), de toda forma, afirma que se deve levar em conta o efeito do ambiente institucional sobre o desempenho econômico. Para ele, um conjunto de regras, tanto de caráter político como econômico, que provê baixo custo de transações e acordos críveis torna possível a eficiência nos mercados de produtos e fatores. Além disso, o autor afirma que uma função básica das instituições é prover estabilidade, o que possibilita a realização de trocas complexas (NORTH, 1997).

Segundo Nelson (2007), após a publicação da obra de North, de 1990, o interesse acerca da influência das instituições sobre o crescimento econômico se tornou maior. No entanto, de acordo com Nelson e Sampat (2001), o termo instituições tem sido utilizado com diferentes significados, sendo que ainda falta consenso no seu conceito. Apesar disso, segundo os autores, esses significados possuem algumas semelhanças. Com base nisso, os autores buscaram desenvolver um conceito de instituições aplicável à atividade econômica, mais especificamente ao crescimento econômico. Para desenvolver esse conceito, os estudiosos passaram a considerar as tecnologias sociais, além da tecnologia física, e fazerem uma associação entre instituições e tecnologias sociais, as quais são referentes à forma como as pessoas agem e interagem em um contexto no qual esses aspectos são fundamentais e, portanto, se tornam uma norma. Dessa 
forma, as tecnologias sociais podem ser entendidas como o "comportamento institucionalizado". Sendo assim, as rotinas possuem um papel fundamental (NELSON; SAMPAT, 2001, p. 41). Nessa definição, as instituições são entendidas como "os fatores e forças que moldam e mantém no lugar as tecnologias sociais" (NELSON, 2007, p. 3, tradução nossa).

Quanto ao nível micro de análise da NEI, que trata das relações contratuais, tem-se como uma das principais correntes a Economia dos Custos de Transação, cujo autor principal é Oliver Williamson. A teoria é apresentada com maior detalhe na seção seguinte.

\subsection{A Economia dos Custos de Transação e as estruturas de governança}

A questão estratégica das firmas e, particularmente, seus limites têm sido abordados por diversos autores ao longo dos últimos anos. O autor que deu início a tais questionamentos foi Ronald Coase, com a publicação de seu trabalho The Nature of the Firm, em 1937. Coase (1937) buscava entender qual a verdadeira função da firma. Para o autor, a visão da firma como a função de produção, como era pensado pelos economistas neoclássicos, não correspondia à sua função na vida real. Para ele, a firma é um modo de governança alternativo ao mecanismo de preço, o qual pode ser substituído por algumas razões, sendo que a principal é o fato de haver custos na utilização do mecanismo de preço, os chamados custos de transação (COASE, 1937). Seu interesse reside, portanto, em entender os limites da firma. O pesquisador argumenta que existe um ponto no qual se dá o limite das operações. Este acontece quando o custo de organizar uma atividade internamente é igual ao custo da coordenação no mercado ou por outra firma. Para o autor, a utilização do mercado incorre em custos de transação, os quais são: o custo de descobrir o preço vigente no mercado e o custo de negociação.

Dessa reflexão surgiu então a Economia dos Custos de Transação (ECT), a qual é uma das abordagens da Nova Economia Institucional. A teoria, desenvolvida por Oliver Williamson, permitiu operacionalizar o insight sobre os custos de transação abordados por Ronald Coase. Williamson define custos de transação como os custos para elaborar, negociar e salvaguardar um acordo, além dos custos de adaptação que surgem devido a um desalinhamento no cumprimento do contrato (WILLIAMSON, 1993). A Economia dos Custos de Transação, 
teoria que começou a ter maior destaque na década de 1970, é uma das principais abordagens que trata sobre os limites das firmas atualmente. Williamson se baseou em autores importantes das áreas de Economia, Direito e Organizações para a construção da teoria, como Knight, Commons, Simon e Coase (WILLIAMSON, 1985).

A teoria estabelece dois pressupostos comportamentais, os quais seriam os pontos de partida dos custos de transação; são eles: a racionalidade limitada e o oportunismo. De acordo com o pressuposto da racionalidade limitada, conceito elaborado por Simon (1971), o ser humano deseja ser racional, mas o é apenas de forma limitada e, portanto, não consegue prever todos os eventos futuros. Conforme Williamson (1993), dada a racionalidade limitada, os contratos tornam-se, inevitavelmente, incompletos, uma vez que não é possível prever todos os eventos futuros ex ante, o que abre espaço para a ação oportunista, o segundo pressuposto comportamental da teoria. O oportunismo é definido como a busca ávida pelo autointeresse, sendo a forma mais forte dessa busca, segundo Williamson (1985). É importante ressaltar que, para a ECT, a ação oportunista não precisa ser efetivada, basta apenas existir a chance de a mesma acontecer.

Além desses pressupostos, a teoria estabeleceu também as características das transações frequência, incerteza e especificidade de ativos (WILLIAMSON, 1979). Segundo o autor, os dois primeiros conceitos são claros. A frequência se refere ao grau de regularidade de uma transação, podendo ser recorrente ou ocasional. Um mecanismo de governança mais complexo é justificável, se uma transação acontece com maior frequência, dada a possibilidade de recuperar os custos incorridos para esse mecanismo. Esse atributo, no entanto, deve ser analisado em conjunto com a especificidade de ativos, atributo que será tratado nos próximos parágrafos; caso o ativo tenha um baixo nível de especificidade, o mercado se torna o mecanismo ideal tanto para transações ocasionais como recorrentes (WILLIAMSON, 1979).

A segunda característica, incerteza, está relacionada à própria incerteza que envolve a transação, que também pode ser entendida como um distúrbio proveniente de fora da firma (ZYLBERSZTAJN, 1995). Esse atributo pode ser derivado de três situações: o desconhecimento de eventos futuros, risco ou assimetria informacional (AZEVEDO, 1997). Williamson (1979) também analisa esse atributo juntamente com a especificidade para determinar o mecanismo de governança mais eficiente. Para o autor, mesmo se o nível de 
incerteza for elevado, caso não exista especificidade, o mercado continua sendo a forma que possibilita reduzir os custos de transação.

O terceiro atributo, no entanto, refere-se à especificidade do ativo e necessita de maior atenção, segundo Williamson (1979). Um ativo específico, ou idiossincrático, é aquele que perde seu valor, se empregado em um segundo melhor uso alternativo (WILLIAMSON, 1979). Quanto maior a perda de valor, maior o nível de especificidade do mesmo. Essa diferença de valores entre o melhor uso e o segundo melhor uso é chamada de quase renda (KLEIN; CRAWFORD; ALCHIAN, 1978). Conforme Williamson (1979), uma transação que envolve um ativo altamente específico cria uma situação de monopólio bilateral entre o comprador e o vendedor, pois ambos ficam altamente comprometidos com essa transação. Para uma transação como essa, é necessário que exista a certeza da continuidade da relação entre o comprador e o produtor. No entanto, deve-se levar em conta que os contratos são incompletos por natureza, dada a racionalidade limitada dos agentes, e que os indivíduos agem de forma oportunista, buscando adquirir sempre o maior ganho possível. Dessa forma, é preciso lançar mão de uma estrutura de governança que permita mitigar esses problemas.

A especificidade de ativos não envolve apenas os ativos físicos, mas é possível identificar também outros cinco tipos de especificidades: locacional, especificidade de ativos humanos, ativos dedicados, especificidade de marca e especificidade temporal (WILLIAMSON, 1991).

Para a ECT, existe um alinhamento ótimo entre as características transacionais e a estrutura de governança, o que permite economizar em custos de transação, como mostra a Figura 1. Assume-se, portanto, que existe um mecanismo de governança mais eficiente diante de determinados atributos da transação. Antes de detalhar cada mecanismo de governança, cabe, primeiramente, definir o conceito. Williamson (1979, p. 239, tradução nossa) define estrutura de governança como "a matriz institucional dentro da qual a integridade da transação é negociada e executada”. Dessa forma, para a ECT, é possível identificar três formas distintas de governança, sendo elas: o mercado, a forma híbrida e a hierarquia. 


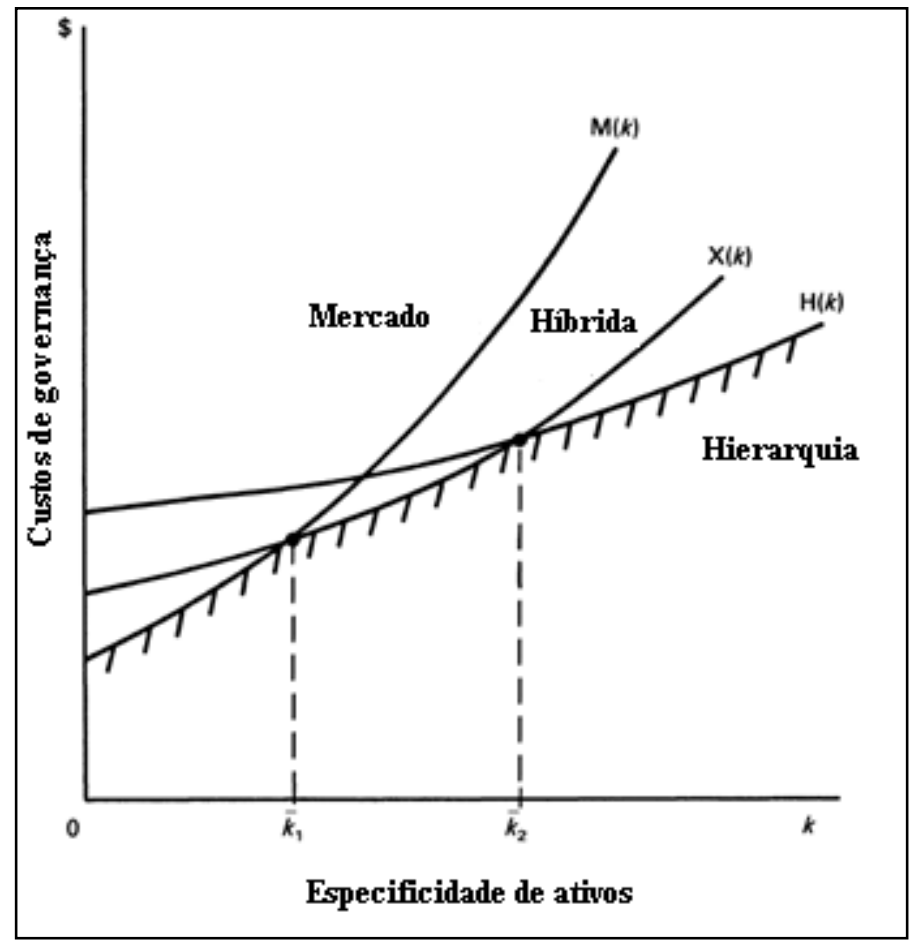

Figura 1 - Estrutura de governança e especificidade de ativos.

Fonte: adaptado de Williamson (1991, p. 284).

Deve-se destacar que a especificidade de ativos é o atributo mais importante para a escolha da forma organizacional ideal (WILLIAMSON, 1996). Dessa forma, quanto menor grau de especificidade do ativo, o mercado é a governança que permite reduzir os custos de transação. Por outro lado, quanto maior o nível de especificidade do ativo transacionado, a hierarquia é o mecanismo de governança mais eficiente. Para níveis intermediários de especificidade, a forma de governança adequada é a forma híbrida.

Segundo Williamson (1979), o mecanismo de governança de mercado acontece quando o vendedor e o comprador não desenvolvem um relacionamento e suas identidades não são importantes para a transação. Além disso, o produto envolvido na troca é encontrado com facilidade, sendo, portanto, um produto comum. Essa estrutura é viável, nessas condições, para transações que ocorrem de forma recorrente ou ocasional. Em relação à adaptação, nessa estrutura, esta acontece de forma unilateral. Para Williamson (1991), cada mecanismo é suportado por uma lei contratual distinta. No caso da estrutura de governança de mercado, o contrato utilizado é o contrato clássico.

A forma híbrida, por sua vez, encontra-se entre a estrutura de mercado e a hierarquia, possuindo características tanto de um extremo quanto de outro. Williamson (1993, p. 102, tradução nossa) 
a define como "relações contratuais de longo prazo que preservam a autonomia, mas fornecem salvaguardas adicionais, comparando com o mercado". Para Ménard (2004), no entanto, as formas híbridas envolvem também contratos de curto prazo, além de possuírem diferentes graus de formalidade. Em analogia às tipologias contratuais de Macneil, a forma contratual que suporta as formas híbridas é o contrato neoclássico (WILLIAMSON, 1991). As formas híbridas são formas complexas de contratação, sendo alguns exemplos: contratos, joint-ventures, subcontratação, redes, franquias, parcerias, cooperativas e alianças; são caracterizadas, portanto, por aspectos de competição e cooperação entre as partes (MÉNARD, 2004; WILLIAMSON, 1991). Segundo Williamson (1991), acordos de troca e comércio recíproco também se enquadram na categoria das formas híbridas. Outro aspecto importante presente nas formas híbridas é o papel da confiança, pois as salvaguardas contratuais nessa categoria são, na maioria das vezes, informais, baseadas na reputação dos agentes (MÉNARD, 2004).

Ménard (2004), baseado no gráfico clássico de Williamson, apresentado na Figura 1, ilustrou a diversidade dos arranjos híbridos, os quais podem partir de acordos, com características mais próximas à estrutura de mercado, tendo a confiança como exemplo, chegando a acordos mais complexos, próximos à estrutura de governança hierárquica, como a instalação de um governo formal para monitorar a transação. Essa diversidade contratual abordada por Ménard pode ser visualizada pela Figura 2.

\section{Custos de transação}

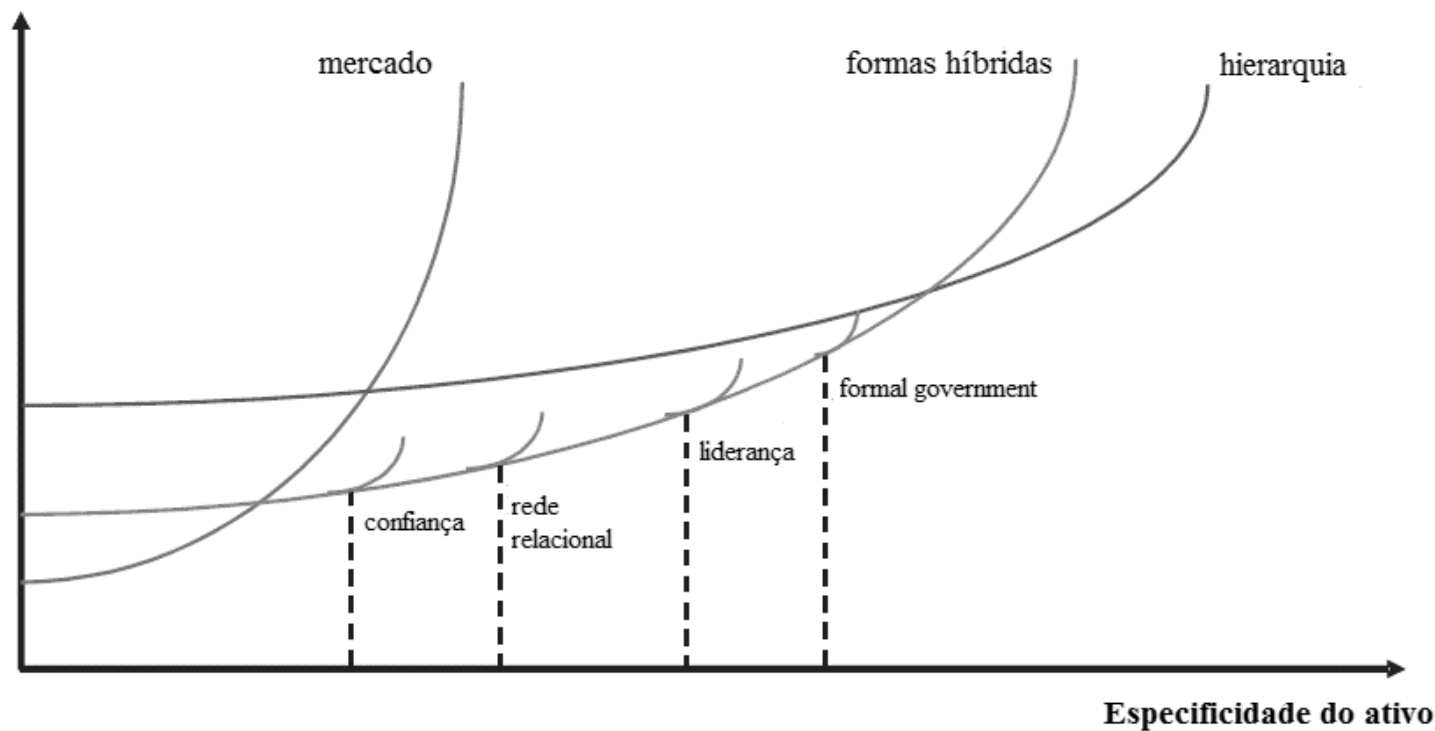

Figura 2 - Diversidade de arranjos contratuais.

Fonte: adaptado de Ménard (2004, p. 369). 
O chamado governo formal, ou formal government, acontece quando algumas decisões referentes a uma transação são passadas para um terceiro, o qual é responsável por organizar as ações dos agentes. Por sua vez, a confiança tem sua coordenação baseada na reciprocidade, além disso, a coordenação entre os atores é descentralizada. Entre essas duas formas híbridas polares, têm-se as redes relacionais, que têm um aspecto mais formal que a confiança e a liderança, que acontece quando uma das partes exerce autoridade sobre o parceiro (MÉNARD, 2004). Ainda segundo o autor, a incerteza somada ao oportunismo define o nível de coordenação dentro do range das formas híbridas. O conceito de confiança, de Ménard, é semelhante ao que Baker, Gibbons e Murphy (2002) chamaram de contrato relacional, o qual, no entanto, aparenta ser mais informal que o primeiro. Segundo os autores, um contrato relacional é "um acordo informal sustentado pelo valor do relacionamento futuro" (BAKER; GIBBONS; MURPHY, 2002, p. 39) e que não pode se fazer valer por uma corte, ou seja, acordos nos quais a reputação tem um papel importante para a sua execução (BAKER; GIBBONS; MURPHY, 2002).

Segundo Ménard (2004), apenas durante a década de 1990 houve um maior interesse no estudo das formas híbridas. Esse mecanismo se justifica para transações que envolvem um nível de especificidade de ativos que varia de médio para alto, tornando a estrutura de mercado ineficiente para mediar a transação e a hierarquia demasiadamente custosa. Ménard (2004) justifica o uso dessa forma organizacional também em função da incerteza, de forma que o arranjo contratual se torna mais vantajoso em relação ao mercado, permitindo solucionar problemas de desalinhamento. De acordo com Williamson (1991), a estrutura de governança híbrida, no entanto, é a mais vulnerável à incerteza, no que diz respeito à frequência dos distúrbios, dado que as adaptações devem ser feitas de forma bilateral.

O enquadramento de organizações cooperativas dentro desse range de governança é um aspecto que merece maior atenção. Ménard (2004) contesta a pouca atenção que é dada para as cooperativas no âmbito da Economia dos Custos de Transação. Diferente das organizações corporativas, as cooperativas possuem membros, os quais são, simultaneamente, donos e clientes, uma vez que podem vender seus produtos para a cooperativa e, também, comprar insumos ou adquirir serviços oferecidos pelas mesmas (OIJEN; HENDRIKSE, 2002; ZYLBERSZTAJN, 2002). Dessa forma, a cooperativa, especificamente a de comercialização, pode ser vista como uma estrutura de governança distinta (HENDRIKSE; VEERMAN, 2000). 
Para os autores, a cooperativa de comercialização pode ser um exemplo de hierarquia, uma vez que uma mesma parte possui o direito de controle residual.

De acordo com Zylbersztajn (2002), a relação entre a cooperativa e o cooperado se caracteriza como uma relação contratual, na qual investimentos são feitos por ambos os lados, gerando, portanto, quase rendas. A quebra desse acordo ex post pode acarretar, então, em perda no valor dos ativos, uma vez que, mesmo que o cooperado seja também dono da cooperativa, ele pode optar pelo rompimento do acordo, caso ele tenha a oportunidade de vender seu produto por um preço melhor fora da cooperativa, por exemplo. Dessa forma, para Ménard (2012), as cooperativas se enquadram dentro das formas híbridas, sendo essa uma das diversas outras formas exploradas pelo autor.

Por fim, no outro extremo, tem-se a integração vertical, ou hierarquia, que acontece quando a firma internaliza as atividades. Essa estrutura de governança é a mais eficiente, quando se tem uma situação na qual a transação é caracterizada por uma frequência recorrente, uma vez que a recorrência da transação permite compensar o custo de uma estrutura mais coordenada, e por um ativo altamente específico (WILLIAMSON, 1979). Klein, Crawford e Alchian (1978) ressaltam a real possibilidade de ação oportunista diante de um investimento altamente específico, dada a geração de quase rendas elevadas, o que justifica o uso de mecanismos mais complexos, como a hierarquia. Outra característica dessa estrutura é que as adaptações se dão por fiat $^{2}$, o que elimina a necessidade de negociação; além disso, os incentivos não possuem influência, ao contrário da estrutura de mercado (WILLIAMSON, 1979; WILLIAMSON, 1991).

Apesar de ser a abordagem dominante no que se refere aos limites da firma, muitos autores contestam a hipótese de alinhamento ótimo da ECT, argumentando que a mesma não oferece suporte teórico para explicar a existência simultânea de mecanismos de governança para coordenar uma mesma transação, fenômeno conhecido como formas plurais (BRADACH; ECCLES, 1989; BRADACH, 1997; LAFONTAINE, 1992; MONTEVERDE; TEECE, 1982; PARMIGIANI, 2007; SILVA; AZEVEDO, 2007).

\footnotetext{
${ }^{2}$ Relação autoritária.
} 
Em suma, para a escolha da forma de governança ideal, devem ser levados em consideração três fatores, sendo eles: as características transacionais, o ambiente institucional e os atributos dos agentes (WILLIAMSON, 1993; ZYLBERSZTAJN, 1995). Williamson (1993) propôs um esquema, denominado de esquema de três níveis, para demonstrar os efeitos do ambiente institucional e dos indivíduos sobre a governança, e vice-versa. Esse esquema é apresentado na Figura 3. Na figura, as setas preenchidas significam os efeitos primários, enquanto as setas pontilhadas são referentes aos efeitos secundários. Dessa forma, o ambiente institucional influencia diretamente nos custos de governança, assim como os atributos comportamentais.

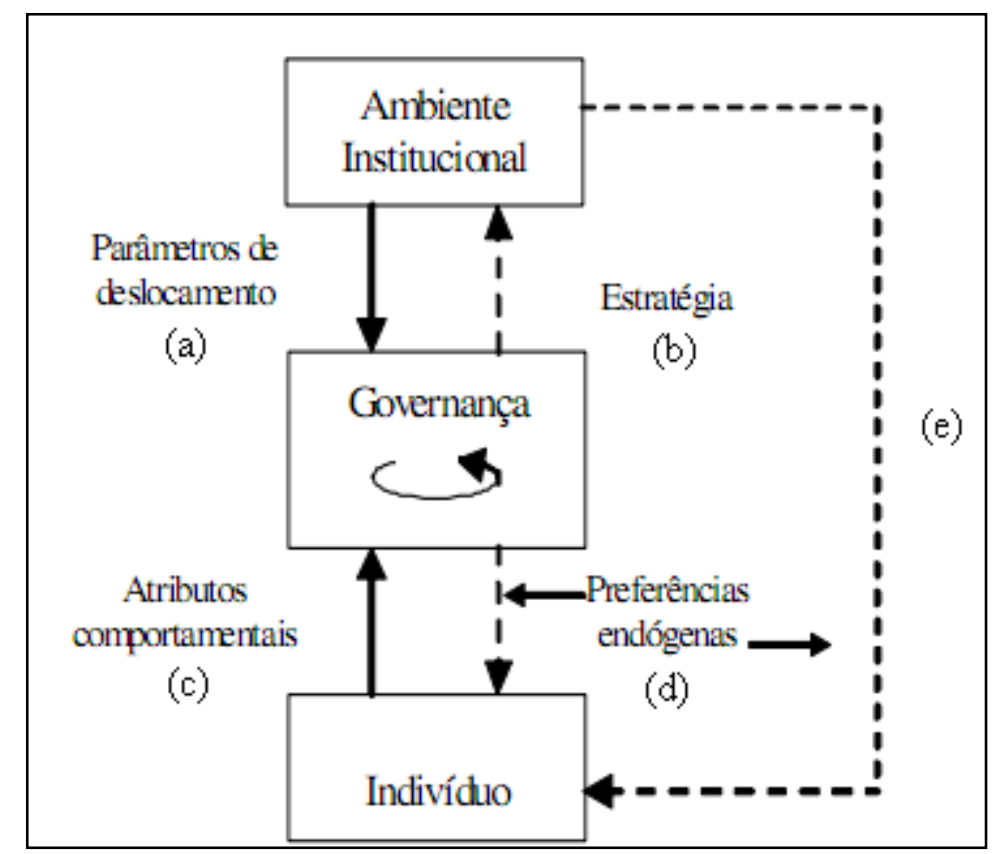

Figura 3 - Esquema de três níveis de Williamson. Fonte: adaptado de Williamson (1993, p. 80).

Apesar da influência que o indivíduo pode exercer sobre a estrutura de governança, pouca atenção é dada pela ECT ao aspecto social. Williamson (1985) destaca alguns pontos que devem ser levados em consideração para compreender a ECT e que se encontram em um contexto mais amplo, como o contexto social no qual a transação está enraizada, citando Granovetter e North. Como contexto social, o autor se refere aos costumes, hábitos, moral etc. Apesar disso, é possível observar que o contexto social não é tratado de forma individual pela ECT. A própria ausência de explicação para o papel do empreendedor e sobre como as firmas surgem, e não apenas o porquê, é um aspecto criticado por Granovetter (1992), em relação à teoria desenvolvida por Williamson. 
Para Granovetter (1985), a Nova Economia Institucional enfatiza a visão subsocializada que a economia possui acerca do indivíduo, uma vez que não considera as relações sociais como um fator capaz de mitigar a ação oportunista, por exemplo. Ainda segundo o autor, a NEI considera o indivíduo como um agente atomizado, isto é, fora de um contexto social. Vale observar que no artigo The New Institutional Economics: taking stock, looking ahead, Williamson (2000) afirma que é preciso dar maior atenção para o que ele chamou de nível i, o nível de enraizamento social, dada a sua importância e o seu baixo nível de desenvolvimento dentro da NEI.

Van de Ven e Lifschitz (2013), da mesma forma, criticam a pouca atenção dada pela ECT ao contexto social e sugerem a inclusão do conceito do comportamento razoável ${ }^{3}$ à análise da ECT, ao invés de considerar apenas o comportamento racional. Segundo os autores, o comportamento razoável pode ser definido como um comportamento resultante da norma social estabelecida. Para os mesmos, considerar o comportamento razoável à ECT permitiria analisar as transações não apenas em termos da racionalidade individual, mas também em termos de valores das partes envolvidas, ou em termos das relações sociais que as envolvem.

Nesse sentido, Hodgson (1998) também apresenta uma crítica à teoria contratual, a qual inclui a Economia dos Custos de Transação. Segundo o autor, um dos problemas relacionados à abordagem contratual é o fato de ignorarem-se as preferências individuais dos agentes. Dessa forma, a influência dos aspectos ambientais e culturais não são levados em consideração.

Foss (2004) critica a ECT dentro desse quadro geral, no qual a teoria não admite que questões sociais ajam de forma diferenciada entre os agentes econômicos. Para o autor, o ambiente institucional em que os indivíduos interagem influencia não apenas as restrições objetivas, mas também como estes se enquadram na interação. Foss (2004) admite que a essência do que as organizações são e do que os gestores fazem poderia ser dispensada, se a interação entre cognição e motivação for suprimida, por isso advoga o aprofundamento de microfundamentos que deem conta da interação entre esses dois elementos. Dando como exemplo a produção conjunta, o autor acrescenta que a motivação para aquele fim não pode se dar apenas pelo poder de fiat, mas também pela forma como os incentivos afetam a motivação dos indivíduos, ou seja, por meio da cognição (FOSS, 2004).

\footnotetext{
${ }^{3}$ Reasonable behavior
} 
Alguns autores defendem a análise dos indivíduos e suas interações para uma melhor compreensão das questões organizacionais, aspecto denominado de microfundamentos (BARNEY; FELIN, 2013; FOSS, 2011; FOSS, 2016). Em relação aos aspectos do indivíduo e seu contexto, um conceito que tem ganhado maior atenção é a questão da identidade, especificamente a identidade social, fazendo com que autores do campo da economia e da estratégia passem a considerá-la em suas análises (AKERLOF; KRANTON, 2005; BOULURESHEF, 2013; KOGUT; ZANDER, 1996; MORITA; SERVÁTKA, 2013; WANG, 2007).

Para uma melhor compreensão desses fenômenos, entende-se ser relevante realizar uma análise sobre como os conceitos de economia dos custos de transação, microfundamentos e identidade social têm sido abordados de forma conjunta na literatura. Para isso, foi realizado um estudo bibliométrico sobre essas três temáticas, o qual é apresentado na seção seguinte. 


\section{ECONOMIA DOS CUSTOS DE TRANSAÇÃO, IDENTIDADE E MICROFOUNDATIONS: UM ESTUDO BIBLIOMÉTRICO ${ }^{4}$}

Com a finalidade de complementar a discussão sobre a inclusão dos microfundamentos e da teoria da identidade social à ECT, será realizado um estudo bibliométrico sobre as três temáticas, buscando verificar uma convergência entre elas na literatura acadêmica. $O$ estudo bibliométrico tem como finalidade analisar informações sobre as publicações, por meio de técnicas estatísticas e matemáticas (DIODATO, 1994). Para tanto, diversas técnicas e métodos têm sido desenvolvidos na área de bibliometria (BOYACK; KLAVANS; BÖRNER, 2005). Dentre os métodos de análises encontrados dentro dessa área, o de citação e co-citação são os mais utilizados (FERREIRA; PINTO; SERRA, 2014). A unidade de análise pode variar entre journals, conteúdos textuais, autores, documentos, dentre outros (DING; CHOWDHURY; FOO, 1999; WHITE; GRIFFITH, 1981).

O método de citação corresponde à própria frequência de citação de determinado trabalho (FERREIRA; PINTO; SERRA, 2014). Já o método de co-citação busca identificar clusters da unidade de análise definida. Dessa forma, quanto mais dois documentos, ou dois autores, por exemplo, forem citados juntos, mais próxima é a relação entre eles (WHITE; GRIFFITH, 1981). Assim, o método de co-citação permite analisar a dinâmica de uma determinada unidade de análise.

Como abordado na seção anterior, é possível verificar alguns avanços em relação ao papel do aspecto social para a tomada de decisão no campo da Economia dos Custos de Transação, como, por exemplo, a inclusão do conceito de identidade à estratégia (KOGUT; ZANDER, 1996; MORITA; SERVÁTKA, 2013). Entretanto, não está claro que a teoria dê respostas convincentes às críticas e continue dominando a explicação da lógica das relações entre os agentes, ou que um novo paradigma esteja surgindo.

A partir dessa breve apresentação, esta seção busca analisar as produções, particularmente, os artigos acadêmicos publicados nas áreas de Economia dos Custos de Transação, Identidade

\footnotetext{
${ }^{4}$ Desta seção surgiu o artigo intitulado "Microfundamentos, teoria da identidade e economia dos custos de transação: um estudo bibliométrico”, apresentado no XXXIX EnANPAD 2015.
} 
Social e Microfundamentos, considerando todos os anos até 2016, a fim de verificar as relações existentes entre tais temáticas. Esse levantamento foi realizado em agosto de 2016.

Para tanto, serão analisadas as citações e co-citações dos trabalhos e dos autores. Será realizada uma análise para cada área, compondo, assim, três análises bibliométricas. Para realizar a busca, foi utilizada a base de dados da Scopus, uma das mais utilizadas para pesquisas bibliométricas (QUEVEDO-SILVA et al., 2016). As palavras escolhidas foram buscadas utilizando-se a opção que inclui título, resumo ou palavras-chave. A descrição dos termos apresentados para a busca é apresentada de forma detalhada em cada subseção deste estudo.

\subsection{Economia dos Custos de Transação}

A proposta desta seção é analisar as publicações referentes à Economia dos Custos de Transação, identificando os principais autores, os temas tratados e os principais journals da área. Os termos utilizados para a busca foram "transaction cost theory" e "transaction cost economics" e suas variações para escrita plural ou singular. Optou-se por não utilizar as abreviações "TCT" e "TCE" pelo fato de as mesmas poderem representar outros significados em diferentes áreas. Além disso, a busca foi feita apenas para documentos do tipo artigo. No total, foram encontrados 1601 artigos.

É possível observar um salto na quantidade de artigos publicados sobre a ECT entre os anos de 2002 e 2009, passando de 45 para 175 artigos. Em relação ao local de publicação, os principais journals da área são: Strategic Management Journal, Journal of International Business Studies, Organization Science, Journal of Economic Behavior and Organization, e Journal of Business Research.

Por meio de uma análise de citações, foi possível identificar os trabalhos mais citados nos artigos sobre Economia dos Custos de Transação. Esses trabalhos são apresentados de forma mais detalhada no Quadro 1. Cabe observar que o trabalho de Granovetter (1985), no qual o autor critica a NEI pela sua visão subsocializada do indivíduo, encontra-se entre os 10 mais citados. 
Quadro 1: Os 10 trabalhos mais citados na área de ECT

Top 10 trabalhos mais citados

WILLIAMSON, O. E. The economic institutions of capitalism: firms, markets, relational contracting. The free press. 1985.

COASE, R. The nature of the firm. Economica, v. 4, n. 16, p. 386-405, nov. 1937.

WILLIAMSON, O. E. Markets and hierarchies, analysis and antitrust implications: a study in the economics of internal organization. New York: Free Press, 1975.

WILLIAMSON, O. E. Comparative economic organization: the analysis of discrete structural alternatives. Administrative Science Quarterly, S.L., v. 36, n. 2, p. 269-296, jun., 1991.

BARNEY, J. B. Firm resources and sustained competitive advantage. Journal of Management, v. 17, p. 99-120, 1991.

WERNERFELT, B. A resource-based view of the firm. Strategic Management Journal, v. 5, n. 2, p. 171-180, 1984.

GHOSHAL, S.; MORAN, P. Bad for practice: a critique of the transaction cost theory. Academy of Management Review, v. 21, n. 1, p. 13-47, 1996.

GRANOVETTER, M. Economic action and social structure: the problem of embeddedness. American Journal of Sociology, v. 91, n. 3, p. 481-510, 1985.

DYER, J. H.; SINGH, H. The relational view: cooperative strategy and sources of contractual advantage. The Academy of Management Review, v. 23, n. 4, p. 660-679, 1998.

GULATI, R. Does familiarity breed trust? The implications of repeated ties for contractual choice in alliances. Academy of Management Journal, v. 38, p. 85$112,1995$.

Fonte: elaborado pela autora.

O mapa de co-citações dos autores é apresentado na Figura 4. A partir da análise de co-citação, é possível analisar a estrutura intelectual entre os autores. Ou seja, na análise de co-citação de autores, quanto mais dois autores são citados juntos, mais próxima é a relação entre eles. Dessa forma, a análise de co-citação permite analisar os clusters existentes e os autores que pertencem a eles. Foram selecionados autores que foram citados, pelo menos, 20 vezes. 


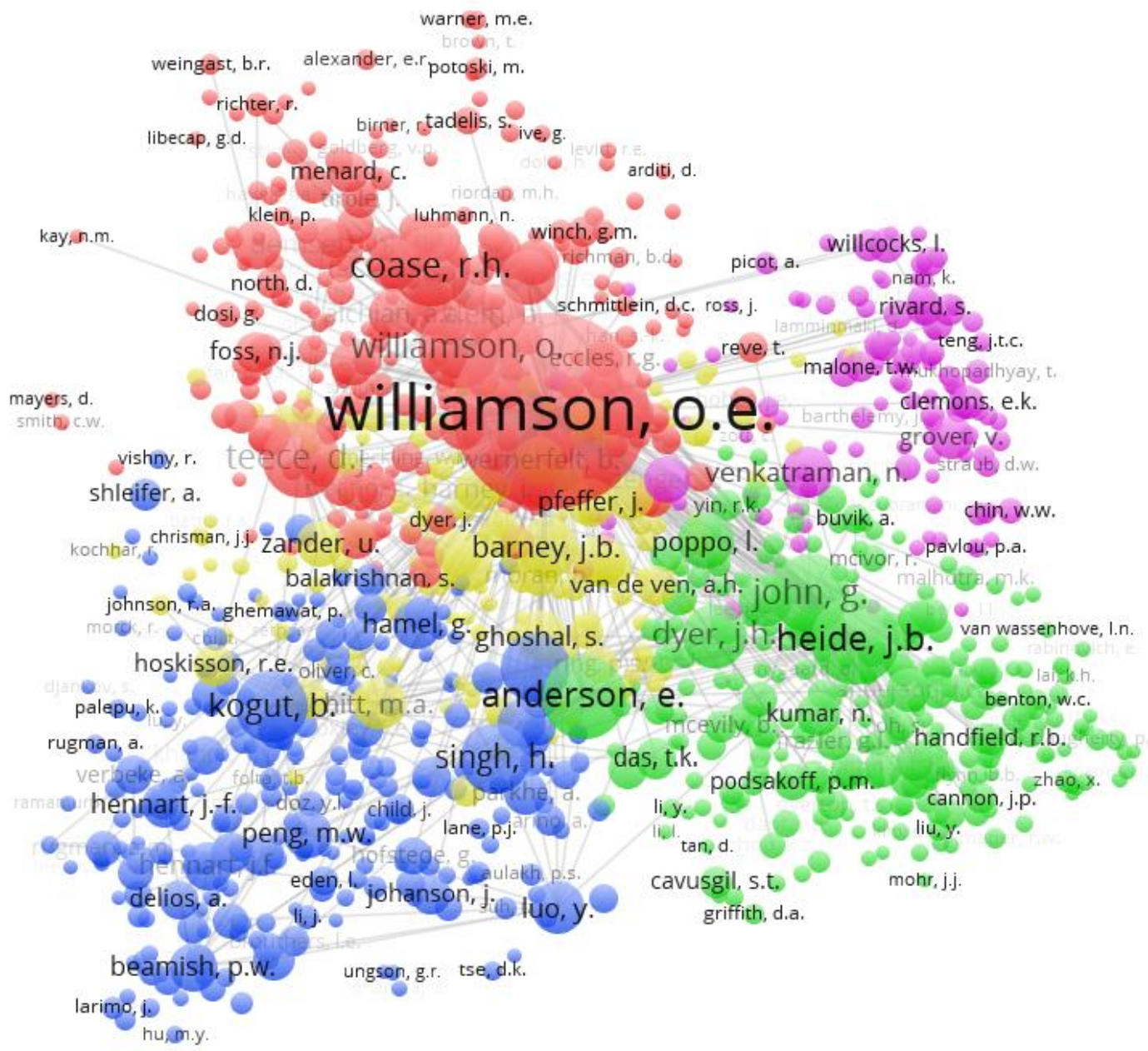

Figura 4 - Mapa de co-citação - ECT.

Fonte: elaborado pela autora.

O mapa de co-citação da ECT é formado por cinco clusters, sendo que um deles, classificado em amarelo, possui certa convergência com outros clusters. Os agrupamentos podem ser definidos da seguinte forma: ECT e sua origem, no qual destacam-se Williamson, Coase, Ménard, North, Foss, Teece, Demsetz, Alchian, Klein, entre outros; Knowledge, Instituições e Comportamento Organizacional, cujo autores de maior relevância são Kogut, Singh, Peng e Gulati; Governança relacional, destacando-se Heide, Poppo, Dyer e Anderson; Visão Baseada em Recursos, tendo Barney, Hitt, Wernerfelt e Pfeffer como uns dos principais autores; Estratégia e Tecnologia, no qual se destacam Venkatraman, Zenger e Willcocks.

\subsection{Teoria da Identidade Social}


Esta seção busca avaliar de que forma os trabalhos publicados sobre teoria da identidade social se relacionam com a área de gestão estratégica e economia dos custos de transação. Os termos utilizados para a busca foram "identity theory", "theory of identity", "economics of identity", "social identity" e "identity economics". Foram encontrados 9458 artigos. Optou-se por selecionar apenas os artigos das áreas business, management e accounting e economics, econometrics e finance. Além disso, foram solicitados na busca apenas artigos científicos. Dessa forma, foram analisados 1249 artigos.

Tem havido um crescimento significativo no número de trabalhos publicados sobre identidade nas áreas descritas acima. Em 2010, foram publicados 66 artigos, tendo sido alcançado o montante de 158 em 2015. Os journals que mais publicam sobre o assunto são: International Journal of Intercultural Relations, Human Relations, Journal of Business Ethics, International Journal of Human Resource Management e Journal of Business Research. O journal Organization Science, um dos principais na área de ECT, aparece em seguida, com um total de 22 artigos publicados. Journal of Economic Behavior and Organization também possui destaque, tendo 18 artigos publicados sobre o tema.

A lista dos trabalhos mais citados é apresentada pelo Quadro 2. Pode-se observar que, apesar de alguns desses artigos estarem em revistas na área de psicologia, a maioria foram publicados em journals de destaque na área de business, com grande convergência com os da área de ECT.

Quadro 2: Os 10 trabalhos mais citados na área de identidade

Top 10 trabalhos mais citados

ASHFORTH, B. E.; MAEL, F. Social identity theory and the organization. The Academy of Management Review, v. 14, n. 1, p. 20-39, 1989.

DUTTON, J. E.; DUKERICH, J. M. HARQUAIL, C. V. Organizational images and member identification. Administrative Science Quarterly, v. 39, p. 239-263, 1994.

HOGG. M. A.; TERRY, D. J. Social identity and self-categorization process in organizational contexts. Academy of Management Review, v. 25, p. 121-140, 2000.

MAEL, F.; ASHFORTH, B. E.; Alumni and their alma mater: a partial test of reformulated model of organizationalidentification. Journal of Organizational Behavior, v. 13, p. 103-123, 1992.

RIKETTA, M. Organizational identification: a meta-analysis. Journal of Vocational Behavior, $v$. 66, p. 358-384, 2005.

FORNELL, C.; LARCKER, D. F.; Evaluating structural equations model with unobervable variables and measurement error. Journal of Marketing Research, 18, n. 1, p. 39-50, 1981.

ASHFORTH, B. E.; HARRISON, S. H.; CORLEY, K. G. Identification in organizations: an examination of four fundamental questions. Journal of Management, v. 34, p. 325-374, 2008. 
BREWER, M. B. The social self: on being the same and different at the same time. Personality and Social Psychology Bulletin, v. 17, p. 475-482, 1991.

TAJFEL, H. Social psychology of intergroup relations. Annual Review of Psychology, v. 33, p. 139, 1982.

Fonte: elaborado pela autora.

A Figura 5 apresenta o mapa de co-citação. Da mesma forma que foi feito na análise da ECT, tanto para a análise dos trabalhos mais citados quanto para a elaboração do mapa de co-citação foram considerados trabalhos e autores citados, no mínimo, 20 vezes.

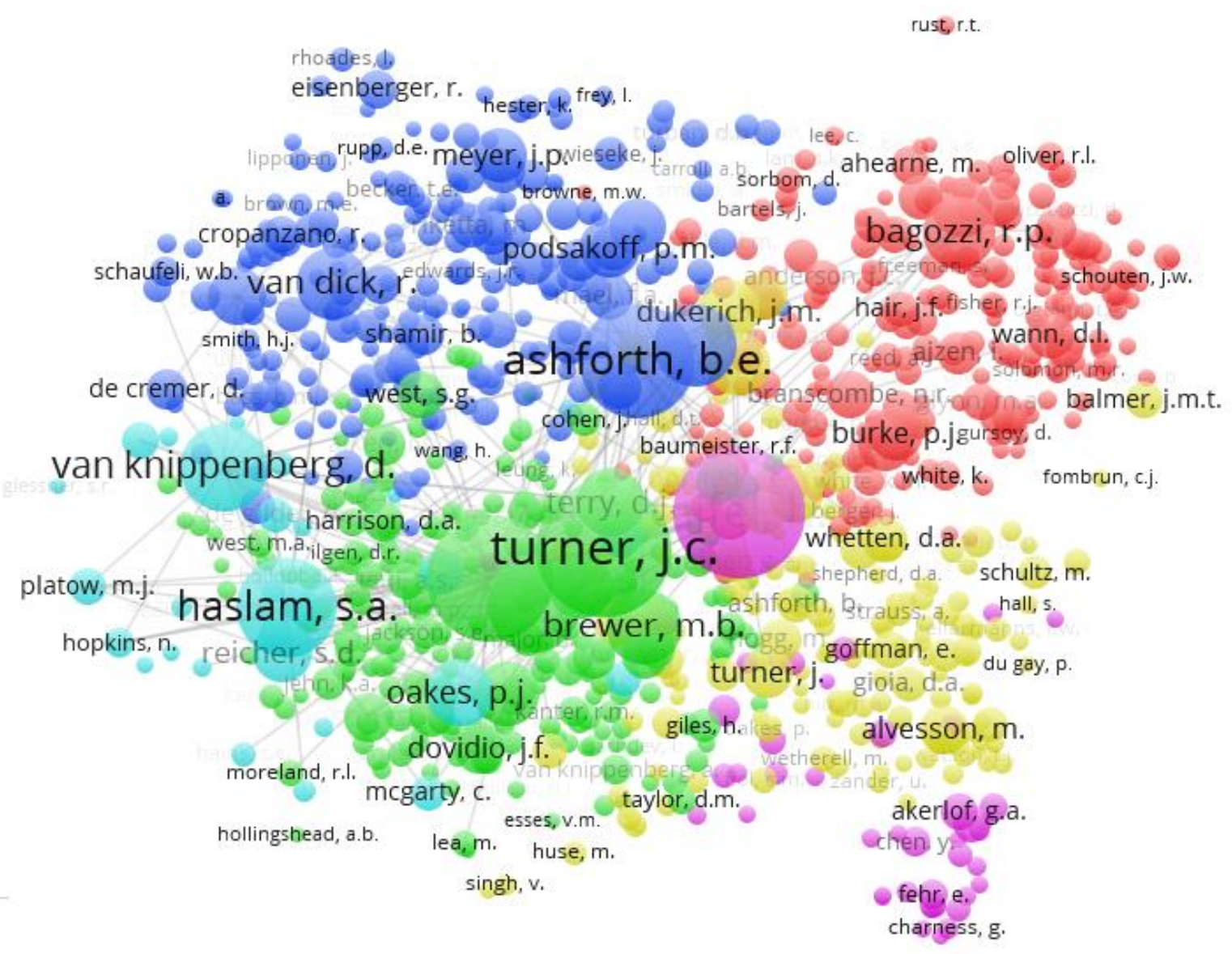

Figura 5 - Mapa de co-citação - identidade.

Fonte: elaborado pela autora.

Os clusters que mais apresentam autores da área de estratégia são os de cor amarela e roxa, sendo que a maioria dos autores apresenta um número pequeno de citações, quando comparados com os autores que aparecem na figura, o que faz com que os mesmos não sejam visíveis na figura. Por meio da análise da lista de autores gerada pelo programa, foi possível verificar a existência de diversos autores em comum com a lista de citação gerada na análise bibliométrica da ECT. Dentre os autores, destacam-se: Bruce Kogut, Sumantra Ghoshal, Henry Mintzberg, Walter Powell, Herbert Simon, Coimbatore Prahalad, Mark Granovetter e George Akerlof. 
Quando a lista de citação em identidade social é estendida para o mínimo de cinco ocorrências, outros autores de destaque aparecem, como Oliver Williamson, Elinor Ostrom, Douglas North, Kenneth Arrow, James Coleman, Kathleen Eisenhardt, David Teece, entre outros. Quando o número mínimo de citações na área de ECT é ampliado para pelo menos duas citações, verificase a presença de Tajfel e Turner, autores importantes da área de identidade social. Pode-se dizer, portanto, que existe uma ligação entre os dois temas. Apesar disso, a identidade tem sido pouco explorada pela literatura de Economia dos Custos de Transação, o que pode ser visto como uma oportunidade para futuros estudos.

\subsection{Microfundamentos}

Para a análise bibliométrica sobre microfundamentos, os termos para busca estabelecidos foram: "microfoundations", "microfoundation", "micro-foundations" e "micro-foundation", filtrando-se apenas trabalhos classificados como artigos. Foram encontrados e analisados 789 artigos. É possível observar que, assim como o tema identidade, o tema microfundamentos também tem apresentado um expressivo crescimento nos últimos anos em número de publicações, especialmente entre 2004 e 2013. Os principais journals da área são: Cambridge Journal of Economics, Journal of Management, Journal of Monetary Economics, Organization Science e International Economics Review. O autor com mais publicações sobre o tema é Nicolai Foss, que também aparece na análise das citações e co-citações da ECT.

O Quadro 3 apresenta os artigos mais citados encontrados nos papers analisados. Pelo fato das pesquisas com foco em microfundamentos serem mais recentes e pelo fato de se ter encontrado uma menor quantidade de trabalhos nessa área, para a análise das co-citações, optou-se por selecionar autores que continham, pelo menos 10, citações. É possível verificar que as fontes das publicações são convergentes com as fontes das análises anteriores. Além disso, diversos autores presentes na lista abaixo também foram encontrados nas análises bibliométricas em ECT e em identidade social. Cabe destacar que, entre os trabalhos mais citados, está o de Eisenhardt, referente a estudo de caso. 
Quadro 3: Os 10 trabalhos mais citados na área de microfundamentos.

Top 10 trabalhos mais citados

FELIN, T.; FOSS, N. J. Strategic Organization: a field in search of microfoundations. Strategic Organization, v. 3, n. 4, p. 441-455, 2005.

KOGUT, B. ZANDER, U. Knowledge of the firm, combinative capabilities, and the replication of technology. Organization Science, v. 3, p. 383-397, 1992.

GAVETTI, G. Cognition and hierarchy: rethinking the microfoundations of capabilities' development. Organization Science, v. 16, p. 599-617, 2005.

EISENHARDT, K.M. Building theories from case study research. The Academy of Management Review, v. 14, n. 4, p. 532-550, 1989.

WINTER, S. G. Understanding dynamic capabilities. Strategic Management Journal, v. 24, p. 991-995, 2003.

TEECE, D. J. Explicating dynamic capabilities: the nature and microfoundation of (sustainable) enterprise performance. Strategic Management Journal, v. 28, p. 1319-1350, 2007.

TEECE, D. J. PISANO, G.; SHUEN, A. Dynamic capabilities and strategic management. Strategic Management Journal, v. 18, n. 7, p. 509-533, 1997.

GRANT, R. M. Toward a knowledge-based theory of the firm. Strategic Management Journal, v. 17, p. 109-122, 1996.

ZOLLO, M. WINTER, S. G.; Deliberate learning and the evolution of dynamic capabilities. Organization Science, v. 13, p. 339-351, 2002.

BARNEY, J. B. Firm resource and sustained competitive advantage. Journal of Management, v. 17, p. 99-120, 1991.

Fonte: elaborado pela autora.

Os autores mais citados são apresentados no mapa de citação e co-citação da Figura 6. Assim como nas análises anteriores, foram selecionados autores que continham, pelo menos, 20 citações.

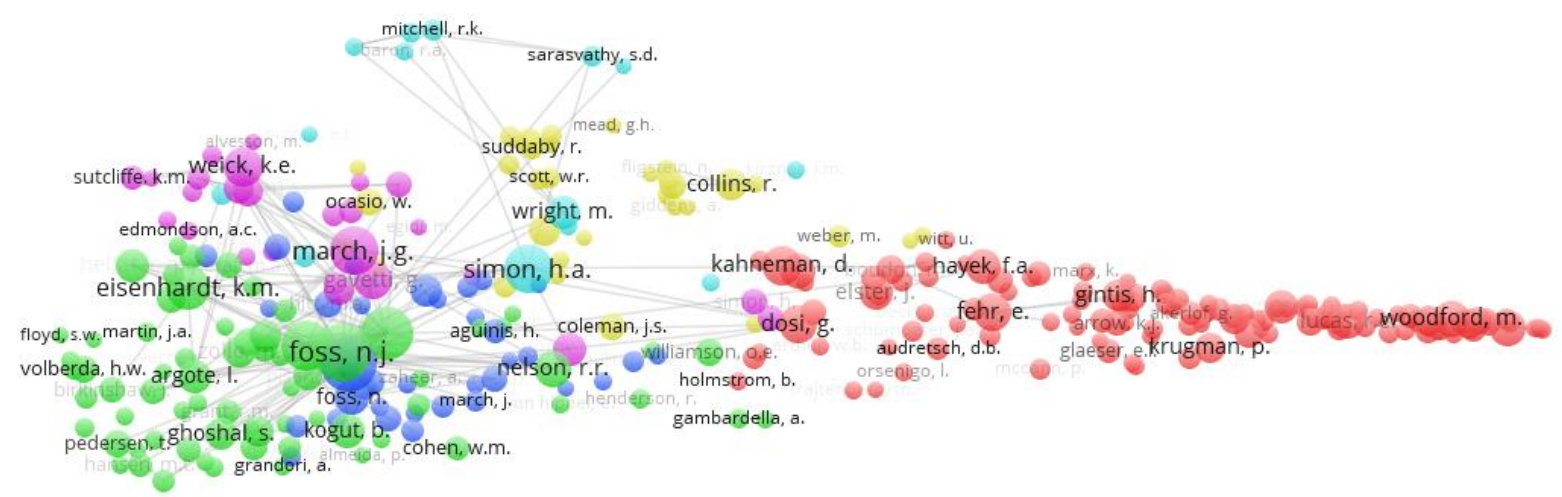

Figura 6 - Mapa de co-citação - microfundamentos.

Fonte: elaborado pela autora. 
Como pode ser visualizado na figura, os autores estão divididos em seis grupos distintos, sendo que os clusters verde, azul e roxo são os que apresentam maior proximidade. Embora não seja possível verificar na figura, por meio do software pode-se observar que o cluster de cor azul é composto, principalmente, por autores relacionados à Resource Based View, que traz autores como Barney e Felin. O cluster roxo, por sua vez é composto, principalmente, por autores da teoria comportamental. Dessa forma, verifica-se que os microfundamentos estão mais relacionados à teoria de recursos. De forma geral, foi possível encontrar algumas citações de autores em comum com as análises bibliométricas realizadas anteriormente, tendo sido possível identificar autores em comum entre ECT e identidade social, ECT e microfundamentos, identidade social e microfundamentos e ECT, identidade social e microfundamentos, simultaneamente. A fim de facilitar a visualização, foi elaborada uma lista de autores que aparecem em comum em cada área, independentemente do número mínimo de citações, a qual pode ser visualizada no Quadro 4.

Quadro 4: Autores em comum nas áreas de ECT, Identidade Social e Microfundamentos.

\begin{tabular}{|c|c|c|c|}
\hline ECT e Identidade & $\begin{array}{c}\text { ECT e } \\
\text { Microfundamentos }\end{array}$ & $\begin{array}{l}\text { Microfundamentos } \\
\text { e Identidade }\end{array}$ & $\begin{array}{l}\text { ECT, Identidade e } \\
\text { Microfundamentos }\end{array}$ \\
\hline $\begin{array}{l}\text { Akerlof, Arrow, } \\
\text { Coleman, Eisenhardt, } \\
\text { Ghoshal, } \\
\text { Granovetter, Hitt, } \\
\text { Kogut, Kranton, } \\
\text { Mintzberg, North, } \\
\text { Ostrom, Powell, } \\
\text { Prahalad, Simon, } \\
\text { Tajfel, Teece, } \\
\text { Turner, Van de Ven, } \\
\text { Williamson }\end{array}$ & $\begin{array}{l}\text { Akerlof, Barney, } \\
\text { Coleman, Eisenhardt, } \\
\text { Foss, Ghoshal, } \\
\text { Granovetter, Hitt, } \\
\text { Hodgson, } \\
\text { Holmstrom, } \\
\text { Kahneman, Kogut, } \\
\text { March, Mintzberg, } \\
\text { Nelson, Olson, } \\
\text { Ostrom, Peteraf, } \\
\text { Pfeffer, Powell, } \\
\text { Prahalad, Rumelt, } \\
\text { Schumpeter, Simon, } \\
\text { Tajfel, Teece, } \\
\text { Turner, Williamson, } \\
\text { Winter, Zander, } \\
\text { Zollo }\end{array}$ & $\begin{array}{l}\text { Akerlof, Eisenhardt, } \\
\text { Fehr, Ghoshal, } \\
\text { Granovetter, Hitt, } \\
\text { Kogut, March, } \\
\text { Mintzberg, Pfeffer, } \\
\text { Powell, Prahalad, } \\
\text { Simon, Tajfel, Teece, } \\
\text { Turner e Williamson }\end{array}$ & $\begin{array}{l}\text { Akerlof, Eisenhardt, } \\
\text { Ghoshal, } \\
\text { Granovetter, Hitt, } \\
\text { Kogut, Mintzberg, } \\
\text { Powell, Prahalad, } \\
\text { Simon, Tajfel, Teece, } \\
\text { Turner e Williamson }\end{array}$ \\
\hline
\end{tabular}

Fonte: elaborado pela autora.

A fim de aprofundar a análise, foi realizada uma busca nos artigos da área de identidade social, com o propósito de verificar em quais trabalhos os autores de ECT foram citados, buscando-se, principalmente, referências a Williamson, tornando possível analisar a temática de tais 
trabalhos. O inverso também foi realizado, por meio de buscas por citações de Akerlof e Kranton, bem como Tajfel e Turner, na área de Economia dos Custos de Transação. Foi possível verificar que existem mais artigos na área de identidade social referenciando a ECT (Williamson) do que artigos em ECT referenciando autores de identidade (Akerlof, Kranton, Tajfel e Turner). Os trabalhos que citam Akerlof fazem referência, principalmente, ao texto The market for lemons, o qual não está relacionado ao tema de microfundamentos, mas à teoria de incentivos, ao tratar da questão da seleção adversa. Nessa busca, considerando citações de Oliver Williamson em trabalhos sobre identidade social, pôde-se encontrar um total de 16 artigos. Apesar de tais achados, foi possível observar a inexistência de estudos sobre a influência da identidade social na escolha dos mecanismos de governança. Alguns dos estudos encontrados nessa busca são apresentados a seguir.

Boulu-Reshef (2013) mostrou como a teoria da firma e a economia da identidade se sobrepõem, tendo como base as três questões fundamentais de ambas literaturas, sendo elas: (i) identificação, (ii) individuação e (iii) múltiplas identidades sociais, pelo lado da economia da identidade, e (i) natureza da firma, (ii) organização interna e (iii) limites da firma, pelo lado da teoria da firma. De acordo com a autora, a teoria da firma dá mais ênfase à identificação, a qual aborda como a identidade afeta o comportamento, isto é, como o senso de afiliação afeta o comportamento. Nessa vertente, se destacam Kogut, Zander, Akerlof e Kranton. No entanto, as outras duas questões a saber: individuação, que se refere a como os indivíduos se distinguem um dos outros (esforço para se relacionar com um grupo social específico) e múltiplas identidades sociais, relacionada à questão de como os indivíduos gerenciam a afiliação de diferentes grupos sociais, têm sido negligenciadas pela teoria da firma. Em suma, a autora busca elucidar o papel das firmas, considerando tanto a sua organização interna quanto os seus limites organizacionais sobre o desenvolvimento da identidade, bem como o seu gerenciamento.

Shi e Tang (2015), por sua vez, demonstraram como as similaridades religiosa e cultural afetam positivamente as alianças estratégicas entre os estados americanos. Sammarra e Biggiero (2001) analisaram distritos industriais, verificando de que forma o processo de identificação afeta o comportamento dos indivíduos, fazendo com que os mesmos se tornem mais comprometidos. Phua (2004) analisou a relação entre identificação organizacional e comportamento cooperativo. $\mathrm{O}$ autor encontrou relação positiva entre esses aspectos, o que indica que os indivíduos com maior identificação organizacional são mais pré-dispostos a exercer um 
comportamento cooperativo. Morita e Servátka (2013) analisaram a relação entre identificação com o grupo e quebra de acordo.

Portanto, em suma, a partir da análise bibliométrica, foi possível identificar a presença de citações em comum nas áreas de ECT e identidade social, ECT e microfundamentos, identidade social e microfundamentos, assim como nas três áreas simultaneamente. Além disso, verificouse a existência de journals que publicam sobre os três temas, como é o caso do The Academy of Management Review e do Organization Science. Outro resultado importante é a pouca ocorrência de termos em comum entre os trabalhos da área de ECT e identidade, resultado obtido por meio de análise dos conteúdos dos títulos, resumos e palavras-chave, o que indica uma possibilidade para futuros estudos.

As seções seguintes irão aprofundar os aspectos teóricos relacionados aos microfundamentos e à teoria da identidade social, temáticas fundamentais para o desenvolvimento da presente pesquisa. 


\section{UMA NOVA PERSPECTIVA DOS MICROFUNDAMENTOS PARA A ECT: INCLUINDO O CONTEXTO SOCIAL}

Para a teoria econômica neoclássica, o agente tomador de decisão possui um papel fundamentalmente passivo, uma vez que suas decisões são realizadas em um ambiente de racionalidade plena e o setor no qual a firma se insere define sua estratégia. Nesse cenário, as estratégias são escolhidas de acordo com os preços, dadas as preferências dos consumidores, as possibilidades tecnológicas e a dotação de recursos. Dessa forma, não há espaço para a tarefa empresarial de coordenar, arbitrar e lidar com a incerteza (BHIDÉ, 2000). Assim, a firma desempenha um papel no qual não só o seu resultado é conhecido, mas também os resultados de seus rivais. No entanto, muitos autores defendem a importância do aspecto cognitivo do indivíduo para o desempenho das firmas (CARROLL, 1993; FOSS, 2010; MOLINA-AZORÍN, 2014; WILLIAMS, 1994).

De acordo com Cyert e March (1963), a visão da teoria neoclássica em relação ao tomador de decisão tem recebido críticas, diante do tratamento dado aos aspectos motivacionais e cognitivos, os quais, para os autores, são tratados de formas não realista, uma vez que os indivíduos são considerados racionais e maximizadores.

Para a Nova Economia Institucional, com foco de atenção aqui à Economia dos Custos de Transação, o agente passa a ser tratado de forma diferenciada, considerando que o mesmo é racional, porém o é apenas de forma limitada, dada a impossibilidade de prever todos os eventos futuros. Apesar desse avanço, o agente tomador de decisão continua sendo considerado maximizador, buscando sempre a opção que irá favorecer a redução dos custos de transação, da mesma forma como para a teoria neoclássica. Dessa forma, para essa abordagem, de acordo com Foss (2004), os indivíduos são homogêneos quanto à sua cognição. Diante dessa ideia, seria necessário, portanto, incluir de que forma a cognição e motivação interagem, uma vez que não considerar isso prejudica o realismo da teoria (FOSS, 2004).

Outra crítica apresentada à teoria diz respeito à falta de análise do contexto social. Cabe destacar que alguns estudiosos enfatizam a importância do contexto social para o comportamento do agente, criticando a ausência desse aspecto para as análises econômicas (COLEMAN, 1988; GRANOVETTER, 1973; GRANOVETTER, 1985). Granovetter (1973), por exemplo, buscou 
elucidar a importância das redes de relacionamento para o indivíduo, argumentando que a análise dessas redes é capaz de prover a ligação entre o aspecto micro e o aspecto macro no campo da sociologia. Especificamente, o autor analisou a influência da força dos laços entre os indivíduos sobre o nível macro.

Granovetter analisou também a questão do enraizamento social, ou embeddedness, e critica a visão subsocializada que o indivíduo possui para a teoria econômica (GRANOVETTER, 1985). Para ele, a NEI, abordagem da qual a ECT faz parte, enfatiza essa visão subsocializada, ao considerar que as relações entre os agentes não são suficientes para gerar confiança, o que reprimiria comportamentos oportunistas. Ao invés disso, para o autor, a NEI estabelece formas organizacionais que permitem substituir a confiança. Granovetter (1985) ainda defende que a visão subsocializada do indivíduo não permite considerar o papel das relações pessoais e, portanto, não permite compreender constructos como confiança e reputação como relevantes na abstenção do oportunismo. Cabe destacar que a crítica de Granovetter tem como base a obra Markets and Hierarchies, de Williamson, publicada em 1975. Nos últimos anos, porém, o papel do trust tem ganhado maior atenção com o avanço dos estudos das formas híbridas de governança ${ }^{5}$. Apesar disso, os indivíduos continuam sendo vistos como homogêneos e maximizadores.

Por sua vez, Granovetter (1985) critica também a visão supersocializada que a sociologia aborda. Nesse sentido, o autor afirma que, na visão sociológica, o contexto social está tão enraizado no indivíduo, que as relações sociais desempenham um papel apenas periférico. Para ambas as visões, apesar dessas diferenças, o indivíduo é visto como um agente atomizado, isto é, fora de um contexto social. No entanto, para o autor, os agentes não tomam decisões de forma atomizada, mas sim dentro de um contexto (GRANOVETTER, 1985; 1992).

Dessa forma, o autor defende a análise do contexto social para os estudos que envolvam os limites da firma. Segundo ele:

What the viewpoint proposed here requires is that future research on the marketshierarchies question pay careful and systematic attention to the actual patterns of personal relations by which economic transaction are carried out. [...] Existing empirical studies of industrial organization pay little attention to patterns of relation, in part because relevant data are harder to find than those on technology and market

\footnotetext{
${ }^{5}$ Ver Ménard C. The economics of hybrid organizations. Journal of Institutional and Theoretical Economics, v, 160, n. 3, 2004.
} 
structure but also because the dominant economic framework remain one of atomizes actors, so personal relations are perceived as frictional in effect (GRANOVETTER, 1985, p. 504).

Nessa linha, tem-se um avanço com a incorporação do conceito de capital social (ADLER; KWON, 2002). Um dos fatores responsáveis pelo maior interesse a essa temática é que esta consegue abarcar diversos conceitos da sociologia, sendo capaz de capturar a essência de tais conceitos (LIN; COOK; BURT, 2008). O capital social existe a partir da interação entre as pessoas e, assim como as outras formas de capital, também busca trazer algum retorno para os indivíduos, além de promover a atividade de produção (COLEMAN, 1988; LIN; COOK; BURT, 2008). Para Coleman (1988), o conceito de capital social é útil para fazer uma ligação entre as duas abordagens ligadas à ação social, uma caracterizada por uma abordagem sociológica, para a qual o agente é um ser socializado, e a outra corrente formada por economistas, para os quais os agentes agem de forma independente. A teoria de redes, por exemplo, incorporou o conceito de capital social, de forma que este passou a ser parte importante dessa abordagem (OMTA; TRIENEKENS; BEERS, 2001).

Dada a relevância do contexto social para as atividades econômicas, como exposto nos parágrafos acima, alguns estudos têm buscado demonstrar a importância do mesmo para as transações econômicas. Uzzi (1997) analisou como a imersão, ou embeddedness, pode criar vantagem para as firmas em uma rede. Para o autor, mais trabalhos devem ser elaborados, visando analisar a importância do contexto social para a atividade organizacional. Outro estudo, realizado por Fehr e Gächter (2000), demonstra que há indivíduos que agem segundo a norma da reciprocidade, demonstrando a relevância do aspecto comportamental para a relação contratual.

Dessa forma, dada a importância das questões relacionadas ao indivíduo e seu contexto para o seu comportamento, alguns autores sugerem incorporar o conceito de microfundamentos à teoria da estratégia. Os microfundamentos são os aspectos relacionados aos indivíduos e suas interações (BARNEY; FELIN, 2013; FOSS, 2011). A preocupação dos microfundamentos é explicar a causalidade entre o nível micro e nível macro, isto é, como o nível individual afeta o nível coletivo (FOSS, 2011).

Para Foss (2011), é preciso deixar claro onde os microfundamentos devem ser estabelecidos, ou seja, qual deve ser sua profundidade. Nesse sentido, levanta-se uma discussão sobre o que é 
chamado de individualismo metodológico versus coletivismo metodológico. Enquanto alguns autores afirmam que o foco deve ser dado ao aspecto coletivo, outros defendem que os indivíduos e suas relações sociais é que devem ser analisados. Essa discussão vai além da área das ciências sociais, chegando, inclusive, ao campo da economia (BARNEY; FELIN, 2013; FOSS, 2010; FOSS, 2011). Dessa forma, a teoria de microfundamentos está relacionada à corrente do individualismo metodológico, não ignorando, porém, o aspecto coletivo, o qual é produto dos indivíduos (FELIN; FOSS, 2005; FOSS, 2010; FOSS, 2011).

Cabe destacar que os estudos recentes acerca dos microfundamentos têm como foco, principalmente, a Resource Based Theory (RBV) e, mais especificamente, a abordagem de capabilities, diante da ausência de microfundamentos nessa teoria (FELIN; FOSS, 2005; FELIN; FOSS, 2006; FOSS, 2011; MOLINA-AZORÍN, 2014). Barney e Felin (2013) afirmam que teorias comportamentais anteriores já enfocaram a questão de como o nível individual afeta o nível coletivo, no entanto, o foco no fator agregado desapareceu ao longo do tempo. Dessa forma, conforme Molina-Azorín (2014), os microfundamentos no campo da estratégia podem ser considerados tanto uma linha de pesquisa antiga quanto nova, dada a sua revitalização dos últimos anos, a qual ganhou força a partir do trabalho de Felin e Foss, publicado em 2005 e que considera o nível individual como um elemento chave.

Para lógica da ECT, os microfundamentos precisam ser mais bem trabalhados, pois a teoria já admite a sua existência, dado o seu olhar para o indivíduo. Esse olhar, no entanto, como descrito anteriormente, é limitado, uma vez que o agente é considerado maximizador e os aspectos cognitivo e social não são levados em consideração. Diante disso, Foss (2004) defende uma interação entre a cognição e a motivação, já que ambas são vistas como dois aspectos separados um do outro, especificamente na teoria da firma. Em relação à ECT, o autor critica o fato do pressuposto da racionalidade limitada ser menos explorado, de modo que o mesmo é utilizado apenas como argumento para explicar a incompletude contratual. Foss afirma que incluir a interação entre cognição e motivação à teoria da firma pode ajudar a entender aspectos importantes da economia das organizações. Quando o autor trata sobre a teoria da firma, faz referência à ECT e à teoria do direito de propriedade.

Além da questão da cognição, outros autores chamam atenção para o contexto no qual o agente está inserido, quando se trata da ECT. Van de Ven e Lifschitz (2013), por exemplo, defendem incorporar o conceito de comportamento razoável à teoria, a fim de garantir maior dinamismo 
à mesma, uma vez que, para os autores, os indivíduos agem de acordo com o que é esperado coletivamente, isto é, o comportamento do agente é tal porque se espera que ele se comporte dessa maneira, e não por causa da racionalidade.

A preocupação de como as questões relacionadas aos indivíduos afetam o nível macro, ou coletivo, foi anteriormente explorada por Coleman (1986). Em seu trabalho, Coleman aponta algumas mudanças que ocorreram na sociedade e nas pesquisas na área social. Em relação às mudanças nas pesquisas, ele destaca a alteração do foco do coletivo para o individual. Para capturar tais mudanças, o autor defende uma teoria social capaz de dar a devida importância para o ator, quando se fala em ação social, e que possibilite analisar a transição do aspecto micro para o macro. Coleman (1986) analisa essa relação, tendo como foco a teoria social, utilizando a sociologia para explicar o fenômeno da transição micro-macro.

Verifica-se, portanto, que a influência dos aspectos individuais e sociais sobre a tomada de decisão tem chamado a atenção de autores, não apenas no campo social, mas também no campo econômico e organizacional, levando-os a aprofundar essa análise a partir da incorporação do conceito de identidade em seus estudos, em particular, os conceitos de identidade social ou identificação com o grupo (BOULU-RESHEF, 2013). Nesse contexto, destacam-se Akerlof e Kranton (2000), os quais buscaram incluir o conceito de identidade à economia. Além de Akerlof e Kranton, Morita e Servátka (2013) identificaram outros autores que introduziram o conceito de identidade ao campo da economia. De acordo com Machado (2003), o estudo da identidade no contexto organizacional representa um campo fértil de estudo; conforme a autora, para entender as firmas, a identidade é um instrumento importante. A teoria da identidade social é apresentada de forma detalhada na seção seguinte. 


\section{A TEORIA DA IDENTIDADE SOCIAL}

O conceito de identificação vem sendo tratado desde a década de $1950^{6}$. Na década de 1970, Tajfel desenvolveu o conceito de identidade social ${ }^{7}$, a fim de compreender o comportamento de grupos (HOGG; WILLIAMS, 2000). Segundo Tajfel (1972), a identidade social de um indivíduo se refere ao seu conhecimento de pertencimento a determinado grupo social, além disso, esse pertencimento possui significado emocional para o sujeito. Dessa forma, dois elementos são fundamentais: o conhecimento de pertencimento e o valor emocional de tal pertencimento (TAJFEL, 1982).

Tajfel e Turner (1986) afirmam que a identidade social é constituída pelos aspectos da autoimagem do indivíduo, os quais são derivados da categoria social à qual ele se percebe como pertencente. Dessa forma, de acordo com Ashforth e Mael (1989), a identidade social é a percepção de pertencimento a um grupo ${ }^{8}$. Nesse sentido, Turner buscou avançar na análise e detalhamento do processo de categorização dos indivíduos, criando o que é chamado de Teoria da Auto Categorização (SCT) (ASHMORE; DEAUX; MCLAUGHLIN-VOLPE, 2004; HOGG; TERRY; WHITE, 1995).

A identidade social se diferencia da identidade pessoal por meio do nível analítico; enquanto a identidade pessoal se refere a aspectos relacionados ao próprio indivíduo, como, por exemplo, talento, competência, ideias e objetivos, a identidade social é o conhecimento de pertencimento a um grupo, conforme visto acima (ASHMORE; DEAUX; MCLAUGHLIN-VOLPE, 2004; LUHTANEN; CROCKER, 1992). Por sua vez, a identidade organizacional é entendida como o significado compartilhado da organização, que é derivado da consciência de pertencimento dos colaboradores. De forma menos comum, pode ser entendida como o pertencimento do indivíduo a um determinado grupo organizacional (CORNELISSEN; HASLAM; BALMER, 2007).

\footnotetext{
${ }^{6}$ Ver Foote (1951).

${ }^{7}$ Alguns autores utilizam a denominação identidade coletiva, ou collective identity (ASHMORE; DEAUX; MCLAUGHLIN-VOLPE, 2004; LUHTANEN; CROCKER, 1992).

${ }^{8}$ Ashforth e Mael (1989) afirmam que o conceito de identificação social é derivado do conceito de identificação com o grupo; no entanto, os autores utilizam os termos de forma equivalente.
} 
Outra distinção que deve ficar clara é a diferença entre a teoria da identidade e a teoria da identidade social. Enquanto a teoria da identidade está ligada à teoria sociológica, buscando explicar de que forma o comportamento do indivíduo é influenciado a partir da interação com a sociedade, sendo possível, portanto, que o mesmo assuma diversas identidades, a teoria da identidade social, da forma como é trabalhada por Tajfel e, como veremos mais à frente, por Akerlof e Kranton, está ligada ao campo da psicologia social, uma vez que busca distinguir os indivíduos que estão dentro de um grupo daqueles que estão fora (DAVIS, 2007; HOGG; TERRY; WHITE, 1995). Casciaro et al. (2015) defendem uma interdisciplinaridade entre a psicologia e os estudos organizacionais para um melhor entendimento dos fenômenos que acontecem no nível das organizações, sendo que esses autores enfocaram, principalmente, aspectos relacionados às redes.

Tajfel e Turner (1986) buscaram apresentar a teoria da identidade social, dando ênfase à teoria do comportamento intergrupo. O conceito de grupo é definido, pelos autores, como "um conjunto de indivíduos que se percebem como membros de uma mesma categoria social, compartilham algum envolvimento emocional nessa definição comum e alcançam um certo grau de consenso social sobre a avaliação do grupo e de seus membros"9 (TAJFEL; TURNER, 1986, p. 15, tradução nossa). Por categoria social, os autores entendem ser esta uma ferramenta cognitiva que classifica o ambiente social e direciona a ação social, fornecendo ao indivíduo, portanto, o seu local na sociedade, ou seja, fornece ao indivíduo sua autorreferência. Nesse sentido, Tajfel (1972) destaca a importância dos valores para a categorização social. Como exemplo de categorias, Tajfel (1972) cita os grupos de pessoas nos quais os indivíduos possuem ações, intenções ou atitudes semelhantes uns aos outros.

Tajfel e Turner (1986) - baseados nos pressupostos de que os indivíduos buscam manter ou aumentar sua autoestima, de que a identidade social pode ser positiva ou negativa e que a avaliação de um grupo é feita com base na comparação com um outro grupo - estabeleceram três princípios; são eles: i) os indivíduos buscam alcançar uma identidade positiva ou aumentála; ii) a identidade social positiva é proveniente da comparação entre o in-group e os out-groups; essa comparação deve diferenciar positivamente o primeiro do segundo e; iii) quando o

\footnotetext{
9 "A collection of individuals who perceive themselves to be members of the same social category, share some emotional involvement in this common definition of themselves, and achieve some degree of social consensus about the evaluation of their group and of their membership in it" (TAJFEL; TURNER, 1986, p. 15).
} 
indivíduo não está satisfeito com sua identidade social, o mesmo irá deixar seu grupo para migrar para um grupo distinto ou irá procurar diferenciar seu grupo atual dos demais.

De acordo com Machado (2003), os estudos relacionados à identidade mencionam, principalmente, dois níveis de análise, a identidade pessoal, referente à identidade do indivíduo de si mesmo, e a identidade social, a qual se refere à identidade do indivíduo enquanto pessoa vinculada a um grupo social; nesse nível, os indivíduos são unidos sob um mesmo fundamento. Este segundo nível analítico será o adotado para este estudo. Dessa forma, buscar-se-á avaliar a percepção de pertença a determinado grupo social, uma vez que o objetivo dessa pesquisa é analisar se o nível de identificação com o grupo ao qual o indivíduo pertence influencia a sua decisão de governança.

O interesse pela temática da identidade, especialmente em relação a seu aspecto econômico, levou Akerlof e Kranton (2000) a criarem o conceito de economia da identidade. De acordo com Davis (2007), o interesse pelo aspecto da identidade social no campo da economia é recente. Ainda segundo o autor, Akerlof e Kranton se basearam na teoria da identidade social, proposta por Tajfel, descrita nos parágrafos anteriores, além de seguir a teoria de autocategorização desenvolvida por Turner.

Para Akerlof e Kranton (2010, p. 13), a identidade é definida como "o conjunto de fatores que caracterizam as pessoas - que estabelecem sua categoria social, influenciando suas decisões". Quando a identidade é inserida nesse campo, considera-se o indivíduo dentro de um contexto social, diferente dos modelos econômicos previamente estabelecidos, os quais consideram que os indivíduos são movidos apenas por motivações econômicas. De acordo com Akerlof e Kranton (2005), para compreender o conceito de identidade, alguns aspectos devem ser considerados, tais como normas, categorias sociais e utilidade da identidade.

Conforme os autores, as normas correspondem à forma como o indivíduo e os demais devem agir, isto é, a forma como se espera que as pessoas ajam. Cabe destacar que a forma como as pessoas devem se comportar é situacional, isto é, depende de aspectos particulares da transação. Além disso, as normas variam também de acordo com a categoria social. O conceito de categoria social se refere à categoria na qual o indivíduo se enquadra. Devido ao fato das pessoas pensarem em si dentro de determinadas categorias, seu comportamento é influenciado por esse aspecto. $\mathrm{O}$ termo identidade apresenta dois usos, pois o mesmo pode ser usado tanto 
para descrever a categoria social na qual um determinado indivíduo se encontra, como para descrever a sua autoimagem (AKERLOF; KRANTON, 2005). O terceiro conceito, utilidade da identidade, se refere aos ganhos e perdas decorrentes do comportamento. Assim, se o indivíduo que ocupa determinada categoria social apresenta um comportamento que condiz com a norma dessa categoria, ele apresenta ganhos de utilidade; caso contrário, se a pessoa apresenta um comportamento que não corresponde à norma da categoria social na qual está inserida, irá sofrer uma perda de utilidade. Portanto, a utilidade é maximizada quando o comportamento corresponde à identidade. Dessa forma, o conceito de função utilidade, estabelecido pelos autores, é situacional (AKERLOF; KRANTON, 2005).

Em resumo, os indivíduos estão inseridos em determinadas categorias sociais e, portanto, assumem certa identidade, seja de forma consciente ou não. Dentro das categorias sociais existem as normas, as quais determinam como cada um e os demais devem agir; os indivíduos maximizam sua utilidade quando apresentam comportamentos convergentes com as normas de sua categoria social.

Para Akerlof e Kranton (2000), a identidade, então, pode ser definida como uma função das ações do indivíduo, das ações dos demais, da categoria social em que está inserido, da extensão em que as características do indivíduo correspondem às características da categoria e da extensão em que o comportamento corresponde ao esperado. Assim, para os autores, a identidade pode ser influenciada por ações próprias e também por ações de terceiros; além disso, ela pode ser escolhida.

Os autores destacam ainda que a identidade é um importante complemento da recompensa monetária, quando se leva em conta a questão motivacional. Ou seja, se o indivíduo se identifica com a organização, apresentará maior esforço na realização de sua tarefa, não sendo necessários, portanto, grandes incentivos monetários para que o mesmo se sinta motivado. Por sua vez, se o mesmo não se identifica com a organização, a norma seria realizar o mínimo de esforço possível, porém o indivíduo se esforça além do mínimo e, portanto, perde utilidade da identidade. Assim, nesse contexto, o incentivo monetário adquire maior importância, tendo o papel de compensar a perda de utilidade. A compreensão da identidade como um importante fator motivacional fez com que este conceito ganhasse maior importância no campo da administração (AKERLOF; KRANTON, 2005). 


\subsection{A identidade social e a Economia dos Custos de Transação}

Embora a identidade seja um campo fértil de estudo, a mesma tem sido pouco explorada pela literatura de economia das organizações e, particularmente, pela Economia dos Custos de Transação, principalmente em relação ao conceito específico de identidade social. Na área de ECT, o conceito de identidade foi abordado por Kogut e Zander (1996). Os autores buscaram explicar porque a transferência de conhecimento aconteceria de forma mais intensa dentro das firmas do que entre as firmas. Para os mesmos, a identidade do agente em relação ao grupo pode explicar esse fenômeno, pois torna a coordenação mais fácil, bem como a aprendizagem, o que faz com que as firmas apresentem um desempenho superior em relação ao mercado.

A relação entre identidade e ECT foi abordada também por Morita e Servátka (2013). Os autores buscaram testar se a identidade social é capaz de minimizar os problemas de hold-up. Segundo os autores, a identidade com o grupo deve ser um fator a ser analisado, quando se estuda uma decisão de integração, além de outros fatores, como o efeito da reputação e o direito de propriedade. Morita e Servátka (2013) verificaram, por meio de experimentos, que a identidade em relação ao grupo fortalece o comportamento altruísta.

Além desses autores, Wang (2007) também traz contribuições a esse tema. O autor apresenta algumas taxonomias para a mensuração dos custos de transação. Dentre elas, está a economia da identidade. Segundo Wang (2007), nesse contexto, a identidade dos agentes ganha relevância. O autor apresenta, como exemplo, a concentração de grupos étnicos em determinados negócios, que pode ser explicada pela redução dos custos de transação que acontece quando agentes de uma mesma etnia transacionam entre si. Tem-se, assim, transações que acontecem via confiança ou contrato relacional, por exemplo.

Dessa forma, com base no estudo de Wang (2007), pode-se dizer que a identidade social pode determinar o surgimento de mecanismos de governança mais complexos do que o mercado, levando ao uso de mecanismos híbridos, mais especificamente. Por sua vez, a escolha da tipologia de mecanismo dentro das formas híbridas, apresentadas anteriormente, irá variar de acordo com o contexto social em análise. 
Para Boulu-Reshef (2013), analisar a relação entre identidade e limites da firma ajuda a entender as estratégias dos agentes, tendo como base suas identidades dentro das firmas. Santos e Eisenhardt (2005) defendem, dentre outros conceitos, a incorporação da identidade para um melhor entendimento dos limites horizontais e verticais das firmas, considerando, porém, a abordagem de identidade organizacional. Dessa forma, para eles, os limites das firmas são definidos, visando uma ligação entre as atividades da firma e sua identidade. Quando sugerem esses novos conceitos para a definição dos limites das firmas, os autores não os consideram como complementares à ECT, mas sim como alternativos a ela. O entendimento dos limites das firmas à luz da ECT é analisado pelos autores por meio do conceito de eficiência.

Dessa forma, os aspectos sociais e, mais especificamente, a identificação social, também devem ser levados em consideração para a decisão dos mecanismos de governança, dada a sua influência para a tomada de decisão, como foi mostrado nos estudos abordados nesse referencial, permitindo, assim, um melhor entendimento acerca dos limites das firmas e seus determinantes. Wang (2007) afirma que incluir a identidade no contexto da ECT permite analisar a importância do contexto social para os resultados econômicos, uma vez que, para o autor, o custo de transação pode ser reduzido, devido às relações sociais. Dessa forma, tendo como base o que foi abordado nesse referencial teórico, foi construído o modelo teórico adotado para esta pesquisa, bem como as hipóteses que foram testadas. Tanto o modelo como as hipóteses serão apresentados na seção seguinte. 


\section{MODELO TEÓRICO E HIPÓTESES DE PESQUISA}

Como visto anteriormente, para a Economia dos Custos de Transação, existe um alinhamento ótimo entre os atributos das transações e os mecanismos de governança, sendo que, dentre os atributos transacionais - frequência, incerteza e especificidade de ativos - a especificidade é o principal para a escolha do mecanismo de governança que irá promover a redução dos custos de transação. Os outros dois, no entanto, devem ser analisados de forma conjunta à especificidade. Essa hipótese de alinhamento já foi testada e verificada por diversos autores (RUESTER, 2010), demonstrando, assim, sua eficácia. Dessa forma, primeiramente, busca-se testar essa hipótese também no objeto de estudo deste trabalho. Tem-se, com isso, a primeira hipótese de pesquisa:

H1: Transações com baixo nível de especificidade de ativos reduzem a probabilidade do uso de mecanismos de governança mais complexos.

Apesar disso, como será apresentado nas seções posteriores sobre a descrição do objeto de pesquisa deste estudo, podem haver casos em que, mesmo para transações com atributos similares, têm-se mecanismos de governança diferentes, fato que não é explicado pela teoria dos custos de transação.

Entende-se, portanto, que existe outro fator que explica a decisão de mecanismo de governança, que não se enquadra nas características transacionais. Esse fator se encontra no contexto social ao qual o indivíduo está enraizado, mais especificamente, está relacionado à sua identificação social ao grupo do qual faz parte, aspecto que será analisado neste trabalho. Quando se trata de contextos nos quais o aspecto social exerce influência no dia a dia dos indivíduos, particularmente, o fator social deve ser levado em consideração para o entendimento das escolhas dos agentes, o que caracteriza a segunda hipótese desta pesquisa:

H2: Quanto maior a identidade social do indivíduo em relação ao grupo, maior a probabilidade de transacionar via formas de governança incentivadas pelo grupo.

Além da adoção da forma de governança incentivada pelo grupo, pretende-se verificar também se, além de adotar, o indivíduo favorece esse mecanismo, em detrimento de outros. Ou seja, se 
o indivíduo deixaria de vender via outros mecanismos para vender via mecanismo incentivado pelo grupo social do qual faz parte. Dessa forma, a terceira hipótese fica estabelecida da seguinte forma:

H3: Quanto maior a identidade social do indivíduo em relação ao grupo, maior a probabilidade de favorecer a forma de governança incentivada pelo grupo.

A partir das hipóteses apresentadas, elaborou-se um modelo teórico, o qual é apresentado na Figura 7. Destaca-se no modelo, em negrito, a contribuição desta pesquisa.

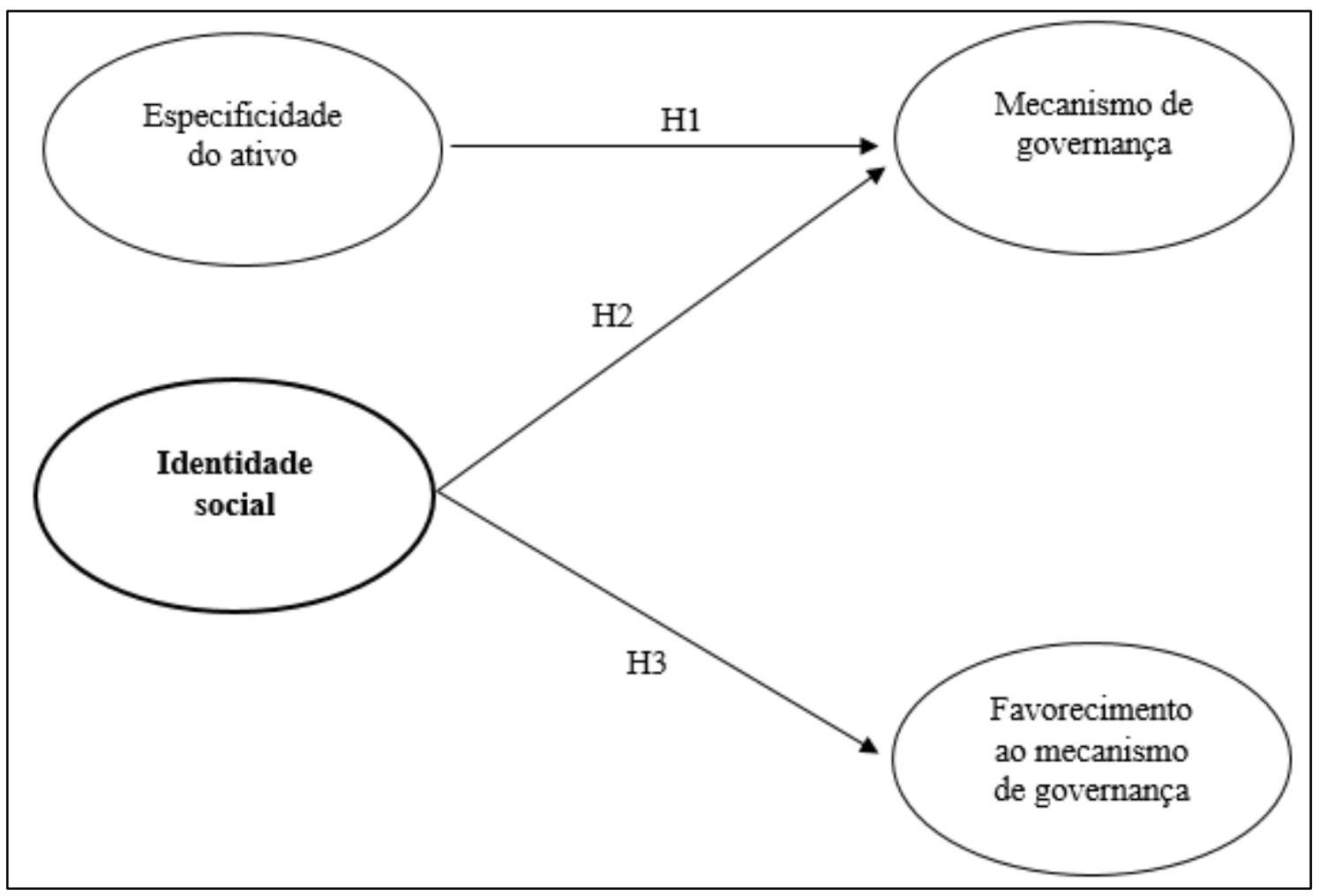

Figura 7 - Modelo teórico.

Fonte: elaborado pela autora. 
PARTE II - ANÁLISE EMPÍRICA

Nesta segunda parte, inicialmente, será detalhada a questão da reforma agrária e do surgimento do Movimento dos Trabalhadores Rurais Sem Terra, uma vez que a análise empírica se deu em um assentamento. A escolha pelo objeto de pesquisa aconteceu devido à diversidade de arranjos verticais encontrados no assentamento, apesar de, aparentemente, as características transacionais não variarem, a depender do produtor. Além disso, a escolha pelo ambiente aconteceu ao se pressupor que a identificação social exerce um importante papel nesse contexto, além de poder variar de produtor para produtor. Posteriormente, o assentamento objeto dessa pesquisa será contextualizado, detalhando como aconteceu o seu processo de formação. Em seguida, será apresentado o método de pesquisa empregado para a condução deste estudo. Por fim, inicia-se a seção referente à análise e discussão dos resultados. 


\section{A REFORMA AGRÁRIA E A ORIGEM DO MOVIMENTO DOS TRABALHADORES RURAIS SEM TERRA}

A Reforma Agrária corresponde a um conjunto de ações que buscam uma melhor distribuição da terra, visando um crescimento da produtividade, bem como assegurar os princípios de justiça social (BRASIL, 1964). Conforme Vilpoux (2014), esse processo acontece por meio da distribuição de terras que estão sem produção ou com baixa produtividade; essas terras são então destinadas para os trabalhadores rurais sem terra. De acordo com dados do INCRA (2016) - Instituto Nacional de Colonização e Reforma Agrária, existem, no Brasil, 9.340 assentamentos, onde vivem 977.039 famílias, que ocupam mais de 88 milhões de hectares.

A questão da reforma agrária brasileira, apesar de ser um tema recorrente ao longo dos anos, veio à tona em decorrência de acontecimentos causados, principalmente, por propostas do regime militar instaurado no país entre 1964 a 1985. O primeiro desses acontecimentos aconteceu no período de 1967 a 1973, período conhecido como "milagre econômico", devido ao acelerado crescimento econômico do país. Apesar de tal crescimento, a política econômica vigente naquele período fez com que aumentassem as desigualdades sociais. Ainda nas décadas de 1960 e 1970, outro fator agravante foi a substituição da mão de obra a partir da mecanização da agricultura. Por fim, outro período importante ocorreu entre 1989 e 1993, quando aconteceu a crise agrícola, a qual resultou em uma perda de 8 milhões de hectares e na expulsão de, aproximadamente, 3 milhões de pessoas do campo. No entanto, os debates referentes à reforma agrária ganharam maiores proporções apenas em 1995, diante de uma maior visibilidade das ações do Movimento dos Trabalhadores Rurais Sem Terra - MST (EID; SCOPINHO; PIMENTEL, 1998).

O MST foi um dos movimentos sociais que surgiram a partir de meados da década de 1970 e que tinham como foco a conquista da terra e questões relacionadas à agricultura. Dentre os fatores que impulsionaram o surgimento desses grupos, destaca-se a construção de diversas barragens pelo país, o que levou à desapropriação de diversos agricultores (SOUZA, 2001). Apesar da garantia de indenização, tal fato não ocorreu, desencadeando uma série de ações dos agricultores, os quais visavam a indenização pela terra que havia sido perdida. Cabe destacar que, durante esse processo, a Igreja teve um papel importante para os movimentos, por meio da Comissão Pastoral da Terra (CPT), bem como o Sindicato dos Trabalhadores Rurais (STR). 
Ainda conforme a autora, alguns movimentos realizados pelos agricultores em busca de indenização foram bem-sucedidos. Diante disso, a CPT e os STR buscaram ampliar o movimento de luta pela terra por meio da inclusão não apenas de agricultores que perderam suas terras, mas também de diversos tipos de classes, como arrendatários, posseiros, assalariados rurais e produtores de pequeno porte com pouca terra.

Com o propósito de possibilitar a troca de experiências entre pessoas que estavam envolvidas nessas ações, foi organizado o $1^{\circ}$ Encontro Nacional dos Sem Terra, em 1984, em Cascavel, Paraná. Foi durante esse encontro que o Movimento dos Trabalhadores Rurais Sem Terra foi consolidado (SOUZA, 2001).

Os objetivos do movimento, além da redistribuição de terras, são também a busca por excedentes na produção e garantia de suporte ao produtor, possibilitando que o mesmo tenha acesso ao crédito e à assistência técnica, por exemplo (EID; SCOPINHO; PIMENTEL, 1998). Para isso, diversas formas de organização produtiva têm sido testadas nos assentamentos. Segundo Borsatto e Carmo (2013), a influência das ideias sobre produção de autores como Marx e Lênin explica o incentivo ao cooperativismo por parte do MST. Segundo o MST (2014), uma de suas principais contribuições é a produção de alimentos saudáveis para a sociedade, o que é possível por meio da cooperação agrícola, a qual é viabilizada pela organização de cooperativas, associações e agroindústrias nos assentamentos.

De acordo com Scopinho e Martins (2003), o Sistema Cooperativista dos Assentados (SCA) é visto, pela Confederação das Cooperativas de Reforma Agrária do Brasil (CONCRAB), como a melhor forma de organizar a produção dos assentamentos. Esse sistema se diferencia da forma cooperativa tradicional por incluir, também, valores políticos e sociais, e não apenas a busca pelo lucro. Conforme Scopinho e Martins (2003), na visão da CONCRAB, a cooperação é um valor, além disso, faz com que a consciência social seja promovida. O objetivo do SCA é estimular o cooperativismo agrícola nos assentamentos. De acordo com a CONCRAB (1997, p. 9):

O SCA é responsável pela organização de base dos assentados, pela organização da produção, da tecnologia, da transformação ou agroindústria, pela boa aplicação do crédito rural, pela comercialização e, também, pela mobilização social dos assentados frente à política agrícola do governo, à política econômica e pelas condições básicas dos assentamentos. 
Existem diversas formas de cooperação nos assentamentos, segundo a CONCRAB (1997), as quais são:

- Núcleos de Produção: corresponde à junção de algumas famílias, cujo critério pode ser a proximidade, o parentesco ou a decisão de produção; os lotes permanecem como lotes individuais, bem como a moradia, sendo que, entretanto, podem existir agrovilas.

- Grupo semicoletivo: nessa forma de cooperação, parte da terra e da produção ficam sobcontrole do indivíduo e a outra parte fica sob o domínio do coletivo. Nos grupos semicoletivos, a moradia geralmente é organizada em agrovilas, mas existem também lotes individuais.

- Grupo coletivo: o processo de produção é organizado de forma coletiva, a posse da terra que fica sob controle individual é a parte destinada para a subsistência, salvo se o grupo decidir pela coletivização de toda a terra. Nos grupos coletivos, a moradia geralmente é organizada em agrovilas.

- Cooperativa de Produção Agropecuária (CPA): o que diferencia uma CPA de um grupo coletivo ou de uma associação coletiva é o aspecto jurídico, uma vez que é regida pela legislação cooperativista brasileira. Nas CPAs, tanto a produção quanto a gestão e o trabalho são coletivos e apenas a terra destinada à subsistência permanece individual; a parte da terra que passa para o controle da cooperativa é cedida por meio de um contrato de comodato ou de um arrendamento simbólico. A divisão do trabalho acontece em setores e a moradia, geralmente, é organizada em agrovilas.

Além das formas cooperativas de produção, existem também as cooperativas de prestação de serviços, sendo elas:

- Associação: em geral, corresponde à uma associação de prestação de serviços, cujo objetivo é viabilizar atividades que são inviáveis, se realizadas individualmente; a associação de máquinas é um exemplo. Em relação à moradia, esta pode ser organizada de forma individual ou em agrovilas;

- Cooperativa de Prestação de Serviços: responsável por aspectos ligados à comercialização, assistência técnica, serviço de máquinas, capacitação técnica etc.; as moradias podem ser tanto individuais quanto coletivas;

- Cooperativa de Produção e Prestação de Serviço: pode ser caracterizada como uma transição entre a cooperativa de prestação de serviço e a de produção agropecuária; ou seja, surge quando uma cooperativa de prestação de serviço passa a produzir determinado produto; as moradias podem ser individuais ou coletivas. 
A organização da moradia em agrovilas é incentivada pela CONCRAB, pois facilita o acesso a serviços como energia, água, escola, posto de saúde e outros. No entanto, as famílias que moram em uma mesma agrovila não são obrigadas a trabalhar de forma coletiva, sendo uma possibilidade também o trabalho individual (CONCRAB, 1997). Para Diniz e Gilbert (2013, p. 28), organizar a moradia em agrovilas é uma forma e "promover o senso de comunidade e de identidade coletiva".

Dentre as formas produtivas testadas nos assentamentos, destacam-se os grupos de produção coletivizados, como as Cooperativas de Produção Agropecuária. Estas foram formalmente estabelecida em 1989. O sistema de produção coletivizado é visto, pelo MST, como uma forma avançada de organizar a produção, em comparação com os sistemas semi-coletivizados e individuais (EID; SCOPINHO; PIMENTEL, 1998). As Cooperativas de Produção Agropecuária podem também agregar valor ao produto, por meio da instalação de agroindústrias para beneficiamento dos produtos (EID; SCOPINHO; PIMENTEL, 1998).

De acordo com Souza (2001), as Cooperativas de Produção Agropecuária foram criadas, principalmente, em resposta a algumas colocações do $1^{\circ}$ Plano Nacional de Reforma Agrária. Tendo em vista o objetivo de viabilização econômica dos assentamentos, essa estrutura organizacional é vista como a principal estratégia do movimento (SOUZA, 2001). De acordo com Eid, Scopinho e Pimentel (1998), a produção coletiva é viabilizada pelo senso de consciência social considerado existente. Em relação à organização do trabalho, nas CPAs, este é dividido em setores. A divisão ocorre a partir das características do grupo como, por exemplo, "o grau de companheirismo via luta pela terra em período anterior ao assentamento e na fase do acampamento", entre outros fatores, como a escolha da cultura que será produzida e se a produção fará uso de maquinário, ou não. "Esse conjunto de aspecto é fortemente influenciado pela trajetória de vida e de trabalho das famílias cooperadas" (EID; SCOPINHO; PIMENTEL, 1998, p. 6).

Outro ponto que merece destaque é a influência direta que o ambiente institucional exerce sobre a atividade da produção familiar e, consequentemente, sobre a atividade dos assentados. No contexto da agricultura familiar, dentro do qual se encontram os assentamentos, o ambiente institucional influência de forma significativa a atividade desses agentes, uma vez que alguns programas governamentais são implantados buscando incentivar a agricultura familiar. Dentre 
esses programas, destacam-se o PAA (Programa de Aquisição de Alimentos) e o PNAE (Programa Nacional de Alimentação Escolar).

O PAA foi instituído pela Lei no 10.696 de 2003. Dentre as finalidades do programa, destacamse o incentivo à agricultura familiar, bem como o incentivo ao consumo de produtos provenientes da agricultura familiar, promoção das compras governamentais de alimentos, formação de estoques públicos de alimentos e apoio à formação de estoques pelas cooperativas e outras organizações formais (BRASIL, 2003). O PNAE, por sua vez, foi instituído anteriormente, durante a década de 1950. O programa, que é reconhecido popularmente como merenda escolar, obteve essa nomenclatura apenas em 1979. Seu objetivo é suprir, de forma parcial, as necessidades alimentares dos alunos. Até 1993, o programa era executado de forma centralizada. Sua descentralização aconteceu apenas em 1994, por meio de convênios realizados com municípios e o Distrito Federal (FNDE, 2015).

Apesar desses programas, os produtores dos assentamentos possuem formas distintas de se relacionarem com o mercado para a comercialização da produção. Além das formas cooperativas tratadas anteriormente e da venda por meio dos programas governamentais, os assentados também podem comercializar seus produtos por meio de atravessadores (SILVA, 2013). Essa constatação chama a atenção para as diferentes estruturas de governança à jusante que os mesmos utilizam, bem como para as motivações que levam a essa diversidade.

\subsection{O surgimento do assentamento objeto de estudo dessa pesquisa}

O assentamento objeto de estudo dessa pesquisa está localizado nas cidades de Itapeva e Itaberá, no estado de São Paulo. Sua formação se deu em 1984/1985 e teve o apoio da Comissão Pastoral da Terra e do Movimento dos Trabalhadores Rurais Sem Terra, embora este último ainda estivesse em processo de formação. Apesar disso, de acordo com Venâncio e Suzuki (2009), é possível notar uma clara influência do Movimento no dia a dia do assentamento; pessoas que participaram das lutas para conquistá-lo fizeram parte da formação do MST. De acordo com Silva (2013), as duas primeiras ocupações da fazenda marcaram o surgimento do MST no estado de São Paulo. As demais ocupações já aconteceram com a existência do Movimento. Venâncio e Suzuki (2009, p. 16) afirmam que a bandeira do MST é vista como "símbolo da 
identidade da maioria dos camponeses do Assentamento". Tal constatação evidencia a influência do ambiente institucional, especialmente das instituições informais, traduzido nos costumes e tradições do MST, sobre o cotidiano dos assentados.

Tal assentamento é de responsabilidade da Fundação Instituto de Terras do Estado de São Paulo (ITESP), órgão responsável pelas questões agrárias e fundiárias no estado. Atualmente, o assentamento possui sete áreas, distribuídas entre as cidades de Itaberá e Itapeva. A fazenda onde hoje é o assentamento foi repassada ao estado de São Paulo em 1950, pela Companhia Agrícola e Industrial de Angatuba, a fim de executar uma dívida da companhia. Com o intuito de desenvolver a cultura de trigo na região, o Estado trouxe um agrônomo italiano, cedendo a ele as benfeitorias da fazenda. No entanto, essa estratégia falhou diante do arrendamento de algumas áreas da fazenda para pecuaristas, feito pelo mesmo agrônomo. As outras áreas ficaram para 190 famílias de lavradores de pequeno porte que já habitavam na fazenda, por meio de arrendamento. Mais tarde, o Estado retomou a área cedida anteriormente. Foi então tentado um acordo entre as famílias de lavradores e os pecuaristas, no qual eles ficariam com 100 hectares de terra e o trabalho deveria acontecer em regime familiar. No entanto, os pecuaristas recusaram a proposta. Diante disso, o Estado optou pelo despejo dos mesmos, mas não obteve sucesso (IOKOI et al., 2005; SILVA, 2013).

De acordo com Iokoi et al. (2005), a fim de executar um projeto de colonização, a fazenda passou da Coordenadoria de Assistência Técnica Integral (CATI) para a Assessoria de Revisão Agrária (ARA). A intenção era dar o título de domínio da terra para as famílias que lá estavam. No entanto, os pecuaristas resistiram, pois ainda dominavam cinco mil hectares de terra. Então, o Instituto de Assuntos Fundiários (IAF) conduziu um trabalho, em 1980, com o objetivo de regularizar a área.

O processo de ocupação das áreas 1 e 2 teve início em 1982, quando cerca de 40 famílias ocuparam as terras durante um período de quatro meses, sendo expulsos pelos pecuaristas. Em 1983 houve uma nova ocupação. Dessa vez, porém, as famílias foram expulsas por decisão judicial. Novamente, em 1984, houve outra tentativa de ocupação, contando com um número maior de famílias, cerca de 250. Diante da situação de conflito, o estado de São Paulo solicitou o despejo dos pecuaristas, em caráter emergencial, ao Poder Judiciário. Além disso, pediu a autorização para assentar 180 famílias de agricultores de terras no local, pedidos esses que 
foram aprovados. Formou-se, então, as áreas 1 e 2, onde 160 famílias foram assentadas. Essas famílias eram provenientes da própria região e também do Paraná (IOKOI et al., 2005).

O processo de construção da área 3 do assentamento, ainda conforme os autores, teve início em 1986, quando cerca de 300 famílias ocuparam uma área irregular. Essas famílias foram expulsas e passaram a acampar nas estradas próximas, onde permaneceram durante um ano. Mais tarde, as famílias foram assentadas de forma provisória, em situação emergencial, até 1996, quando foi realizada a seleção das famílias.

Em 1989, foi iniciado o processo de ocupação da área 4 do assentamento. Naquele ano, 150 pessoas ocuparam um lote que estava sendo utilizado por um grupo de colonos, o qual era considerado irregular. As pessoas envolvidas nessa ocupação eram parentes das famílias que já estavam assentadas no assentamento. No entanto, os trabalhadores sem-terra foram expulsos por meio de uma liminar de reintegração de posse. Após a expulsão, essas pessoas montaram acampamento próximo a um rio e, posteriormente, na beira de uma rodovia, com a possibilidade de uma ação de despejo, até 1990. A disputa continuou, dada a investida em outras terras. Com essas disputas, as famílias ficaram em lotes de outros assentados, em caráter provisório. Em 1991, foi atendido o pedido de sequestro dos lotes feito pelo governo do estado de São Paulo (IOKOI et al., 2005).

A área 5 do assentamento começou a ser formada em 1992. Essa área era de propriedade do estado de São Paulo e foi destinada à reforma agrária. Nessa área, ainda havia a presença de alguns colonos, fato que gerou conflito entre estes e os trabalhadores sem-terra. No entanto, o direito de permanecer na terra foi dado para as famílias. O número de famílias que ocuparam a área foi 39. A ocupação dessa área se efetivou em 1998 (IOKOI et al., 2005). Por fim, houve o processo de ocupação da área 6, o qual ainda está em curso; as famílias estão assentadas por meio de um projeto emergencial, tendo sido conquistada apenas a área da agrovila (SILVA, 2013). Conforme dados do INCRA (2016), existe também a área 7, em caráter emergencial, com capacidade para 47 famílias, tendo apenas 6 famílias assentadas, totalizando 42 hectares.

No assentamento, as moradias são divididas por agrovilas. Segundo Souza (2013), as decisões sobre produção e sobre a forma de organizar as moradias aconteceram durante os processos de ocupação das áreas. Em relação ao número de famílias assentadas, existe certa divergência. Segundo informações passadas pelos assentados, existem, atualmente, 506 famílias assentadas, 
divididas em sete áreas. No entanto, segundo dados do INCRA (2016), existem 363 famílias. Para o ITESP, no assentamento vivem 410 famílias, divididas em oito áreas, informação que será considerada para a condução dessa pesquisa. A localização (município), o número de famílias assentadas e o tamanho de cada área, segundo dados do INCRA, podem ser visualizados na Tabela 1.

Tabela 1 - Caracterização das áreas do assentamento

\begin{tabular}{ccccc}
\hline Assentamento & Município & $\begin{array}{c}\text { Capacidade } \\
\text { de Famílias } \\
\text { Assentadas }\end{array}$ & $\begin{array}{c}\text { Número de } \\
\text { Famílias } \\
\text { Assentadas }\end{array}$ & Área Total (ha) \\
\hline Área 1 & Itapeva & 107 & 107 & 2.511 \\
Área 2 & Itapeva & 56 & 55 & 1.341 \\
Área 3 & Itaberá & 73 & 73 & 2.142 \\
Área 4 & Itapeva & 51 & 50 & 1.096 \\
Área 5 & Itaberá & 39 & 39 & 807 \\
Área 6 & Itaberá & 52 & 39 & 126 \\
Área 7 & Itaberá & 47 & 6 & 42 \\
Total & - & $\mathbf{4 2 5}$ & $\mathbf{3 6 3}$ & $\mathbf{8 . 0 6 5}$ \\
\hline
\end{tabular}

Fonte: INCRA (2016).

Segundo pesquisa realizada em 2000, existiam, nesse assentamento, cinco CPAs; são elas: Coprocol e Treze de Maio (Área 1), Copava (Área 3), Copadec (Área IV) e Copanossa (Área 5), além de uma Cooperativa Regional, denominada COAPRI, duas Associações e três Núcleos de Família. À época, cerca de metade dos produtores do assentamento eram cooperados e metade eram não cooperados (PIMENTEL; EID, 2000). Segundo Silva (2013), para além das cooperativas, os produtores podem entregar a produção para atravessadores, para os quais, muitas vezes, o pagamento acontece em espécie. Em conversa com os assentados, pôde-se constatar que alguns produtores, especialmente os produtores de quiabo, entregam a produção diretamente para entrepostos. A Figura 8 ilustra as diferentes formas de comercialização utilizadas pelos assentados, as quais aparecem destacadas na figura. A venda para os atravessadores acontece por meio do mercado spot ou forma híbrida; esta última se caracteriza quando o produtor e o atravessador desenvolvem uma relação de confiança. A venda para os Ceasa's acontece via mercado e, por fim, a entrega dos produtos para cooperativas é caracterizada também como uma forma híbrida de governança. Cabe ressaltar que a organização em cooperativas para, além de outros aspectos, comercializar a produção é 
incentivada pelo Movimento dos Trabalhadores Rurais Sem Terra (MST, 2014), portanto, a cooperativa é tratada nesse estudo como a forma híbrida incentivada pelo grupo social.

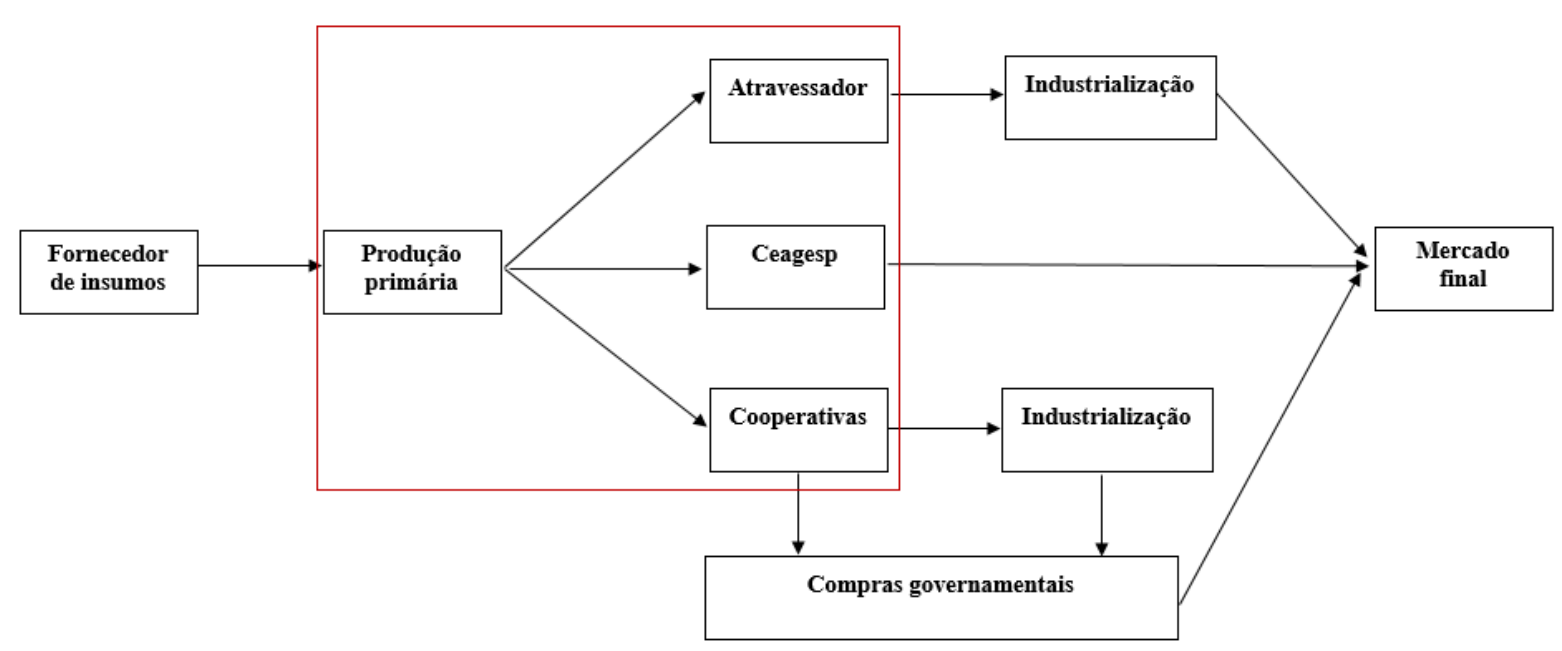

Figura 8 - Cadeia de produção dos produtos do assentamento analisado.

Fonte: elaborado pela autora.

Ao tratar da cooperação, Grassi (2006) afirma que a decisão em cooperar está na crença de que os ganhos são maiores por meio da cooperação, se comparados a outras formas organizacionais. Esses ganhos, de acordo com Thévenot (apud Vilpoux, 2014), não se traduzem apenas em benefícios econômicos, mas envolve também outros benefícios, como por exemplo, o respeito à tradição e ao interesse coletivo. Vilpoux (2014) parte da hipótese de que o estabelecimento de arranjos cooperativos é uma importante ferramenta para a sobrevivência dos assentamentos, além de ser um dos principais fatores para que a reforma agrária seja factível. O autor trata os arranjos cooperativos como a "implantação de cooperativas e associações com objetivos mercantis, tais como produção, armazenamento, compra e organização de vendas. Essas entidades podem ser formais ou informais" (VILPOUX, 2014, p. 66). Mansfield (2005), que analisou cooperativas de produção rural no sudeste do Brasil, afirma que estudos destacam quatro principais motivos internos que levam à cooperação, sendo eles o altruísmo, princípios, justiça e autointeresse.

Diante do apresentado nesta seção, pôde-se verificar que as formas cooperativas são incentivadas pelo MST, a fim de viabilizar a produção dos produtores do assentamento. Dessa forma, é esperado que os produtores que se identificam com o MST buscarão utilizar e favorecer as formas cooperativas para a comercialização de seus produtos. 


\section{PROCEDIMENTOS METODOLÓGICOS}

Esta seção irá apresentar os métodos que foram utilizados para a realização desta pesquisa. Para a descrição dos procedimentos metodológicos, será seguido o critério proposto por Collis e Hussey (2005). Os autores classificam a pesquisa quanto ao objetivo, ao processo, à lógica e quanto ao método. Além disso, serão apresentadas as variáveis de pesquisa, o plano amostral, a técnica de coleta de dados e a forma de análise dos resultados.

\subsection{Objetivo da pesquisa}

Em relação ao objetivo da pesquisa, este trabalho se classifica como descritivo e analítico. A classificação como descritiva se deve ao fato de se buscar, neste estudo, descrever o comportamento de determinado fenômeno, neste caso, como se dão as transações dentro do assentamento, bem como a influência da identidade social sobre os mecanismos de governança (VERGARA, 2003). Ainda segundo a autora, a pesquisa descritiva fornece base para a explicação do que está sendo observado.

Além de descrever de que forma esse fenômeno acontece, esta pesquisa buscará explicações para o mesmo, caracterizando-se, portanto, como uma pesquisa analítica (COLLIS; HUSSEY, 2005). Ainda conforme os autores, a pesquisa analítica tem como objetivo descobrir relações causais que envolvam o fenômeno estudado.

\subsection{Processo da pesquisa}

Quanto ao processo, essa pesquisa se caracteriza como quantitativa. A pesquisa quantitativa se preocupa em mensurar determinado fenômeno (COLLIS; HUSSEY, 2005). Nesse sentido, para analisar a influência dos aspectos individuais e da identidade sobre a decisão da estrutura de governança, bem como os aspectos relacionados à ECT, foi utilizado o método quantitativo. $\mathrm{O}$ 
método utilizado para a análise dos resultados será apresentado com maior detalhe no item 8.8 da presente seção.

\subsection{Lógica da pesquisa}

De acordo com Collis e Hussey (2005), em relação à lógica, a pesquisa pode ser classificada como dedutiva ou indutiva. Essa pesquisa lança mão da lógica dedutiva-hipotética, a qual busca testar a evidência empírica a partir do contexto teórico. Dessa forma, diz-se que ela parte do geral para o específico (COLLIS; HUSSEY, 2005). Esta pesquisa se baseia nos conceitos teóricos da Economia dos Custos de Transação e da Teoria da Identidade Social para explicar os mecanismos de governança utilizados no assentamento em análise.

\subsection{Método de pesquisa}

Quanto ao método, esta pesquisa emprega o bibliográfico e a pesquisa de campo. Caracterizase como bibliográfica, pois foram utilizados materiais publicados em livros e revistas para a elaboração do referencial teórico (VERGARA, 2003).

Ademais, foi feita uma investigação empírica no local onde o fenômeno ocorre, caracterizando, assim, uma pesquisa de campo, a qual é apresentada de forma mais detalhada na seção 8.7 deste capítulo.

\subsection{Variáveis de pesquisa}

Por meio da revisão de literatura, foi possível definir as variáveis para este estudo. A identidade social é avaliada com base na definição de Tajfel (1972), para o qual a identidade social é caracterizada como a percepção de pertença a um grupo, carregada por um valor emocional. Buscou-se avaliar a percepção de pertença em dois níveis: MST e assentamento. Segundo Leach 
et al., (2008), ainda não existe um consenso sobre a forma de mensuração da identificação, e o que se sabe é que, segundo os autores, as medidas unidimensionais não têm se mostrado adequadas. Dessa forma, novas maneiras de mensurar identificação social vêm surgindo e tornando a mensuração mais sofisticada (WACHELKE, 2012), de forma multidimensional. Outros autores também defendem a mensuração da identidade social por meio de uma medida multidimensional (CAMERON, 2004; LUHTANEN; CROCKER, 1992).

Luhtanen e Crocker (1992) estabeleceram quatro itens para mensurar a autoavaliação da identidade social. Os itens propostos pelos autores foram: filiação, avaliação própria em relação ao grupo, percepção da avaliação de terceiros em relação ao grupo e, por fim, a própria identidade, que reflete a importância do pertencimento ao grupo, para a forma como a pessoa se vê.

Cameron (2004) elaborou e testou um modelo de três fatores para mensurar a identidade social. Esses fatores foram derivados da definição de identidade social elaborada por Tajfel, a qual foi detalhada no referencial teórico deste trabalho. Dessa forma, os três componentes da identidade social propostos pelo autor foram a centralidade, a emoção com o grupo e o laço com o grupo. Para mensurar, os autores utilizaram uma escala Likert de seis pontos.

Leach et al. (2008) propuseram um modelo multicomponente hierárquico, constituído por cinco constructos provenientes de estudos anteriores, buscando incorporar esses construtos em dois maiores. O modelo foi composto por 20 itens, os quais foram baseados em outros autores que estudaram a temática. Dos 20 itens, seis foram excluídos do modelo. Os autores utilizaram escala Likert de sete pontos. Os constructos utilizados pelos autores foram: autoestereótipo, homogeneidade do grupo, solidariedade, satisfação e centralidade. Esses constructos foram enquadrados em dois mais amplos, chamados autodefinição, o qual é composto pelas duas primeiras dimensões apresentadas, e autoinvestimento, formado pelas últimas três dimensões. Para validar o modelo, os autores elaboraram sete estudos.

É possível perceber que, apesar das diferenças em relação à denominação dos fatores em cada trabalho mencionado acima, existe certa semelhança quanto ao conceito de tais fatores. Por exemplo, as variáveis que Luhtanen e Crocker (1992) enquadraram-se no fator que eles chamaram de identidade, sendo que Leach et al. (2008) enquadram tais variáveis no constructo denominado centralidade. 
Para este estudo, para analisar a identificação social, utilizaram-se variáveis propostas por esses três trabalhos, entendendo que, dessa forma, o conceito de identidade social proposto por Tajfel (1972) estaria mais bem abarcado. Assim, a presente pesquisa mensurou a identidade social com base em 13 itens $^{10}$, para os quais os respondentes deram uma nota de 0 a 10 , de acordo com o seu nível de concordância, sendo $0=$ não, nem um pouco e $10=$ sim, muito. A escala de identificação é apresentada a seguir.

Quadro 5: Escala de identificação social.

\begin{tabular}{|l|c|}
\hline \multicolumn{1}{|c|}{ Variável } & Autor \\
\hline Eu me vejo como um membro do grupo. & Leach et al. (2008) \\
\hline $\begin{array}{l}\text { Eu geralmente sinto que sou um membro útil para o } \\
\text { grupo. }\end{array}$ & Luhtanen e Crocker (1992) \\
\hline $\begin{array}{l}\text { Tenho muito em comum com os membros desse } \\
\text { grupo (tenho muitas características parecidas). }\end{array}$ & Cameron (2004); Leach et al. (2008) \\
\hline $\begin{array}{l}\text { No geral, o grupo é considerado bom pelas pessoas de } \\
\text { fora. }\end{array}$ & Luhtanen e Crocker (1992) \\
\hline $\begin{array}{l}\text { As pessoas do grupo têm muito em comum umas com } \\
\text { as outras. }\end{array}$ & Leach et al. (2008) \\
\hline Sinto que tenho uma ligação com o grupo. & Cameron (2004); Leach et al. (2008) \\
\hline Me sinto comprometido com o grupo. & Leach et al. (2008) \\
\hline Sou feliz por participar desse grupo. & Cameron (2004); Leach et al. (2008) \\
\hline As pessoas desse grupo têm muito do que se orgulhar. & Cameron (2004); Leach et al. (2008) \\
\hline Me sinto bem por participar desse grupo. & $\begin{array}{c}\text { (2008) } \\
\text { (1992) }\end{array}$ \\
\hline $\begin{array}{l}\text { O fato de ser membro desse grupo é parte importante } \\
\text { de quem eu sou. }\end{array}$ & Leach et al. (2008); Luhtanen eror \\
\hline Penso com frequência sobre o grupo. & Cameron (2004); Leach et al. (2008) \\
\hline Eu sinto os problemas do grupo como se fossem meus. & Foote (1951) \\
\hline
\end{tabular}

Fonte: elaborado pela autora.

A partir disso, foi possível categorizar os indivíduos, distinguindo-os entre indivíduos que se identificam com MST/Assentamento e aqueles que não se identificam (AKERLOF; KRANTON, 2005). A norma social esperada para o primeiro grupo é que esse busque promover a forma incentivada pelo grupo, no caso, a cooperativa. Por sua vez, o segundo grupo, o que não se identifica, buscará outras formas para transacionar, não favorecendo, assim, a forma cooperativa.

Além disso, o questionário traz uma open-ended question (ASHMORE; DEAUX; MCLAUGHLIN-VOLPE, 2004), que se caracteriza como uma questão aberta no final, na qual

\footnotetext{
${ }^{10}$ A variável 76 (“se a liderança decide sobre uma questão eu tenho que obedecer”) não foi incluída na análise uma vez que a mesma não está relacionada à identidade social.
} 
o entrevistado deve apontar o grupo ao qual ele se considera pertencente. A pergunta foi colocada da seguinte forma: "em termos de movimentos sociais, eu me considero membro de:__ _. A descrição mais detalhada das variáveis de pesquisa pode ser visualizada no Quadro 6.

Quadro 6: Variáveis de pesquisa

\begin{tabular}{|c|c|c|}
\hline \multicolumn{2}{|c|}{ Variáveis da pesquisa } \\
\hline Objetivo & Variáveis & Autores \\
\hline Caracterização do produtor & 1 a 17 & - \\
\hline Caracterização da atividade & 18 a 36 & Eid, Scopinho e Pimentel (1998) \\
& & $\begin{array}{c}\text { Pimentel e Eid (2000) } \\
\text { Concrab (1997) }\end{array}$ \\
\hline Caracterização das transações & 37 a 53 & Williamson (1979) \\
& Williamson (1996) \\
\hline Utilidade da identidade & 43 & Akerlof e Kranton (2000; 2005; 2010) \\
& & Ashforth e Mael (1989) \\
Microfundamentos e & 54 a 77 & Ashmore; Deaux; Mclaughlin-Volpe (2004) \\
identidade social & & Barney e Felin (2013) \\
& & Cameron (2004) \\
& & Felin e Foss (2005) \\
& & Felin e Foss (2006) \\
& & Foote (1951) \\
& Leach et al. (2008) \\
& & Luhtanen e Crocker (1992) \\
& & Tajfel (1972) \\
\end{tabular}

Fonte: elaborado pela autora.

O quadro seguinte (Quadro 7) apresenta a descrição das variáveis que foram utilizadas nas regressões, mostrando o que cada uma significa, bem como a forma como foi mensurada. A escala de identificação social, que era composta por 13 itens $(\alpha=0,942)$, foi substituída pela média aritmética.

Quadro 7: Variáveis utilizadas para a análise.

\begin{tabular}{|c|c|c|}
\hline \multicolumn{3}{|c|}{ Variáveis utilizadas para a análise } \\
\hline Variável & Significado & Forma de apresentação \\
\hline mec_gov & $\begin{array}{c}\text { Mecanismo de governança } \\
\text { utilizado }\end{array}$ & $\begin{array}{c}\text { 0 - venda via mercado ou forma } \\
\text { híbrida via contrato relacional com } \\
\text { atravessador } \\
1 \text { - venda via forma híbrida } \\
\text { incentivada pelo grupo } \\
\text { (cooperativa) }\end{array}$ \\
\hline agrovila & $\begin{array}{l}\text { Agrovila à qual o } \\
\text { entrevistado pertence }\end{array}$ & 1 a 6 \\
\hline tempo_assentamento & $\begin{array}{l}\text { Tempo que está no } \\
\text { assentamento }\end{array}$ & $\begin{array}{c}1-0 \text { a } 10 \text { anos } \\
2-11 \text { a } 20 \text { anos } \\
3-21 \text { a } 30 \text { anos } \\
4-\text { mais de } 31 \text { anos }\end{array}$ \\
\hline
\end{tabular}




\begin{tabular}{|c|c|c|}
\hline part_ocupação & $\begin{array}{l}\text { Participação da ocupação } \\
\text { do assentamento }\end{array}$ & $\begin{array}{l}1-\text { sim } \\
2-\text { não }\end{array}$ \\
\hline escolaridade & Nível de escolaridade & $\begin{array}{c}1 \text { - Nunca estudou } \\
\text { 2- Ensino fundamental incompleto } \\
3 \text { - Ensino fundamental completo } \\
4 \text { - Ensino médio incompleto } \\
5 \text { - Ensino médio completo } \\
6 \text { - Ensino superior incompleto } \\
7 \text { - Ensino superior completo } \\
8 \text { - Pós-graduação incompleto } \\
9 \text { - Pós-graduação completo }\end{array}$ \\
\hline tipo_produto & Tipo do produto vendido & $\begin{array}{c}0 \text { - grãos/cereais/semente } \\
1 \text { - outros }\end{array}$ \\
\hline favorece_coop & $\begin{array}{l}\text { Se deixaria de vender para } \\
\text { outro para vender para a } \\
\text { cooperativa do } \\
\text { assentamento }\end{array}$ & $\begin{array}{l}0-\text { não } \\
1-\text { sim }\end{array}$ \\
\hline coop_aceitação & $\begin{array}{l}\text { Companheiros irão aceitar } \\
\text { mais o assentado se este } \\
\text { vender para a cooperativa }\end{array}$ & Likert de cinco pontos \\
\hline $\begin{array}{l}\text { dif_produto (proxy para } \\
\text { especificidade de ativos) }\end{array}$ & Diferenciação do produto & $\begin{array}{c}1 \text { - não possui } \\
2 \text { - possui qualidade diferenciada } \\
3 \text { - orgânico certificado } \\
4-\text { orgânico sem certificação }\end{array}$ \\
\hline frequência & Frequência da venda & $\begin{array}{c}1 \text { - diariamente } \\
2 \text { - semanalmente } \\
3 \text { - quinzenalmente } \\
4-\text { mensalmente } \\
5 \text { - uma vez por semestre } \\
6 \text { - uma vez por ano }\end{array}$ \\
\hline $\begin{array}{c}\text { facilidade_vender_outro } \\
\text { (proxy para especificidade de } \\
\text { ativos) }\end{array}$ & $\begin{array}{l}\text { Facilidade para vender para } \\
\text { outro comprador sem ter } \\
\text { prejuízo }\end{array}$ & Likert de cinco pontos \\
\hline $\begin{array}{c}\text { sempre_comprador (proxy para } \\
\text { incerteza) }\end{array}$ & $\begin{array}{l}\text { Produto sempre terá } \\
\text { comprador }\end{array}$ & Likert de cinco pontos \\
\hline $\begin{array}{c}\text { planta_colhe (proxy para } \\
\text { incerteza) }\end{array}$ & Planta e sabe que irá colher & Likert de cinco pontos \\
\hline membro_mst & $\begin{array}{l}\text { Se vê como membro do } \\
\text { MST }\end{array}$ & $\begin{array}{l}0-\text { não } \\
1-\text { sim }\end{array}$ \\
\hline média_id_mst & $\begin{array}{l}\text { Média da escala de } \\
\text { identificação social em } \\
\text { relação ao MST }\end{array}$ & 0 a 10 \\
\hline
\end{tabular}

Fonte: elaborado pela autora.

\subsection{População da pesquisa}


A pesquisa foi realizada com produtores de um assentamento localizado entre as cidades de Itapeva e Itaberá, no estado de São Paulo. Nesse assentamento vivem cerca de 410 famílias assentadas entre as áreas de 1 a 7, além de uma oitava área, denominada João Moreira de Macedo, segundo o censo do ITESP (Fundação Instituto de Terras do Estado de São Paulo), de 2011.

Sendo assim, por meio do cálculo de amostra para população finita, considerando 410 famílias, 95\% de confiabilidade e um erro de 10\%, a amostra deveria ser composta por 78 respondentes. No entanto, foi feito um esforço de pesquisa para coletar informações de um número maior de respondentes. Com isso, foram obtidos 125 questionários respondidos, sendo 109 questionários válidos, após a exclusão de observações com missing values, o que permitiu reduzir o erro para aproximadamente $8 \%$. Optou-se pela exclusão pelo fato de se tratarem de variáveis que serão utilizadas como dependentes. Após essa limpeza, foi verificado que seis células de variáveis independentes ainda apresentavam missing value. Para esses casos, o método adotado para a correção foi a substituição dos dados faltantes pela média de cada variável (RODRIGUES; PAULO, 2007). O método de amostragem dessa pesquisa é a amostragem por conveniência, um tipo de amostragem não-probabilística que implica na escolha de indivíduos disponíveis para responderem a pesquisa (HAIR JR. et al., 2005).

\subsection{Procedimento de coleta de dados}

Para a coleta dos dados, foram aplicados questionários semiestruturados. Os questionários foram aplicados entre os dias 12 e 15 do mês de abril de $2016^{11}$. A coleta de dados foi facilitada pelo fato do período escolhido corresponder à época de entressafra, sendo possível, portanto, encontrar os produtores em suas casas. O instrumento de coleta de dados pode ser visualizado no Apêndice A.

Foram realizados dois pré-testes do questionário. O primeiro foi realizado em julho de 2015 , com dois assentados do assentamento em análise. Após a adequação do questionário, foi realizado um segundo pré-teste, que ocorreu entre os dias 21 e 23 de outubro de 2015, durante

\footnotetext{
${ }^{11}$ A pesquisa de campo foi realizada por meio de recursos da FAPESP.
} 
uma feira de reforma agrária que aconteceu na cidade de São Paulo. Nessa feira, o questionário foi aplicado junto a 30 produtores.

\subsection{Forma de análise dos resultados}

Para verificar a influência da identidade social sobre o mecanismo de governança, foi feita uma regressão logística. A regressão logística é a mais adequada quando se tem variáveis dependentes limitadas, ou seja, quando a variável dependente é uma variável binária com valores de 0 e 1 . Esta técnica prevê a probabilidade de ocorrência de determinado evento (HAIR JR. et al., 2009; WOOLDRIDGE, 2009). Para essa análise, buscou-se saber se a identidade social influencia na decisão de governança e, especificamente, se influencia a decisão de vender a produção via mecanismo incentivado pelo grupo MST. Os mecanismos utilizados pelos assentados para comercializar sua produção foram classificados como: 0 (venda por meio do mercado spot ou forma híbrida via contrato relacional com atravessador) e 1 (venda por meio da forma híbrida incentivada pelo grupo - cooperativas). Dado que o MST incentiva o uso de formas cooperativas, é esperado que a identidade social em relação ao MST irá influenciar na decisão sobre como vender a produção.

A fim de analisar o favorecimento pela forma cooperativa, foi feita uma segunda regressão logística. Nessa análise, a variável dependente foi o favorecimento pela forma cooperativa $(0=$ não deixaria de vender para outro comprador para vender para a cooperativa e $1=$ deixaria de vender para outro para vender para a cooperativa). 


\section{ANÁLISE E DISCUSSÃO DOS RESULTADOS}

Nesta seção, serão apresentados os resultados encontrados nesta pesquisa, que tem como objetivo analisar qual o papel da identidade social sobre a escolha dos mecanismos de governança. Inicialmente, será apresentado o perfil da amostra retirada do assentamento, a qual foi formada por 109 assentados, informando o sexo dos entrevistados, bem como a escolaridade, religião, agrovila em que estão assentados, caracterização da atividade produtiva e quantidade de associados a cooperativas. Em seguida, será detalhada a forma utilizada para a comercialização dos produtos, seguindo a lógica da Economia dos Custos de Transação. Posteriormente, será analisada a influência da identidade social sobre a escolha da forma organizacional, bem como a influência que a identidade social exerce sobre o favorecimento a formas cooperativas visando a comercialização. Finalmente, será analisada a satisfação dos indivíduos em relação à forma organizacional, relacionando-a também à identificação social.

\subsection{Caracterização da amostra}

Esta seção apresenta o perfil dos assentados entrevistados no assentamento em relação à agrovila a que pertence, sexo, faixa etária, nível de escolaridade, além de apresentar o percentual de entrevistados em cada agrovila, a proporção de participantes no processo de ocupação do assentamento, o tempo em que os entrevistados estão no assentamento e, por fim, o percentual de assentados que participam de alguma cooperativa ou associação.

A quantidade de entrevistados por agrovila pode ser visualizada na Figura 9. Da mesma forma como acontece com o número de famílias/lotes, o número de agrovilas também varia. Segundo informação passada pelos assentados e segundo dados do INCRA (2016), existem sete agrovilas no assentamento. Por sua vez, para o ITESP, existem oito agrovilas. Dentre as agrovilas apresentadas pela Figura 9, apenas a número 6 não foi visitada; a aplicação de questionários com membros dessa agrovila aconteceu durante reunião dos assentados na assembleia geral da Cooperativa dos Assentados de Reforma Agrária e Pequenos Produtores da Região de Itapeva (COAPRI). As demais entrevistas foram realizadas em cada agrovila. 
Distribuição dos entrevistados nas agrovilas

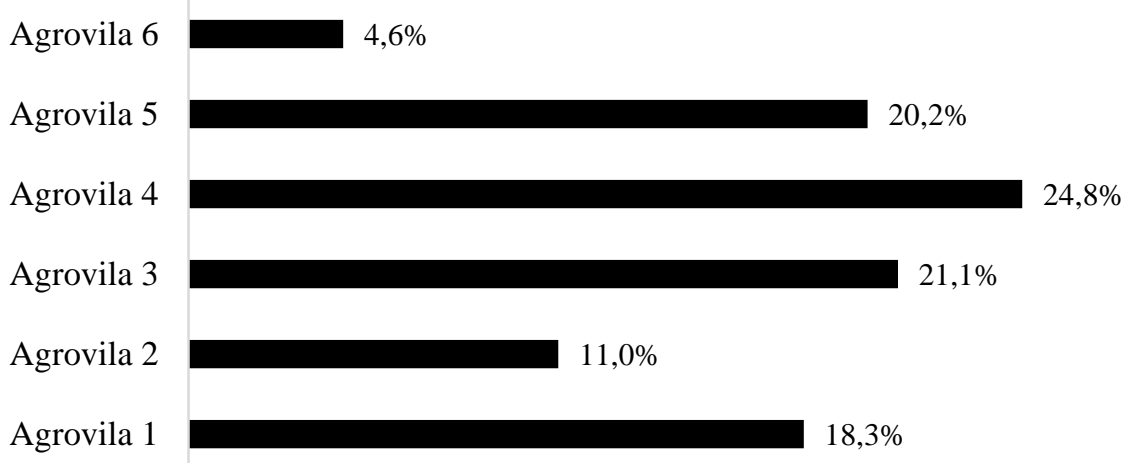

Figura 9 - Distribuição dos entrevistados nas agrovilas.

Fonte: elaborado pela autora.

Em relação ao sexo, a maior parte dos entrevistados é do sexo masculino, sendo que os entrevistados do sexo feminino representam um terço da amostra (Figura 10). Em muitos casos, a resposta do público feminino era decorrente da ausência do marido no momento da pesquisa, devido ao trabalho na lavoura, o qual, geralmente, é realizado pelo chefe da família. Apesar disso, como muitas vezes a decisão de produção e comercialização envolve a família, as mulheres apresentavam domínio sobre o que estava sendo perguntado.

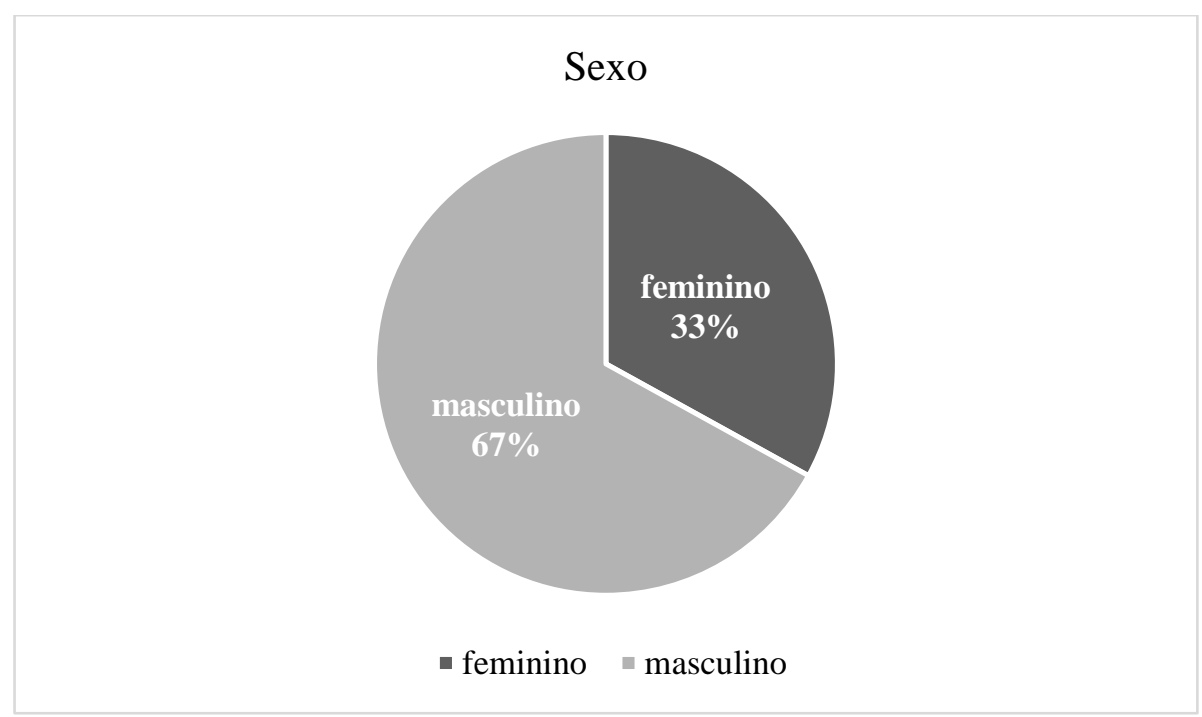

Figura 10 - Sexo dos entrevistados.

Fonte: elaborado pela autora.

Quanto à faixa etária, cerca de $60 \%$ dos entrevistados têm entre 41 e 60 anos, como pode ser visto na Figura 11. 


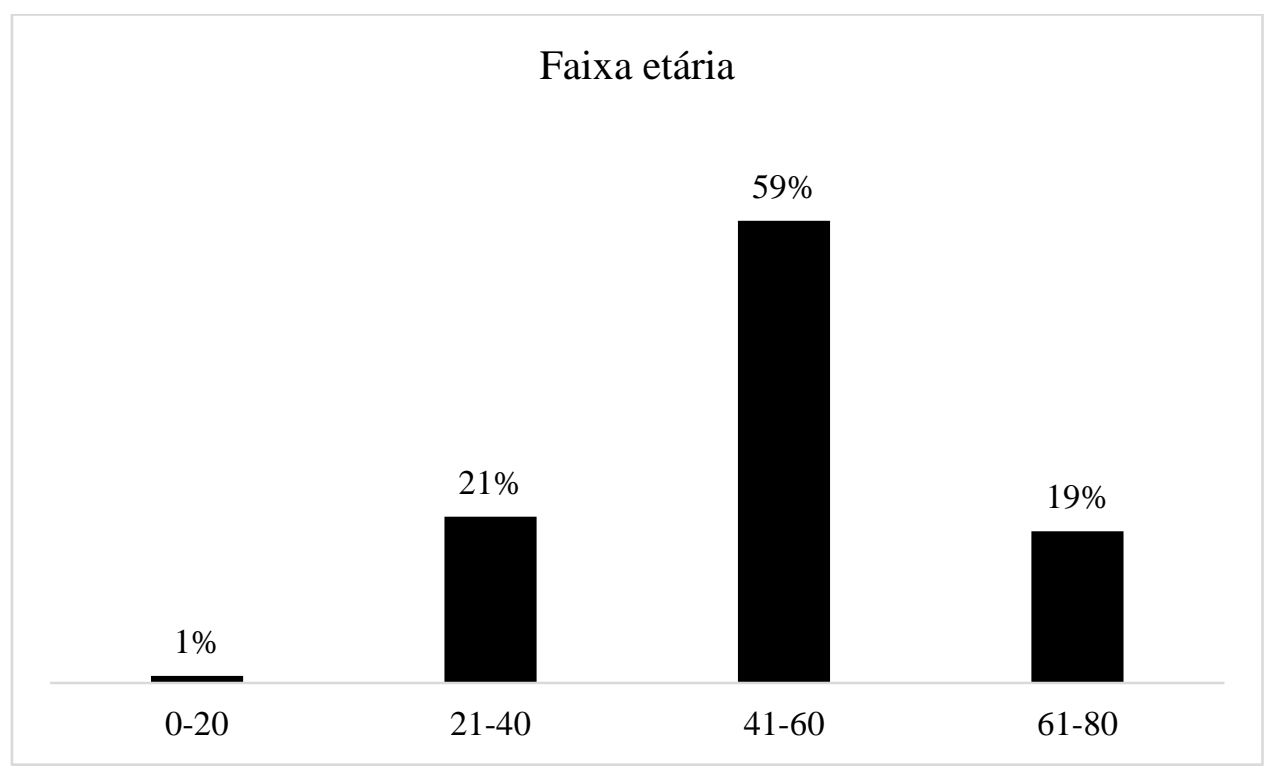

Figura 11 - Faixa etária.

Fonte: elaborado pela autora.

Em relação ao nível de escolaridade, grande parte dos entrevistados possui apenas o ensino fundamental incompleto, cerca de $60 \%$, perfil semelhante ao encontrado em um estudo anterior sobre os assentamentos no estado de São Paulo (ITESP, 1998). Desses 60\% com ensino fundamental incompleto, 76,9\% têm entre 41 e 60 anos. Uma quantidade considerável dos entrevistados possui ensino médio completo (18,5\%), dos quais $60 \%$ possuem entre 21 e 40 anos; apenas um entrevistado, que corresponde a $0,9 \%$ da amostra, tem ensino superior (Figura 12), com formação em Filosofia.

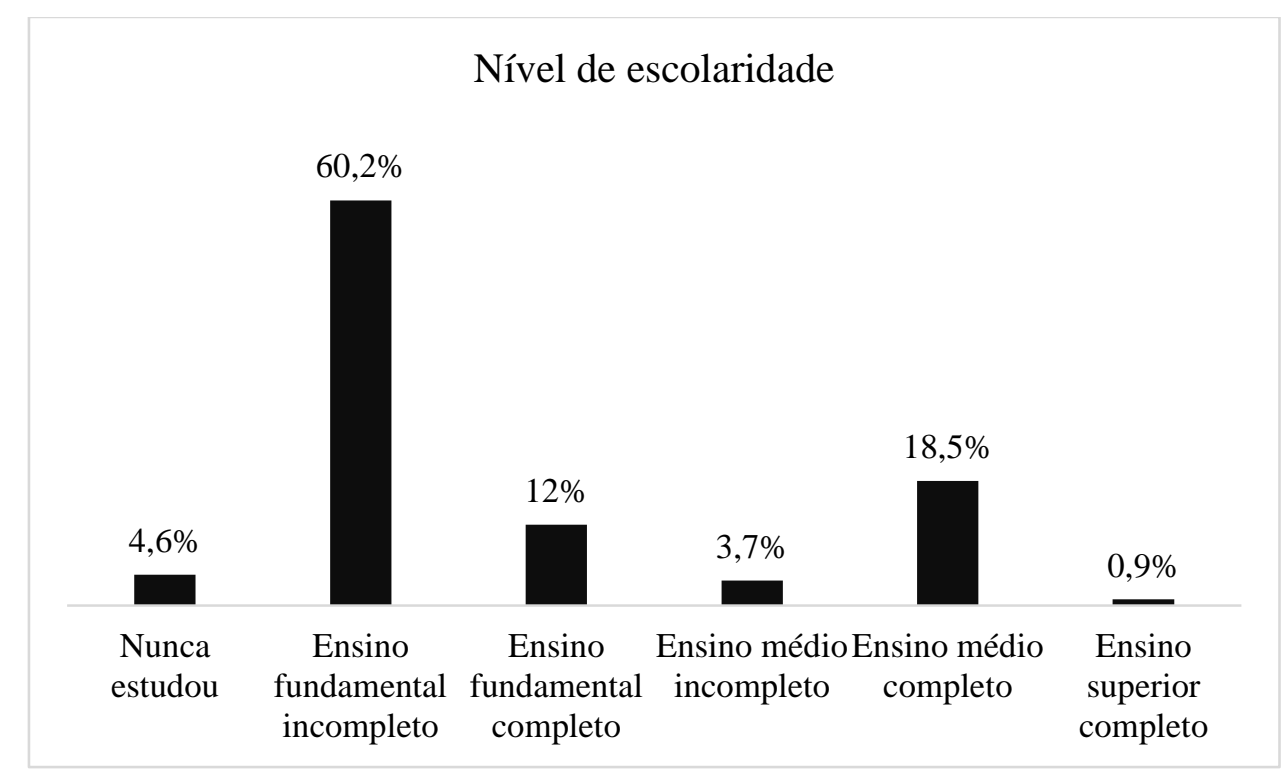

Figura 12 - Nível de escolaridade dos assentados entrevistados.

Fonte: elaborado pela autora. 
Quanto à escolaridade dos filhos, três filhos de assentados têm ensino superior completo, com formação em Agronomia. A maior parte dos filhos dos entrevistados tem ensino médio completo, sendo que alguns possuem curso técnico.

Em relação ao processo de ocupação, a maioria dos entrevistados $(75,2 \%)$ participou do processo de ocupação da área do assentamento na qual está assentado atualmente (Figura 13). Dentre os entrevistados, considerando tanto os que participaram do processo de ocupação como os que não participaram, 27,5\% eram, antes de ir para o assentamento, produtores por conta própria. Os que não tiveram experiência anterior no campo foram $23,9 \%$ da amostra, $12,8 \%$ haviam sido trabalhadores temporários, $10,1 \%$ relataram outras atividades anteriores como arrendatário, trabalho com a família e trabalho na cooperativa, 9,2\% foram trabalhadores permanentes, $9,2 \%$ foram meeiros e $0,9 \%$ exerceram atividade como caseiros. Os que não responderam foram $1,8 \%$, e os outros $4,6 \%$ relataram ter exercido mais de uma dessas atividades. A quantidade de assentados que não tiveram experiência anterior, tanto entre os que participaram quanto os que não participaram da ocupação, foi semelhante entre os dois grupos.

\section{Participação no processo de ocupação}

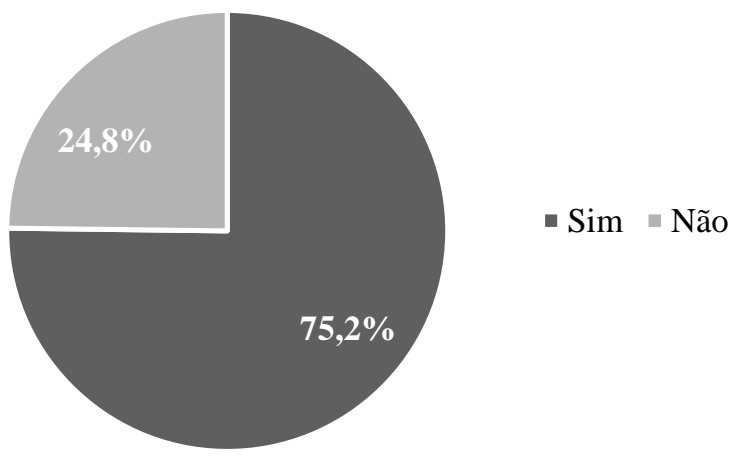

Figura 13 - Participação no processo de ocupação do assentamento em análise. Fonte: elaborado pela autora.

Para caracterizar o tempo dos entrevistados no assentamento, separou-se esse em quatro faixas: de 0 a 10 anos, de 11 a 20 anos, de 21 a 30 anos e mais de 31 anos, já que o processo de ocupação da área 1, a mais antiga, teve início em 1982. A maior parte dos entrevistados, 61,5\%, está no assentamento em um período entre 21 e 30 anos (Figura 14). 


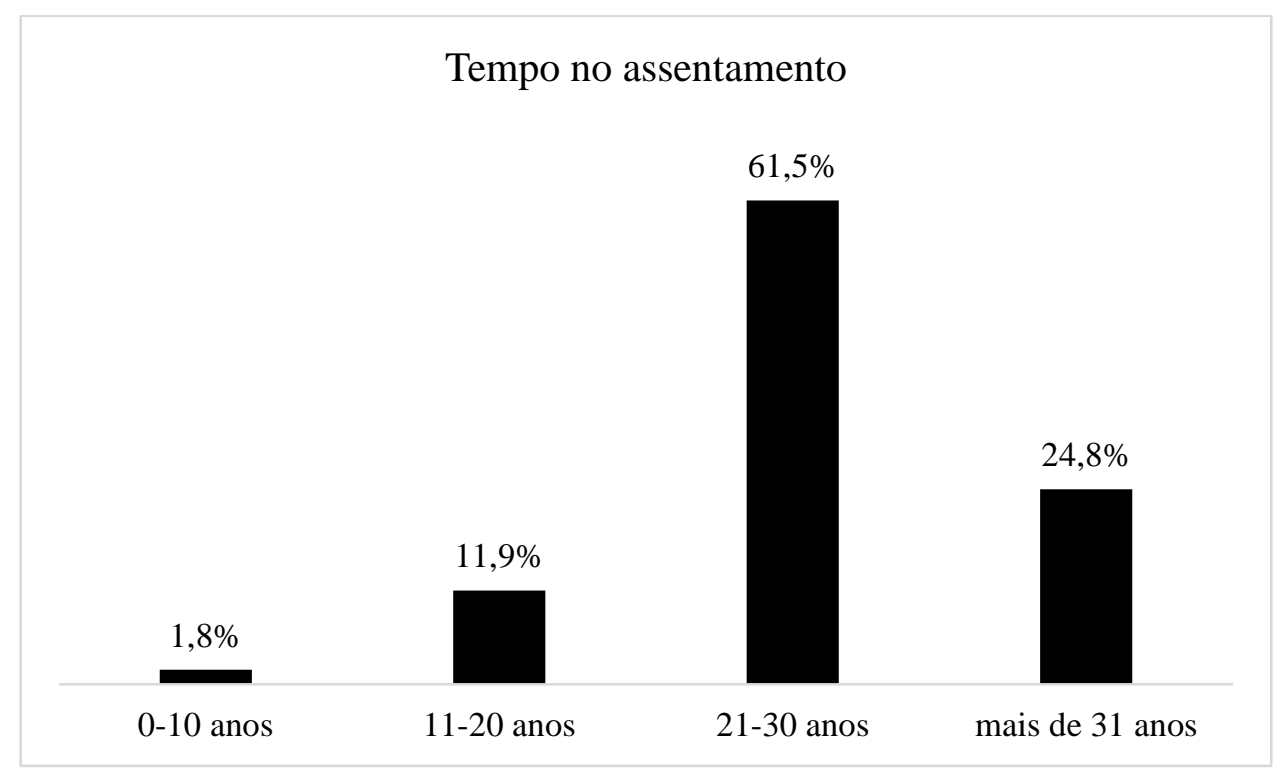

Figura 14 - Tempo dos entrevistados no assentamento.

Fonte: elaborado pela autora.

A Tabela 2 mostra a quantidade de entrevistados associados a cooperativas ou associações.

Tabela 2 - Participação em cooperativas ou associações.

\begin{tabular}{cc}
\hline Participação em cooperativa ou associação \\
\hline Sim & $58,3 \%$ \\
Não & $41,7 \%$ \\
\hline
\end{tabular}

Fonte: elaborado pela autora.

Como pode ser visualizado, cerca de $58 \%$ dos entrevistados afirmaram que participam de cooperativas ou associações. A cooperativa com a maior adesão dos assentados entrevistados é a COAPRI, visto que 44,9\% dos assentados são associados a ela. A segunda com maior adesão é a Cooperativa de Produção Agropecuária Vó Aparecida (COPAVA), com 3,6\% dos entrevistados. Esta última é caracterizada como uma cooperativa coletiva, ou cooperativa de produção agropecuária.

\subsection{Caracterização da produção e mecanismos de governança utilizados}

A maior parte dos assentados do assentamento estudado tem como principal produto de venda a soja. Além da soja, outras culturas tidas como principal também foram encontradas, como 
milho, feijão, trigo e quiabo, como mostra a Figura 15. Um dos entrevistados afirmou vender grão, mas não detalhou qual, assim como o entrevistado que afirmou vender verduras.

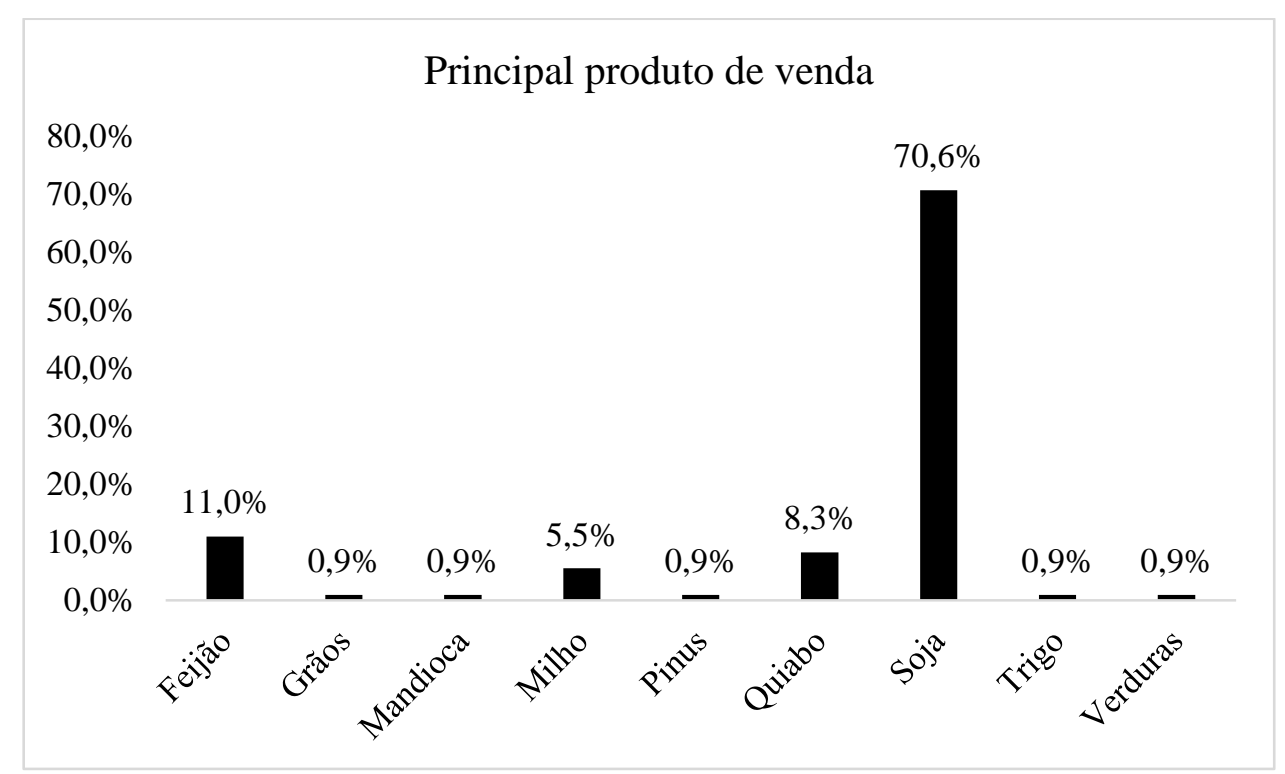

Figura 15 - Principal produto de venda dos assentados.

Fonte: elaborado pela autora.

Em relação à frequência da transação, a maioria dos produtores relatou vender o seu principal produto uma vez por ano. Como pode ser visualizado na figura acima, entre os principais produtos vendidos, as sementes (soja e feijão) e os grãos/cereais (milho e trigo) apresentam destaque. Cabe salientar que a produção dos mesmos ocorre em função da safra. No caso da soja, por exemplo, a colheita acontece anualmente, entre os meses de fevereiro e abril, e a venda, como será visto posteriormente, se dá, na maioria das vezes, por meio de um atravessador conhecido pelos assentados. Entende-se, portanto, que essa transação é recorrente, possibilitando que formas de governança mais coordenadas que o mercado, no entanto ainda próximas a ele, como os contratos relacionais, surjam para mediar essa transação. A frequência difere, de acordo com o tipo do produto transacionado; para outros produtos, além de sementes, grãos e cereais, a frequência é ainda maior, como é o caso das frutas, legumes e verduras (FLVs), podendo acontecer até três vezes por semana em alguns casos. A frequência para a venda de FLVs é significativamente maior, em comparação com os demais produtos, devido à própria característica desse tipo de produto.

Quanto à incerteza que envolve a transação, para a maioria dos entrevistados, o nível de incerteza é baixo, independente se o produto de venda principal é grão ou não. Para a maioria 
deles $(95,4 \%)$, os seus produtos sempre terão comprador, isto é, não existe incerteza em relação à demanda para os produtos. Outro aspecto analisado relacionado à incerteza se refere a saber que o que foi plantado será produzido. Apesar de as atividades agrícolas estarem sujeitas à aspectos naturais como o clima, o que leva a um alto nível de incerteza (COOK; KLEIN, ILIOPOULOS, 2008; MÉNARD; KLEIN, 2004), para a maior parte dos assentados (96,3\%), existe a certeza de que, na maioria das vezes, planta-se e sabe-se que irá vender. O nível de incerteza é o mesmo, independentemente do tipo do produto, se grãos, cereais, FLVs ou outro.

Por fim, quanto ao atributo especificidade de ativos, este é considerado baixo. Para cerca de 94\% dos entrevistados, o seu principal produto de venda não apresenta nenhuma diferenciação em relação aos demais produtores, mesmo para os que produzem FLVs, as quais são produzidas por meio do método orgânico. Além disso, para a maioria dos produtores do assentamento (76,1\%), se um comprador quebrar um acordo, é possível vender para outro sem prejuízos, o que demonstra o baixo nível de especificidade de ativos. Isso acontece devido ao fato de a maioria dos produtores trabalharem com produtos que são considerados commodities, isto é, que não se diferenciam, como é o caso dos produtores de soja, os quais são maioria na amostra da pesquisa. Para 19,3\% dos entrevistados, no entanto, se um comprador desistir de comprar, a venda para outro acarreta em prejuízo; os outros 4,6\% são indiferentes. Essa diferença não é derivada do tipo de produto produzido, uma vez que não houve diferença estatisticamente significativa entre os produtores de semente, grãos e cereais e os demais. No entanto, deve-se levar em conta que, diferentes dos grãos, produtos como frutas, verduras e legumes possuem especificidade temporal, uma vez que são altamente perecíveis (JACÓIA; AZEVEDO, 2003; RAYNAUD; SAUVEE; VALCESCHINI, 2005).

Diante dessas características transacionais apresentadas pela maior parte dos produtores do assentamento - frequência recorrente, baixa incerteza e baixo nível de especificidade de ativos - é sabido que as formas de governança menos complexas são as que levam a uma redução dos custos de transação (WILLIAMSON, 1979; WILLIAMSON, 1991). Esse fator pode ser observado também no contexto do assentamento em estudo, como será apresentado na sequência.

Para analisar os mecanismos de governança utilizados pelos assentados, considerando apenas o principal produto vendido por cada produtor, adotou-se a seguinte classificação: mercado, forma híbrida via contrato relacional e forma híbrida via cooperativas. Optou-se por separar as 
formas híbridas em duas, uma vez que, para Ménard (2004), o contrato relacional se aproxima mais da característica do mercado, diferente da forma cooperativa. Outra razão para essa classificação está no fato de que a presente pesquisa buscar analisar a adoção das formas cooperativas no assentamento.

Além das formas apresentadas acima, foi possível classificar dois casos de formas plurais, sendo que um deles vende a sua produção por meio dos mecanismos de mercado e da forma híbrida via cooperativa, uma vez que metade da produção do principal produto é entregue para a cooperativa do assentamento e a outra metade é vendida para quem passar para comprar. $\mathrm{O}$ segundo caso de formas plurais acontece entre a venda por meio da forma híbrida via contrato relacional ( $80 \%$ da venda) e forma híbrida via cooperativa ( $20 \%$ da venda). Para o primeiro caso, o principal produto é a mandioca; para o segundo, o quiabo. As formas de governança adotadas pelos produtores são apresentadas na Figura 16.

Mecanismos de governança

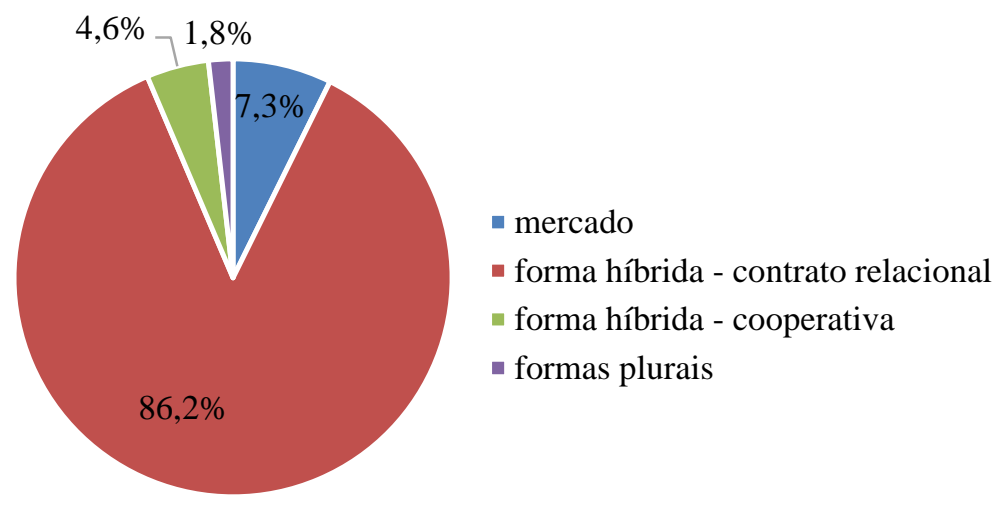

Figura 16 - Mecanismos de governança adotados.

Fonte: elaborada pela autora.

Como mostra o gráfico, as formas híbridas são as principais estruturas de governança utilizadas pelos assentados, corroborando achados anteriores. que também encontraram o uso de formas híbridas no agronegócio (COOK; KLEIN, ILIOPOULOS, 2008; MÉNARD, 1996; MÉNARD; KLEIN, 2004; MONDELLI; ZYLBERSZTAJN, 2008). O mecanismo mais utilizado pelos assentados é a forma híbrida via contrato relacional. Nessa modalidade, os produtores entregam a produção para atravessadores que já são conhecidos pelos mesmos. Entre os diversos motivos relatados por eles para escolher essa forma, estão "segurança", "confiança", "garantia de que 
vai receber", "por conhecer o atravessador", “quem paga melhor e paga certo". Muitos também preferem essa forma por não terem outra opção ou por receberem o dinheiro no momento da venda. Dentre os produtores que vendem dessa forma, $71,3 \%$ têm a soja como principal produto de venda.

Esse mecanismo de governança é o mais viável para os produtores de soja e milho, que produzem de forma individual, uma vez que a principal cooperativa do assentamento, a COAPRI, atende apenas às compras governamentais, captando apenas frutas, legumes, verduras e feijão. Segundo uma funcionária da COAPRI, a cooperativa, no entanto, pretende atender também o mercado convencional, passando a não depender apenas das compras provenientes do governo. Em relação aos grãos, apenas os que produzem soja no modelo de produção coletiva conseguem entregar a produção para a cooperativa, no caso a COPAVA. Dentre o total dos entrevistados, apenas 4,6\% vendem seu principal produto exclusivamente via cooperativas.

Ainda em relação à entrega de produtos para as cooperativas, destaca-se o fato de que, antes dos programas de compra governamentais, os assentados produziam FLVs apenas para consumo próprio. Com o início do cadastramento dos assentados no PAA/PNAE, o que aconteceu por volta de 2008 para a maioria dos assentados, os mesmos passaram a produzir em maior quantidade, a fim de auferirem renda extra. Em relação à forma de venda dos demais produtos, dentre os que produzem trigo e milho de forma individual, $100 \%$ vendem por meio do contrato relacional; dentre os que produzem soja, $87 \%$ e, dentre os que produzem feijão, $83,3 \%$.

\subsection{Influência da identidade social sobre a escolha organizacional}

Inicialmente, a fim de retomar os aspectos conceituais e operacionais desta pesquisa, será apresentado um esquema, denominado Libby Box (BLOOMFIELD, 2015; LIBBY; BLOOMFIELD; NELSON, 2002), o qual pode ser visualizado na Figura 17. Na figura, os quadros localizados na parte de cima demonstram a relação de causa e efeito entre os conceitos. Já os quadros localizados na parte inferior da figura indicam de que forma tais conceitos foram operacionalizados, além de indicar as variáveis de controle utilizadas. 


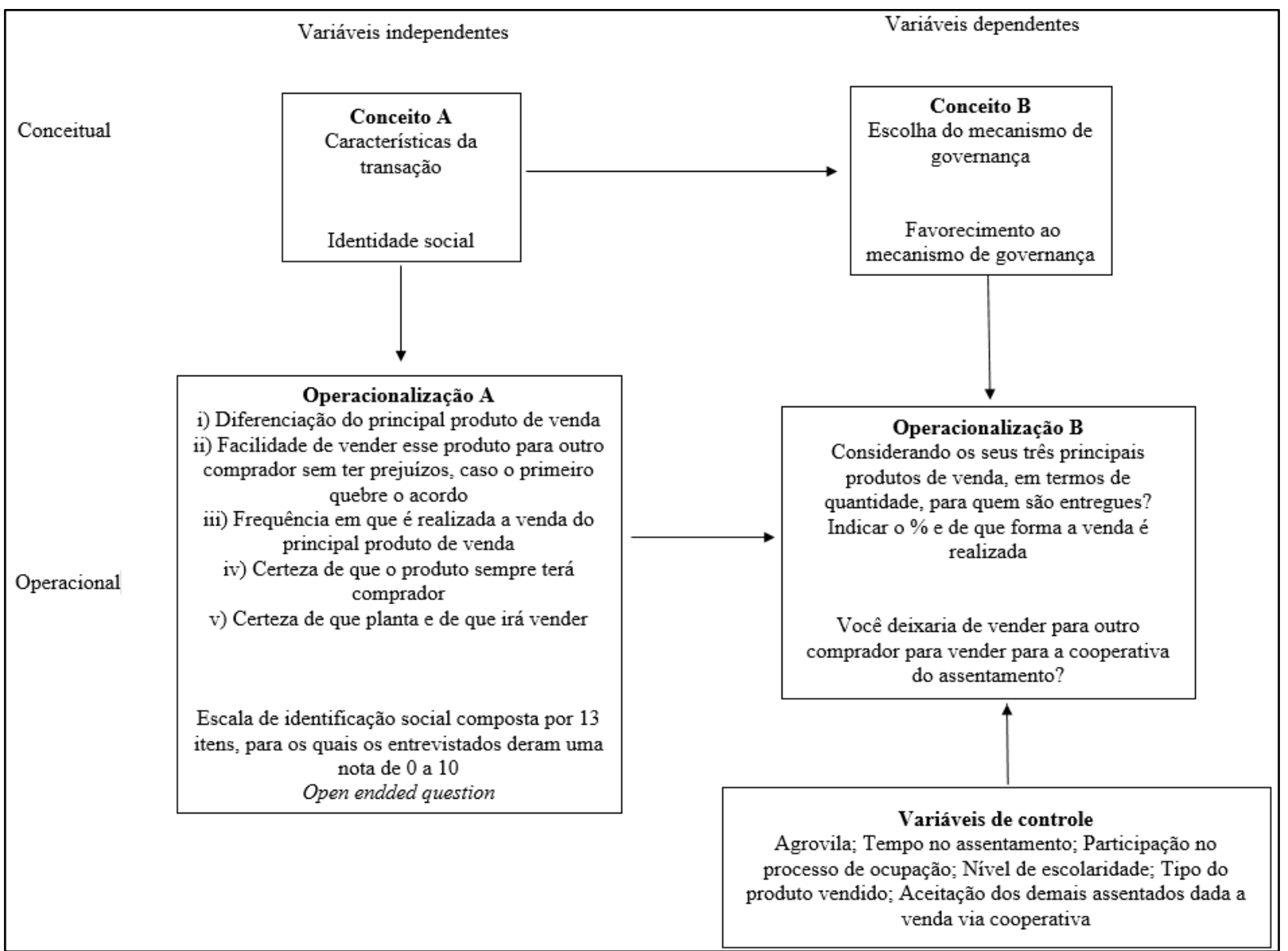

Figura 17 - Estruturas conceitual e operacional da pesquisa.

Fonte: elaborado pela autora.

Como foi descrito no método, a identidade social foi mensurada com base em uma escala multidimensional e também por meio de uma pergunta caracterizada como open-ended question (ASHMORE; DEAUX; MCLAUGHLIN-VOLPE, 2004). Em termos de sentimento de pertencimento a algum movimento social, cerca de 53\% dos assentados se veem como membros do Movimentos dos Trabalhadores Rurais Sem Terra. A média de identificação social, a qual foi obtida por meio da escala com 13 componentes, para os quais os respondentes deveriam dar uma nota de 0 a 10 , foi de 6,8 , com desvio padrão de 2,8. Pode-se dizer, portanto, que, no geral, não existe uma elevada identificação com o grupo MST, o que vai de encontro ao que foi colocado por Venâncio e Suzuki (2009), os quais afirmaram que existe uma clara influência do MST no dia a dia do assentamento.

Essa não elevada identificação pode ser decorrente do fato de os produtores já estarem assentados há um tempo, o que os levou a se distanciarem da luta pela terra de forma direta, fazendo com que houvesse uma mudança de objetivos. Por meio de conversas com os assentados, foi possível notar que a preocupação deles agora é cuidar da produção e da família. 
Outro fator que pode afetar o nível de identidade social com o movimento é o fato dos assentados lidarem com a produção, na maioria dos casos, de forma individual. Caso contrário, quando existe o uso de recursos comuns, esse geralmente acontece entre familiares.

A fim de analisar a influência da identidade social sobre a escolha do mecanismo de governança, verifica-se, inicialmente, a correlação entre as variáveis (ver Quadro 7). Pelo fato de existirem variáveis tanto de caráter quantitativo como qualitativo, além da correlação de Pearson, será apresentada também a correlação de Spearman, adequada para variáveis nominais ou ordinais (HAIR JR. et al., 2005). Na parte inferior da matriz, é apresentada a correlação de Pearson; na parte superior, a de Spearman. A matriz é apresentada na Tabela 3.

Uma das funções da matriz de correlação é permitir a identificação de problemas de multicolinearidade, os quais existem quando duas variáveis independentes apresentam correlação. Para Hair Jr. et al. (2005), pode-se considerar multicolinearidade quando o coeficiente de correlação entre duas variáveis é igual a 0,70. Esse valor, no entanto, segundo os autores, pode ser menor, caso todas as variáveis independentes estejam inter-relacionadas. Outra forma de testar a colinearidade entre as variáveis é por meio do FIV (Fator de Inflação de Variância). O valor máximo aceitável para esse teste é 5 (HAIR JR. et al., 2005). Esse teste foi realizado para todas as variáveis e não foi encontrado problema de multicolinearidade. 
Tabela 3 - Matriz de correlação

\begin{tabular}{|c|c|c|c|c|c|c|c|c|c|c|c|c|c|c|c|}
\hline & mec_gov & agrovila & $\begin{array}{c}\text { tempo } \\
\text { assentamento }\end{array}$ & $\begin{array}{c}\text { part__ } \\
\text { ocupação }\end{array}$ & escolaridade & $\begin{array}{l}\text { tipo_- } \\
\text { produto }\end{array}$ & $\begin{array}{l}\text { favorece } \\
\text { coop }\end{array}$ & $\operatorname{coop}_{\text {aceitação }}$ & $\begin{array}{l}\text { dif }_{-} \\
\text {produto }\end{array}$ & frequência & $\begin{array}{c}\text { facilidade_} \\
\text { vender_outro }\end{array}$ & $\begin{array}{l}\text { sempre } \\
\text { comprador }\end{array}$ & $\begin{array}{l}\text { planta_ } \\
\text { colhe }\end{array}$ & $\begin{array}{c}\mathrm{membro}_{-} \\
\mathrm{mst}\end{array}$ & $\begin{array}{c}\text { média_id_ } \\
\text { mst }\end{array}$ \\
\hline mec_gov & 1 & $-0,120$ & $0,200 * *$ & 0,023 & $-0,042$ & $0,250 * * *$ & $-0,005$ & 0,141 & 0,081 & $-0,149$ & $-0,232 * *$ & $-0,127$ & $-0,068$ & $-0,054$ & $0,202 * *$ \\
\hline agrovila & $-0,105$ & 1 & $-0,373 * * *$ & 0,038 & 0,066 & $-0,236 * *$ & 0,121 & $-0,084$ & $-0,130$ & $0,192 * *$ & $-0,093$ & 0,078 & 0,024 & $0,293 * * *$ & $0,268 * * *$ \\
\hline tempo_assentamento & $0,191 * *$ & $-0,358 * * *$ & 1 & $-0,345^{* * *}$ & $-0,191 * *$ & 0,080 & 0,018 & 0,153 & $-0,093$ & $-0,094$ & $-0,025$ & $-0,021$ & 0,021 & $-0,139$ & $-0,039$ \\
\hline part_ocupação & 0,023 & 0,037 & $-0,371 * * *$ & 1 & 0,093 & $0,182 *$ & $-0,137$ & $-0,070$ & 0,020 & 0,006 & $-0,052$ & $-0,181^{*}$ & $-0,079$ & $-0,101$ & $-0,095$ \\
\hline escolaridade & $-0,006$ & 0,129 & $-0,179 *$ & 0,065 & 1 & $-0,114$ & 0,121 & $-0,196^{* *}$ & 0,0340 & 0,110 & $-0,042$ & 0,018 & $-0,112$ & 0,067 & $-0,038$ \\
\hline tipo_produto & $0,250 * * *$ & $-0,229 * *$ & 0,078 & $0,182 *$ & $-0,125$ & 1 & 0,011 & 0,056 & 0,017 & $-0,229 * *$ & $-0,046$ & 0,036 & 0,057 & 0,005 & 0,089 \\
\hline favorece_coop & $-0,005$ & 0,109 & 0,033 & $-0,137$ & 0,161 & 0,011 & 1 & $0,347 * * *$ & $-0,002$ & $0,158^{*}$ & $-0,048$ & 0,036 & $-0,066$ & $0,241 * *$ & $0,268 * * *$ \\
\hline coop_aceitação & 0,128 & $-0,078$ & 0,152 & $-0,076$ & $-0,178 *$ & 0,040 & $0,348 * * *$ & 1 & $0,166^{*}$ & $-0,026$ & $-0,161 *$ & $-0,064$ & $-0,149$ & $-0,026$ & 0,102 \\
\hline dif_produto & 0,023 & $-0,190 * *$ & $-0,120$ & $-0,033$ & $-0,033$ & $-0,019$ & 0,151 & $0,205^{* *}$ & 1 & $-0,082$ & $-0,138$ & $-0,121$ & $-0,064$ & $-0,053$ & $-0,153$ \\
\hline frequência & $-0,188^{*}$ & $0,167 *$ & $-0,091$ & 0,021 & 0,130 & $-0,390 * * *$ & 0,134 & $-0,012$ & 0,032 & 1 & $0,165^{*}$ & 0,070 & 0,143 & 0,102 & 0,011 \\
\hline facilidade_vender_outro & $-0,228 * *$ & $-0,153$ & $-0,021$ & $-0,021$ & $-0,050$ & $-0,024$ & $-0,077$ & $-0,112$ & $-0,014$ & 0,070 & 1 & $0,461 * * *$ & $0,623 * * *$ & 0,029 & 0,093 \\
\hline sempre_comprador & $-0,193 * *$ & 0,038 & $-0,065$ & $-0,133$ & $-0,002$ & 0,037 & 0,070 & 0,002 & $-0,052$ & 0,027 & $0,403 * * *$ & 1 & $0,675 * * *$ & 0,093 & 0,024 \\
\hline planta_colhe & $-0,024$ & $-0,014$ & 0,014 & $-0,003$ & $-0,034$ & 0,073 & $-0,015$ & $-0,060$ & 0,030 & 0,069 & $0,477 * * *$ & $0,629 * * *$ & 1 & 0,042 & 0,023 \\
\hline membro_mst & $-0,054$ & $0,283 * * *$ & $-0,149$ & $-0,101$ & 0,085 & 0,005 & $0,234 * *$ & $-0,030$ & 0,006 & 0,088 & 0,018 & 0,115 & 0,061 & 1 & $0,518 * * *$ \\
\hline média_id_mst & $0,172 *$ & $0,295 * * *$ & $-0,078$ & $-0,070$ & $-0,051$ & $-0,005$ & $0,191 * *$ & 0,076 & $-0,075$ & 0,035 & 0,101 & $-0,003$ & 0,028 & $0,534 * * *$ & 1 \\
\hline
\end{tabular}

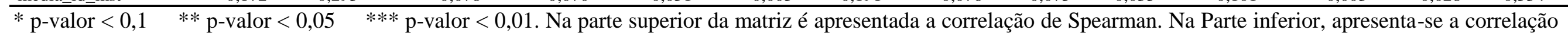
de Pearson. 
Por meio da matriz de correlação, é possível identificar uma relação positiva e significativa entre o mecanismo de governança e tempo no assentamento, tipo do produto e média de identificação. Além dessas, pode-se identificar também uma relação negativa e significativa entre o mecanismo de governança e facilidade para vender para outro comprador. Outra relação importante que foi encontrada na matriz é a relação positiva e significativa ( $\mathrm{p}$-valor $<0,01$ ) entre a média de identificação social e o favorecimento à forma cooperativa.

Para analisar a influência da identificação sobre a forma de governança, especificamente sobre o uso da forma cooperativa, caracterizada como uma governança híbrida associada ao grupo social, foi realizada uma regressão logística. O objetivo dessa análise é verificar a influência da identidade social sobre a escolha de governança. Dessa forma, classificou-se como " 0 ”" (venda via mercado spot ou forma híbrida via contrato relacional com atravessador) e"1" (venda via forma híbrida incentivada pelo grupo, no caso desse estudo, a forma cooperativa). Os dois casos vistos anteriormente sobre formas plurais se enquadraram nessa última categoria, uma vez que ambos utilizam, como uma das formas de governança, a forma híbrida cooperativa. Antes de iniciar a exposição dos testes das hipóteses, cabe aqui relembrá-las e indicar o sinal esperado para as variáveis em análise.

Quadro 8: Hipóteses de pesquisa e sinal esperado.

\begin{tabular}{|l|c|}
\hline \multicolumn{1}{|c|}{ Hipóteses } & $\begin{array}{c}\text { Sinal } \\
\text { esperado }\end{array}$ \\
\hline $\begin{array}{l}\text { H1: Transações com baixo nível de especificidade de ativos } \\
\text { reduzem a probabilidade do uso de mecanismos de } \\
\text { governança mais complexos. }\end{array}$ & - \\
\hline $\begin{array}{l}\text { H2: Quanto maior a identidade social do indivíduo em } \\
\text { relação ao grupo, maior a probabilidade de transacionar via } \\
\text { formas de governança incentivadas pelo grupo. }\end{array}$ & + \\
\hline $\begin{array}{l}\text { H3: Quanto maior a identidade social do indivíduo em } \\
\text { relação ao grupo, maior a probabilidade de favorecer a forma } \\
\text { de governança incentivada pelo grupo. }\end{array}$ & + \\
\hline
\end{tabular}

Fonte: elaborado pela autora.

Para a análise, adotaram-se as seguintes variáveis de controle: agrovila, tempo no assentamento, participação no processo de ocupação, nível de escolaridade, tipo do produto vendido e aceitação dos demais assentados dada a venda via cooperativa. As variáveis independentes foram: diferenciação do produto, frequência da transação, facilidade de vender para outro comprador em caso de quebra de acordo, certeza de plantar e colher, certeza de que sempre 
haverá comprador e média de identificação com o MST. Dentre as duas variáveis relacionadas à identificação social, optou-se por incluir no modelo apenas a média da escala de identificação, por se entender que a escala aborda exatamente o conceito de identificação, que trata tanto da percepção de pertencimento quanto do aspecto emocional desse pertencimento.

O método adotado na regressão logística foi o backward wald. Nesse método, inicialmente inserem-se todas as variáveis ao modelo. Em seguida as variáveis são retiradas conforme o impacto que causam no modelo, dessa forma, elimina-se primeiro a variável que causa menor impacto no ajuste do mesmo (FIELD, 2009). Segundo Field (2009), o método backward é preferível quando o método utilizado é o passo a passo, dado que minimiza a ocorrência do erro do Tipo II, que acontece quando uma variável que tem poder explicativo é excluída do modelo.

O modelo se mostrou adequado, sendo que o teste de coeficientes de modelo Omnibus apresentou significância estatística para rejeitar a hipótese nula ${ }^{12}$ (p-valor $\left.<0,01\right)$. O teste de Hosmer e Lemeshow também se mostrou adequado, tendo aceitado a hipótese nula ${ }^{13}$. Cerca de 46,4\% da variância da variável dependente é explicada pelo modelo final (Pseudo $\mathrm{R}^{2}$ ). Os modelos obtidos na análise em cada etapa são apresentados na Tabela 4. Apesar da amostra ser desbalanceada, contendo mais casos de venda via mercado e forma híbrida via contrato relacional do que forma híbrida via cooperativa, o modelo classificou corretamente $92,7 \%$ dos casos. Esse valor, no entanto, foi menor que a classificação inicial, que foi de 93,6\%.

\footnotetext{
${ }^{12}$ A hipótese nula do teste de coeficientes de modelo Omnibus é de que todos os coeficientes da equação logística são nulos (DIAS FILHO; CORRAR, 2007).

${ }^{13}$ A hipótese nula do teste de Hosmer e Lemeshow é de que não há diferenças significativas entre os resultados preditos pelo modelo e os observados (DIAS FILHO; CORRAR, 2007).
} 
Tabela 4 - Modelo - variável dependente: mecanismo de governança ${ }^{14}$

\begin{tabular}{|c|c|c|c|c|c|c|c|c|}
\hline Variáveis independentes & Etapa 1 & Etapa 2 & Etapa 3 & Etapa 4 & Etapa 5 & Etapa 6 & Etapa 7 & Etapa 8 \\
\hline $\mathrm{n}^{\circ}$ agrovila (1) & 12,417 & $-6,020$ & $-83,898$ & & & & & \\
\hline $\mathrm{n}^{\mathrm{o}}$ agrovila (2) & $-11,959$ & $-24,233$ & $-103,049$ & & & & & \\
\hline $\mathrm{n}^{\mathrm{o}}$ agrovila (3) & 21,399 & $-11,602$ & $-34,416$ & & & & & \\
\hline $\mathrm{n}^{\mathrm{o}}$ agrovila (4) & $-21,429$ & $-55,323$ & $-119,355$ & & & & & \\
\hline $\mathrm{n}^{\circ}$ agrovila (5) & $-27,911$ & $-64,526$ & $-137,508$ & & & & & \\
\hline tempo_assentamento (0 a 10 anos) & 43,582 & 53,139 & 74,993 & $-17,577$ & $-17,492$ & $-17,017$ & & \\
\hline tempo_assentamento (11 a 20 anos) & $-54,549$ & $-53,676$ & $-138,309$ & $-20,715$ & $-20,228$ & $-20,784$ & & \\
\hline tempo_assentamento (21 a 30 anos) & $-8,775$ & $-29,382$ & $-72,723$ & $-2,245$ & $-2,245$ & $-2,283$ & & \\
\hline part_ocupação (sim) & $-12,895$ & $-13,647$ & $-47,893$ & $-1,925$ & $-1,842$ & $-1,880$ & 0,162 & \\
\hline escolaridade (nunca estudou) & $-9,294$ & & & & & & & \\
\hline escolaridade (ens. fund. incomp.) & $-25,398$ & & & & & & & \\
\hline escolaridade (ens. fund. comp.) & $-70,035$ & & & & & & & \\
\hline escolaridade (ens. médio incomp.) & $-28,594$ & & & & & & & \\
\hline escolaridade (ens. médio comp.) & $-19,427$ & & & & & & & \\
\hline tipo_produto (grãos/cereais/semente) & $-71,275$ & $-77,049$ & $-99,576$ & $-2,937 * *$ & $-2,911 * *$ & $-3,250 * *$ & $-3,87 * *$ & $-3,823 * *$ \\
\hline coop_aceitação & 3,803 & 6,767 & 10,441 & 0,758 & 0,753 & 0,871 & $1,205^{*}$ & $1,203^{*}$ \\
\hline dif_produto (não possui) & $-58,329$ & $-43,797$ & $-183,778$ & $-1,817$ & & & & \\
\hline dif_produto (qualidade diferenciada) & $-123,978$ & $-102,120$ & $-215,442$ & $-0,781$ & & & & \\
\hline dif_produto (orgânico certificado) & $-27,755$ & $-1,441$ & $-67,856$ & $-14,77$ & & & & \\
\hline frequência (diariamente) & 89,625 & 86,719 & & & & & & \\
\hline frequência (semanalmente) & 61,380 & 81,719 & & & & & & \\
\hline frequência (mensalmente) & 108,382 & 164,756 & & & & & & \\
\hline frequência (uma vez por semestre) & 81,503 & 60,268 & & & & & & \\
\hline frequência (uma vez por ano) & 100,435 & 118,584 & & & & & & \\
\hline
\end{tabular}

\footnotetext{
${ }^{14}$ A descrição entre parênteses é derivada da codificação interna do SPSS. O software solicita, para uma regressão logística, que sejam identificadas as variáveis qualitativas do modelo.
} 
conclusão

\begin{tabular}{|c|c|c|c|c|c|c|c|c|}
\hline Variáveis independentes & Etapa 1 & Etapa 2 & Etapa 3 & Etapa 4 & Etapa 5 & Etapa 6 & Etapa 7 & Etapa 8 \\
\hline facilidade_vender_outro & $-15,529$ & $-16,767$ & $-26,925$ & $-0,928 *$ & $-0,956^{*}$ & $-0,945^{*}$ & $-0,695^{*}$ & $-0,708 *$ \\
\hline sempre_comprador & $-20,388$ & $-33,878$ & $-0,685$ & $-0,839$ & $-1,005$ & $-0,781$ & $-1,118^{*}$ & $-1,104^{*}$ \\
\hline planta_colhe & 12,955 & 23,277 & 4,431 & 0,659 & 0,783 & & & \\
\hline média_id_mst & 2,673 & 1869,303 & 6,978 & 0,603 & 0,578 & 0,530 & $0,798 *$ & $0,802 *$ \\
\hline Constante & 101,531 & 65,496 & 348,664 & 0,637 & $-0,721$ & 2,109 & $-3,221$ & $-3,176$ \\
\hline $\begin{array}{c}\text { Pseudo } \mathbf{R}^{2} \text { (R quadrado de } \\
\text { Nagelkerke) }\end{array}$ & $100,00 \%$ & $100,00 \%$ & $100 \%$ & $55,70 \%$ & $\mathbf{5 5 , 5 0 \%}$ & $54,60 \%$ & $46,40 \%$ & $46,40 \%$ \\
\hline
\end{tabular}

$*$ p-valor $<0,1 \quad * * \mathrm{p}$-valor $<0,05 \quad * * * \mathrm{p}$-valor $<0,01$ 
Como pode ser visto na Tabela 4, tendo como base o modelo final (etapa 8), as variáveis que apresentaram significância estatística para o uso da forma híbrida via cooperativas no assentamento são: tipo do produto vendido ( -valor $=0,016$ ), aceitação dos demais assentados ao vender para cooperativa ( $\mathrm{p}$-valor $=0,078$ ), facilidade de vender para outro comprador sem ter prejuízo ( $\mathrm{p}$-valor $=0,076)$, produto sempre terá comprador $(\mathrm{p}$-valor $=0,074)$ e média de identificação com o MST (p-valor = 0,068). Dentre essas variáveis, verificou-se que as relacionadas às características transacionais ("tipo_produto (grãos/cereais/semente)", "facilidade_vender_outro" e "sempre_comprador") apresentaram sinal negativo, como esperado, justificando, assim, o uso de mecanismos menos complexos.

Dessa forma, os produtos do tipo grãos/cereais/semente reduzem a probabilidade do uso de formas cooperativas, destacando o fato de que esses produtos possuem características de commodities. Ainda em relação a esse aspecto, cabe ressaltar que a principal cooperativa do assentamento - a COAPRI - atende apenas programas governamentais, como PAA e PNAE, como dito anteriormente. Os produtos que se enquadram nessa modalidade são FLVs e feijão. Deve-se considerar também que, segundo entrevistados, dentro desses programas, existe uma quota anual para cada família, ou seja, durante o ano, o produtor pode entregar a produção para esses programas até alcançar um determinado valor que, quando alcançado, impossibilita a continuidade de venda para os programas, fazendo com que o produtor tenha que buscar outras alternativas.

Apesar disso, a maioria dos produtores que se enquadram no tipo de produto que essa cooperativa repassa para os programas governamentais vendem sua produção para terceiros, na maioria dos casos para atravessadores, por meio de um contrato relacional. Dentre os produtores, apenas o que tem como principal produto as verduras e outro que tem o quiabo como principal produto entregam para a cooperativa. No caso do quiabo, um produto comumente encontrado no assentamento, por exemplo, é comum a entrega para os Ceasas. Dessa forma, a cooperativa acaba sendo mais utilizada por produtores que tem a soja como principal produto, porém de forma coletiva, na qual a produção é encaminhada para a cooperativa coletiva, também chamada de Cooperativa de Produção Agropecuária (CPA).

Um dos principais fatores que levam os produtores a decidirem vender para terceiros, especificamente para o atravessador, segundo os entrevistados, é a questão do pagamento, o qual muitas vezes é realizado no momento da compra. Além disso, muitos afirmam conseguir 
um pagamento melhor e que também podem confiar no comprador, que, segundo eles, paga certo e é de confiança. $\mathrm{O}$ atravessador é também fornecedor de insumos para os produtores. Dessa forma, alguns produtores vendem para ele como forma de saldarem suas dívidas de compra de insumos, o que pode ser caracterizado como um comércio recíproco (WILLIAMSON, 1991).

Ainda em relação à entrega dos produtos para a cooperativa, no que se refere à COAPRI, muitos assentados reclamam da forma como o pagamento é feito, relatando atrasos no recebimento. Tal atraso pode ser derivado de problemas no repasse das verbas dos programas governamentais para as cooperativas que atendem ao PAA e PNAE, por exemplo, desestimulando, assim, a entrega dos produtos às cooperativas.

Além da variável "tipo_produto (grãos/cereais/semente)", a facilidade de vender para outro comprador sem sofrer prejuízos também reduz a probabilidade de transacionar via cooperativa, ou seja, quanto mais fácil a venda para outro comprador, dado que o primeiro desistiu de comprar (baixo nível de especificidade), menor a probabilidade de vender para a cooperativa. Além disso, foi verificado que quanto maior a certeza de que sempre haverá comprador (baixo nível de incerteza) menor a probabilidade de transacionar via cooperativa. Esses achados corroboram a Teoria dos Custos de Transação, uma vez que o baixo nível de especificidade de ativos e a baixa incerteza estão relacionados ao uso de formas de governança de mercado ou próximas a ele, como o contrato relacional (MÉNARD, 2004; WILLIAMSON, 1993), o que leva, portanto, à aceitação da H1.

Outro aspecto importante é o papel da aceitação dos demais sobre a decisão de governança. Foi possível verificar que quanto maior a crença de que os demais irão ter uma maior aceitação, se o indivíduo vender a sua produção para a cooperativa, maior a probabilidade de transacionar via cooperativa, o que demonstra que o grupo exerce influência sobre as decisões do mesmo.

Por fim, foi possível constatar a existência de relação entre a identidade social e o uso de forma de governança híbrida incentivada pelo grupo social, no caso dessa pesquisa, a forma cooperativa. Verificou-se que houve relação positiva e estatisticamente significativa entre a identificação social com o MST e o uso de formas cooperativas, forma de governança incentivada pelo MST, o que leva, portanto, à aceitação de H2. Dessa maneira, quanto maior a identificação social com o MST, maior a probabilidade de vender a produção via cooperativa. 
Por meio de uma analogia entre os conceitos de especificidade de ativos, sendo aquele que perde valor se empregado em um segundo uso alternativo, e de utilidade da identidade, segundo o qual o indivíduo apresenta uma perda de utilidade se o seu comportamento não condiz com a norma que é esperada para a sua categoria social, e com base no achado de $\mathrm{H} 2$, entende-se que a identidade social exerce função semelhante à da especificidade de ativos. Assim, a identidade social leva ao uso de formas de governança mais complexas, uma vez que, se o agente se enquadra na categorial social "se identifica com o MST", o mesmo irá perder utilidade da identidade caso aja de forma diferente do que é esperado para essa categoria, que é transacionar via forma de governança incentivada pelo grupo, no caso, a forma cooperativa.

Além da adoção do mecanismo de governança, buscou-se analisar a possibilidade de, se fosse possível para os assentados entregarem a produção para a cooperativa, eles o fariam, e de que forma a identificação social com o MST poderia influenciar nessa decisão, uma vez que muitos não entregam devido à falta de possibilidade, como os produtores de soja e milho, como foi discutido nos parágrafos anteriores.

Para tanto, foi realizada uma segunda regressão logística, a qual buscou analisar a influência da identidade social sobre o favorecimento da forma cooperativa, isto é, se o produtor deixaria de vender para outro comprador para vender para a cooperativa. Por favorecimento à forma cooperativa, entende-se a escolha por esse mecanismo, independentemente do aspecto financeiro, isto é, o produtor escolheria essa forma de governança porque é importante para ele, e não porque visa obter ganhos. Dessa forma, a variável dependente foi classificada como "0" para aqueles que não favorecem a cooperativa, e " 1 " para aqueles produtores que a favorecem. Assim, com base nessa classificação, 70,6\% se enquadraram na categoria " 0 ” e 29,4\%, na categoria " 1 ".

As variáveis de controle utilizadas foram as mesmas do modelo anterior, a saber: agrovila, tempo no assentamento, participação no processo de ocupação, nível de escolaridade, tipo do produto vendido e aceitação dos demais assentados dada a venda via cooperativa. Como variável independente, foi adotada a média de identificação com o MST. Da mesma forma como feito no modelo anterior, categorizou-se as variáveis qualitativas. Isso faz com que o SPSS crie uma codificação interna para as variáveis. 
O modelo se mostrou adequado, tendo como base o teste de Omnibus e de Hosmer e Lemeshow. Para essa regressão, o método adotado também foi o backward wald, pelo fato do modelo ter apresentado um melhor ajuste, além do fato de ser o mais adequado para o método passo a passo. A seguir, é apresentado o detalhamento de cada etapa, indicando os coeficientes e as significâncias das variáveis (Tabela 5). O modelo final explica 23,9\% da variância da variável dependente (Pseudo $\mathrm{R}^{2}$ ). Diferente da regressão anterior, a inclusão das variáveis independentes ao modelo aumentou o nível de classificações corretas, tendo classificado corretamente $78 \%$ dos casos. 
Tabela 5 - Modelo - variável dependente: favorecimento à cooperativa ${ }^{15}$.

\begin{tabular}{|c|c|c|c|c|c|c|}
\hline Variáveis independentes & Etapa 1 & Etapa 2 & Etapa 3 & Etapa 4 & Etapa 5 & Etapa 6 \\
\hline \multicolumn{7}{|l|}{$\mathrm{n}^{\circ}$ agrovila } \\
\hline $\mathrm{n}^{\mathrm{o}}$ agrovila (1) & 20,513 & 20,549 & & & & \\
\hline $\mathrm{n}^{\mathbf{o}}$ agrovila (2) & 20,653 & 20,702 & & & & \\
\hline $\mathrm{n}^{\mathrm{o}}$ agrovila (3) & 20,679 & 20,741 & & & & \\
\hline $\mathrm{n}^{\mathrm{o}}$ agrovila (4) & 19,999 & 20,090 & & & & \\
\hline $\mathrm{n}^{\mathrm{o}}$ agrovila (5) & 21,489 & 21,455 & & & & \\
\hline \multicolumn{7}{|l|}{ tempo_assentamento } \\
\hline tempo_assentamento(0-10 anos) & $-20,039$ & & & & & \\
\hline tempo_assentamento(11-20 anos) & 0,229 & & & & & \\
\hline tempo_assentamento(21-30 anos $)$ & 0,025 & & & & & \\
\hline part_ocupação (sim) & 1,241 & $1,321 *$ & 1,073 & 0,876 & & \\
\hline \multicolumn{7}{|l|}{ Escolaridade } \\
\hline escolaridade(nunca estudou) & $-42,955$ & $-43,002$ & $-22,409$ & $-22,095$ & $-22,091$ & \\
\hline escolaridade(ens. fund. incomp.) & $-41,341$ & $-41,322$ & $-20,657$ & $-20,615$ & $-20,804$ & \\
\hline escolaridade(ens. fund. comp.) & $-41,541$ & $-41,587$ & $-20,901$ & $-20,824$ & $-21,055$ & \\
\hline escolaridade(ens. médio incomp.) & $-62,124$ & $-62,206$ & $-41,566$ & $-41,559$ & $-41,611$ & \\
\hline $\begin{array}{l}\text { escolaridade(ens. médio comp.) } \\
\text { tipo_produto }\end{array}$ & $-39,359$ & $-39,428$ & $-18,586$ & $-18,748$ & $-19,005$ & \\
\hline (grãos/cereais/semente) & $-0,844$ & $-0,883$ & $-0,902$ & & & \\
\hline coop_aceitação & $0,789 * * *$ & $0,810 * * *$ & $0,879 * * *$ & $0,824 * * *$ & $0,816^{* * *}$ & $0,611 * * *$ \\
\hline média_id_mst & $0,281 * *$ & $0,283 * *$ & $0,288 * * *$ & $0,273 * *$ & $0,276^{*}$ & $0,217 * *$ \\
\hline Constante & 14,981 & 14,863 & 14,811 & 14,460 & 15,344 & $-4,179$ \\
\hline $\begin{array}{c}\text { Pseudo } \mathbf{R}^{2} \text { (R quadrado de } \\
\text { Nagelkerke) }\end{array}$ & $48,8 \%$ & $47,7 \%$ & $41,9 \%$ & $40,6 \%$ & $38,6 \%$ & $23,9 \%$ \\
\hline
\end{tabular}

${ }^{15}$ A descrição entre parênteses é derivada da codificação interna do SPSS. 
Da mesma forma como aconteceu com a primeira análise, inicialmente, todas as variáveis foram inseridas. Em cada etapa, uma variável foi retirada, tendo como base a baixa contribuição que a mesma apresentou para o modelo. Quando nenhuma variável mais foi retirada, chegou-se, então, ao modelo final, o qual se encontra na Etapa 6. Como pode ser visto na tabela, dentre as variáveis de controle, apenas a variável referente à aceitação dos demais assentados se realizar a venda para a cooperativa apresentou significância estatística a um nível de 1\% (p-valor = 0,001). Dessa forma, quanto mais o produtor acredita que os demais assentados irão aceitá-lo mais se vender para a cooperativa, maior a probabilidade de favorecimento à cooperativa, isto é, de deixar de vender para um terceiro para vender para a cooperativa. Essa variável também apresentou significância no modelo anterior.

Além dessa, a variável independente, média de identificação ao MST, também se mostrou significativa ( $\mathrm{p}$-valor $=0,028)$, o que indica que quanto maior a identificação com MST, ou seja, quanto mais o indivíduo se vê como membro, maior a probabilidade de favorecer as cooperativas para a venda da produção. Aceita-se, portanto, a H3 desta pesquisa, demonstrando, assim, a relação entre a identidade social e o favorecimento de um determinado mecanismo, mesmo que, para alguns, esse mecanismo não possa ser de fato adotado. O Quadro 9 apresenta uma sistematização das hipóteses, com seus respectivos resultados.

Quadro 9: Resultado das hipóteses de pesquisa.

\begin{tabular}{|l|c|c|}
\hline \multicolumn{1}{|c|}{ Hipóteses } & $\begin{array}{c}\text { Sinal } \\
\text { esperado }\end{array}$ & Resultado \\
\hline $\begin{array}{l}\text { H1: Transações com baixo nível de especificidade de ativos } \\
\text { reduzem a probabilidade do uso de mecanismos de } \\
\text { governança mais complexos. }\end{array}$ & - & $\begin{array}{c}\text { Hipótese } \\
\text { aceita }\end{array}$ \\
\hline $\begin{array}{l}\text { H2: Quanto maior a identidade social do indivíduo em } \\
\text { relação ao grupo, maior a probabilidade de transacionar via } \\
\text { formas de governança incentivadas pelo grupo. }\end{array}$ & + & $\begin{array}{c}\text { Hipótese } \\
\text { aceita }\end{array}$ \\
\hline $\begin{array}{l}\text { H3: Quanto maior a identidade social do indivíduo em } \\
\text { relação ao grupo, maior a probabilidade de favorecer a forma } \\
\text { de governança incentivada pelo grupo. }\end{array}$ & + & $\begin{array}{c}\text { Hipótese } \\
\text { aceita }\end{array}$ \\
\hline
\end{tabular}

Fonte: Elaborado pela autora.

Assim, conclui-se que a identificação social é um fator importante para as decisões que acontecem no nível da firma, especialmente em ambientes nos quais o aspecto social e grupal exerce grande influência sobre os indivíduos. Assim, a ECT não é capaz de explicar por completo os determinantes das escolhas dos mecanismos de governança, sendo necessário levar em consideração, também, a identidade do indivíduo para a determinação dos limites da firma, 
corroborando Santos e Eisenhardt (2005), que sugeriram ampliar os determinantes dos limites da firma em busca de um melhor entendimento do contexto organizacional, considerando a identidade como um dos pontos de partida. No entanto, o aspecto de identidade abordado pelos autores é o de identidade organizacional, não fazendo referência à identidade social.

Os achados deste trabalho demonstram também a implicação de aspectos micro, aqueles relacionados aos indivíduos e suas interações para a tomada de decisão, o que evidencia a importância do tratamento dos microfundamentos para o campo da estratégia. Por fim, reforça a influência dos aspectos sociais, especialmente a identificação social, sobre aspectos organizacionais, como já havia sido abordado por Kogut e Zander (1996), Morita e Servátka (2013) e Wang (2007). Mas, mais especificamente, esta pesquisa mostra a relação entre a identidade social e a escolha do mecanismo de governança, ponto que ainda não havia sido explorado pela literatura. 


\section{CONSIDERAÇÕES FINAIS}

Os questionamentos acerca dos limites das firmas surgiram na década de 1930, com Ronald Coase, tendo ganhado destaque apenas mais tarde, com o desenvolvimento da teoria dos custos de transação. Desde então, diversos estudos foram realizados, comprovando a eficácia da teoria proposta por Oliver Williamson. Apesar do fato, defendido pela ECT, de que os indivíduos influenciam as questões de governança, e de que se faz necessário adentrar no nível social para entender de forma mais completa a Economia dos Custos de Transação, esse aspecto é pouco abordado pela literatura, a qual, nesse sentido, faz referência aos pressupostos comportamentais da racionalidade limitada e do oportunismo, que são dados independente do contexto, isto é, assume-se que tais pressupostos existem. A falta de atenção à questão social é um fator que leva à algumas críticas à teoria, o que tem levado alguns autores a incorporarem essas questões em estudos no campo da estratégia, verificando, por exemplo, questões como hold up e transferência de conhecimento.

Apesar disso, entende-se que, em ambientes nos quais o aspecto social e grupal é altamente enraizado, as questões referentes aos indivíduos e suas interações afetam também decisões que acontecem mais ao nível da firma, como a escolha dos mecanismos de governança. Indo além, nesses ambientes, a identificação social dos indivíduos pode ser determinante para seguir ou não as estratégias de governança propostas pelo grupo do qual faz parte, o que faz com que essa identificação também influencie na decisão da forma de transacionar, além dos atributos da própria transação.

Diante disso, este trabalho buscou analisar a influência da identidade social sobre a escolha do mecanismo de governança. Para tanto, foram aplicados questionários semiestruturados junto a 109 produtores de um assentamento localizado no interior do estado de São Paulo. Cabe destacar que o surgimento desse assentamento teve apoio do Movimento dos Trabalhadores Rurais Sem Terra (MST), mesmo que esse ainda estivesse em processo de formação, quando se deu a ocupação das primeiras áreas do assentamento.

É importante ressaltar que, para a viabilidade econômica dos negócios dos pequenos produtores, o MST incentiva as formas cooperativas, tanto para produção como para comercialização, incentivando, principalmente, as cooperativas de produção agropecuária, as 
quais são um modelo de produção coletiva. Cabe destacar que as formas cooperativa se enquadram dentro do mecanismo de governança denominado de formas híbridas. Dessa forma, é esperado que os indivíduos que se identificam com o grupo MST irão favorecer as formas cooperativas de maneira geral, coletivas ou não, para as suas atividades. No caso específico desta pesquisa, foi analisada a comercialização dos produtos dos assentados. Ou seja, buscouse analisar se a identificação social com o MST aumenta a probabilidade de entregar a produção via forma de governança híbrida incentivada grupo social, nesse caso específico, via cooperativas do assentamento, bem como se a identificação social aumenta a probabilidade de favorecer a entrega da produção para a cooperativa, em detrimento da venda para terceiros através de outros mecanismos.

Por meio da análise dos dados, constatou-se que a maioria dos assentados participaram do processo de ocupação do assentamento e, portanto, grande parte dos entrevistados estão no assentamento durante um período entre 21 e 30 anos. Isso pode tê-los levado a se afastarem do contato direto do processo de conquista de terra, ocasionando uma identificação social não muito elevada em relação ao MST; a média de identificação social dos entrevistados em relação a esse grupo foi de 6,8 .

Quanto às formas de comercialização utilizadas pelos produtores para a venda do principal produto produzido pelos mesmos, foi possível observar que a maior parte transaciona por meio de formas híbridas, mais especificamente, por meio de contrato relacional. Apenas uma pequena parte entrega a sua produção para as cooperativas do assentamento. Cabe destacar que a principal cooperativa, a COAPRI, atende apenas os programas governamentais, ficando restrita, portanto, à comercialização de frutas, legumes, verduras e feijão, restringindo, assim, as opções de venda dos produtores dos demais produtos. Apesar desse fato, pôde-se constatar que, além das características transacionais, principalmente a incerteza e o nível de especificidade de ativos, a identidade social também influencia na decisão do mecanismo de governança. Dessa forma, quanto maior a identidade social com o MST, maior a probabilidade de transacionar via cooperativa do assentamento. Tem-se, portanto, que a identidade social leva ao uso da forma de governança híbrida associada ao grupo social do indivíduo, sendo possível afirmar que a identidade social atua como uma especificidade, fazendo com que mecanismos mais complexos do que o mercado spot ou contratos relacionais com agentes de fora do assentamento sejam utilizados. 
Além da escolha de fato do mecanismo de transação, buscou-se verificar se os assentados favoreceriam a entrega dos produtos para as cooperativas, caso essa forma de transação fosse possível, ou seja, considerando que as cooperativas pudessem pegar os demais produtos, além de FLVs e feijão. Por meio da análise, foi possível verificar que a identidade social influencia também no favorecimento pela forma cooperativa para a venda das mercadorias. Tais achados demonstram a importância dos aspectos sociais para as questões estratégicas das firmas, como, por exemplo, a escolha dos mecanismos de governança, tornando necessário incluir tais aspectos à análise os limites das firmas, especialmente em locais onde os aspectos sociais exercem grande influência.

Dessa forma, como contribuição à teoria, esta pesquisa traz um estudo empírico que evidencia a importância de fatores sociais para decisões que acontecem no nível da firma, demonstrando a aplicabilidade dos microfundamentos, além de abordar outro determinante para os limites das firmas, indo além dos atributos transacionais e da influência do ambiente institucional. Como contribuições gerenciais, a nível de assentamento, destaca-se que a identificação social é um fator importante para o favorecimento à forma cooperativa, fator que pode ser considerado para a fidelização dos produtores.

Destaca-se, como limitação, o fato de que a análise foi realizada tendo como base apenas o principal produto de venda, não sendo possível analisar a produção de cada assentado como um todo, dada a necessidade de perguntas específicas para cada produto, o que não foi viável devido à complexidade do questionário. Outra limitação deste estudo é o desbalanceamento da amostra para a primeira regressão logística, havendo uma quantidade grande de produtores que vendem para terceiros, em comparação com os que vendem para cooperativas do assentamento. Esse fato, no entanto, não invalida o estudo, dado o bom ajuste do modelo apresentado e do elevado valor de casos classificados corretamente.

Para futuros estudos, sugere-se analisar a identidade social em assentamentos de diferentes estados, a fim de verificar se o processo de formação influencia na identificação. Além disso, recomenda-se que o estudo seja estendido para outros contextos, além de assentamentos, como o ambiente cooperativista em geral. Sugere-se também o uso de outras técnicas para analisar essa questão, como a realização de experimentos. 


\section{REFERÊNCIAS}

ADLER, P. S.; KWON, S. Social capital: prospects for a new concept. Academy of Management Review, v. 27, n.1, p. 17-40, 2002.

AKERLOF, G. A.; KRANTON, R. E. Economics and identity. The Quarterly Journal, v. 115, n. 3, p. 715-753, 2000.

. Identity and economics of organization. Journal of Economics Perspectives, v. 19, n. 1, p. 9-32, 2005.

. A economia da identidade: como a nossa personalidade influencia nosso

trabalho, salário, bem-estar e a economia global. Rio de Janeiro: Elsevier, 2010.

ASHFORTH, B. E.; MAEL, F. Social identity theory and the organization. The Academy of Management Review, v. 14, n. 1, p. 20-39, 1989.

ASHMORE, R. D.; DEAUX, K.; MCLAUGHLIN-VOLPE, T. An organizing framework for collective identity: articulation and significance of multidimensionality.

Psychological Bulletin, v. 130, n. 1, p. 80-114, 2004.

AZEVEDO, P. F. A nova economia institucional. In: FARINA, E. M. M. Q.; AZEVEDO, P. F.; SAES, M. S. F. Competitividade: mercado, estado e organizações. São Paulo:

Singular, 1997.

BAKER, G.; GIBBONS, R.; MURPHY, K. J. Relational contracts and the theory of the firm. The Quarterly Journal of Economics, p. 39-84, 2002.

BARNEY, J.; FELIN, T. What are microfoundations? Academy of Management Perspectives, v. 27, n. 2, p. 138-155, 2013.

BHIDÉ, A. The origin and evolution of new business. Ney Work: Oxford University Press, 2000.

BLOOMFIEDL, R. J. Rethinking managerial reporting. Journal of Management Accounting Research, v. 27, n. 1, p. 139-150, 2015. 
BORSATTO, R. S.; CARMO, M. S. A construção do discurso agroecológico no Movimento dos Trabalhadores Rurais Sem-Terra (MST). Revista de Economia e Sociologia Rural, v. 51, n. 4, p. 645-660, 2013.

BOULU-RESHHEF, B. Economics of identity and economics of the firm: why and how their three central questions overlap. Journal of Institutional Economics, v. 9, n. 3, p. 363-379, 2013.

BOYACK, K. W.; KLAVANS, R.; BÖRNER, K. Mapping the backbone of science. Scientometrics, v. 64, n. 3, p. 351-374, 2005.

BRADACH, J. L.; ECCLES, R. G. Price, authority, and trust: from ideal types to plural forms. Annual Review of Sociology. v. 15, 1989.

BRADACH, J. L. Using the plural form in the management of restaurant chains. Administrative Science Quarterly, v.42, n.2, p. 276-303, jun. 1997.

BRASIL. Lei n ${ }^{\circ}$ 4.504, de 30 de novembro de 1964. Dispõe sobre o Estatuto da Terra, e dá outras providências. Diário Oficial da República Federativa do Brasil, Brasília, DF, 30 de novembro de 1964. Disponível em: <

http://www.planalto.gov.br/ccivil_03/leis/L4504.htm>. Acesso em: 21 mai. 2015.

BRASIL. Lei $\mathrm{n}^{\mathrm{o}}$ 10.696, de 2 de julho de 2003. Dispõe sobre a repactuação e o alongamento de dívidas oriundas de operações de crédito rural, e dá outras providências. Diário Oficial da República Federativa do Brasil, Brasília, DF, 2003. Disponível em: <http://www.planalto.gov.br/ccivil_03/leis/2003/L10.696.htm>. Acesso em: 18 nov. 2015.

CASCIARO, T.; BARSADE, S. G.; EDMONDSON, A. C.; GIBSON, C. B.;

KRACKHARDT, D.; LABIANCA, G. J. The Integration of Psychological and Network Perspectives in Organizational Scholarship. Organization Science, v. 26, n. 4, p. 1162-1176, 2015.

CAMERON, J. E. A three-factor model of social identity. Psychology Press, v. 3, p. 239$262,2004$.

CARROLL, G. R. A sociological view on why firms differ. Strategic Management Journal, v. 14, n. 4, p. 237-249, 1993.

COASE, R. The nature of the firm. Economica, v. 4, n. 16, p. 386-405, nov. 1937. 
COLEMAN, J. S. Social theory, social research, and a theory of action. The American Journal of Sociology, v. 91, n. 6, p. 1309-1335, 1986.

Social capital in the creation of human capital. The American Jornal of Sociology, v. 94, p. 95-120, 1988.

COLLIS, J.; HUSSEY, R. Pesquisa em administração: um guia prático para alunos de graduação e pós-graduação. 2. ed. Porto Alegre: Bookman, 2005.

CONCRAB - CONFEDERAÇÃO DAS COOPERATIVAS DE REFORMA AGRÁRIA DO BRASIL. Caderno de cooperação agrícola n 5, São Paulo, 1997.

COOK, M. L.; KLEIN, P. G.; ILIOPOULOS, C. Contracting and organization in food and agriculture. In: BROUSSEAU, E.; GLACHANT, J. New Institutional Economics: a guidebook. New York: Cambridge University Press, 2008.

CORNELISSEN, J. P.; HASLAM, S. A.; BALMER, J. M. T. Social identity, organizational identity and corporate identity: towards an integrated understanding of processes, patternings and products. British Journal of Management, v. 18, p. 1-16, 2007.

CORRAR, L. J.; DIAS FILHO, J. M. Regressão Logística. In: CORRAR, L. J.; PAULO, E.; DIAS FILHO, J. M. Análise multivariada: para os cursos de administração, ciências contábeis e economia. São Paulo: Atlas, 2007.

CYERT, R. M.; MARCH, J. G. A behavioral theory of the firm. Englewood Cliffs: Prentice-Hall, 1963.

DAVIS, J. B. Akerlof and Kranton on identity in economics: inverting the analysis.

Cambridge Journal of Economics, v. 31, p. 349-362, 2007.

DING, Y.; CHOWDHURY, G.; FOO, S. Mapping the intellectual structure of information retrieval studies: an author co-citation analysis, 1987-1997. Journal of Information Science, v. 25, n. 1, p. 67-78, 1999.

DINIZ, A. S.; GILBERT, B. Socialist values and cooperation in Brazil's Landless Rural Workers Movement. Latin American Perspectives, v. 40, n. 4, p. 19-34, 2013. 
DIODATO, V. Dictionary of bibliometrics. Bighamton: Haworth Press, 1994.

EID, F.; SCOPINHO, R. A.; PIMENTEL, A. E. B. A dinâmica recente da organização social e produtiva em cooperativas de reforma agrária. In: AGUIAR, D. R. D.; PINHO, J. B. (Orgs.). Agronegócio brasileiro: desafios e perspectivas. Brasilia: Sober, 1998.

FEHR, E.; GÄCHTER, S. Fairness and retaliation: the economics of reciprocity. Journal of Economic Perspectives, v. 14, n. 3, p. 159-182, 2000.

FELIN, T.; FOSS, N. J. Strategic organization: a field in search of micro-foundations. Strategic Organization, v. 3, n. 4, p. 441-455, 2005.

Individuals and organizations: thoughts on a micro-foundations project for strategic management and organizational analysis. SMG Working Paper, n. 2, 2006.

FERREIRA, M. P.; PINTO, C. F.; SERRA, F. R. The transaction costs theory in international business research: a bibliometric study over three decades. Scientometrics, v. 98, p. 1899-1922, 2014.

FIELD, A. Descobrindo a estatística usando o SPSS. 2. ed. Porto Alegre: Artmed, 2009.

FNDE - FUNDO NACIONAL DE DESENVOLVIMENTO DA EDUCAÇÃO. PNAE: Histórico. 2015. Disponível em: <http://www.fnde.gov.br/programas/alimentacaoescolar/alimentacao-escolar-historico>. Acesso em: 7 dez. 2015.

FOOTE, N. N. Identification as the basis for a theory of motivation. American Sociological Review, v. 16, p. 14-21, 1951.

FOSS, N. J. Cognition and motivation in the theory of the firm: interaction or "never the twain shall meet”? Journal des Économistes et des Études Humaines, v. 14, n. 1, 2004.

Micro-foundations for management research: what, why, and whither?

Cuadernos de Economía y Dirección de la Empresa, n. 42, p. 11-34, 2010.

Why micro-foundations for Resource Based Theory are needed and what they may look like. Journal of Management, v. 37, n. 5, p. 1413-1428, 2011. 
$120,2016$.

Reflections on a decade of microfoundations studies. Rausp, v. 51, n. 1, p. 117-

FURUBOTN; E. G.; RICHTER, R. Institutions and economic theory: the contribution of the New Institutional Economics. United Sates: The University of Michigan, 2000.

GRANOVETTER, M. The strength of weak ties. American Journal of Sociology, v. 78, n. 6, p. 1360-1380, 1973.

Economic action and social structure: the problem of embeddedness. American Journal of Sociology, v. 91, n. 3, p. 481-510, 1985.

Economic institutions as social constructions: a framework for analysis. Acta Sociologica, v. 35, p. 3-11, 1992.

GRASSI, R. A. Capacitações dinâmicas, coordenação e cooperação interfirmas: as visões Freeman-Lundvall e Teece-Pisano. Estudos Econômicos (São Paulo), v. 36, n. 3, p. 611$635,2006$.

HAIR JR., J. F.; BABIN, B.; MONEY, A. H.; SAMOUEL, P. Fundamentos de métodos de pesquisa em administração. Porto Alegre: Bookman, 2005.

HAIR JR., J. F.; BLACK, W. C.; BABIN, B. J.; ANDERSON, R. E.; TATHAM, R. L. Análise multivariada de dados. 6. ed. Porto Alegre: Bookman, 2009.

HELMKE, G.; LEVITSKY, S. Informal institutions and comparative politics: a research agenda. Perspective on Politcs, v. 2, n. 4, p. 725-740, 2004.

HENDRIKSE, G. W. J.; VEERMAN, C. P. Marketing cooperatives and financial structure: a transaction costs economics analysis. ERIM Report Series Research in Management. 2000.

HODGSON, G. M. Evolutionary and competence-based theories of the firm. Journal of Economic Studies, v. 25, n. 1, p. 25-56, 1998.

HOGG, M. A.; TERRY, D. J.; WHITE, K. M. A tale of two theories: a critical comparison of identity theory with social identity theory. Social Psychology Quarterly, v. 58, n. 4 , p. $255-269,1995$. 
HOGG, M. A.; WILLIAMS, K. D. From I to We: social identity and collective self.

Group Dynamics: Theory, Research, and Practice, v. 4, n. 1, p. 81-97, 2000.

INCRA - INSTITUTO NACIONAL DE COLONIZAÇÃO E REFORMA AGRÁRIA. Reforma Agrária. 2016. Disponível em: < http://www.incra.gov.br/reforma_agraria>. Acesso em: 13 out. 2016.

Incra nos estados: informações gerais sobre os assentamentos da Reforma Agrária. Disponível em: < http://painel.incra.gov.br/sistemas/index.php>. Acesso em: 01 set. 2016. 2016.

IOKOI, Z. M. G.; ANDRADE, M. R. O.; REZENDE, S.; RIBEIRO, S. Vozes da terra: histórias de vida dos assentados rurais de São Paulo. São Paulo: Fundação Instituto de Terras do Estado de São Paulo, 2005.

ITESP - INSTITUTO DE TERRAS DO ESTADO DE SÃO PAULO. Retrato da terra: perfil socioeconômico dos assentamentos do estado de São Paulo - 96/97, 1998.

KLEIN, B. CRAWFORD, R. G.; ALCHIAN, A. A. Vertical integration, appropriable rents, and the competitive contracting process. Journal of Law and Economics, v. 21, n. 2, p. 297-326, 1978.

KLEIN, B. Fischer-General Motors and the Nature of the firm, Journal of Law and Economics, v. 43, p. 105-141, 2000.

KOGUT, B.; ZANDER, U. What firms do? Coordination, identity, and learning. Organization Science, v. 7, n. 5, p. 502-518, 1996.

LAFONTAINE, F. Agency theory and franchising: some empirical results. The RAND Journal of Economics. v. 23, n. 2, p. 263-283, summer, 1992.

LEACH, C. W. et al. Group-level self-definition and self-investment: a hierarchical (multicomponent) model of in-group identification. Journal of personality and social psychology, v. 95, n. 1, p. 144-165, 2008.

LIBBY, R.; BLOOMFIELD, R.; NELSON, M. W. Experimental research in financial accounting. Accounting, Organizations and Society, v. 27, p. 775-810, 2002. 
LIN, N.; COOK, K.; BURT, R. S. Social capital: theory and research. 4. ed. New Jersey: Transaction Publishers, 2008.

LUHTANEN, R.; CROCKER, J. A collective self-esteem scale: self-evaluation of one's social identity. Personality and Social Psychology Bulletin, v. 18, p. 302-318, 1992.

MACHADO, H. V. A identidade e o contexto organizacional: perspectivas de análise. Revista de Administração Contemporânea, n. Edição Especial, p. 51-73, 2003.

MANSFIELD, F. Discipline, internal motivation, and cooperation in a rural production cooperative. Environments Journal, v. 33, n. 1, p. 61-80, 2005.

MÉNARD, C. On clusters, hybrids, and other strange forms: the case of the French poultry industry. Journal of Institutional and Theoretical Economics, v. 152, p. 154183, 1996.

The economics of hybrid organizations. Journal of Institutional and

Theoretical Economics. v. 160, n. 3, p. 345-376, 2004.

Hybrids modes of organization. Alliances, joint ventures, networks, and other "strange" animals. In: GIBBONS, R.; ROBERTS, J. The Handbook of Organizational Economics. Princeton: Princeton University Press, 2012.

MÉNARD, C.; KLEIN, P. G. Organizational issues in the agrifood sector: toward a comparative approach. American Journal of Agricultural and Economics, v. 86, n. 3, p. 750-755, 2004.

MÉNARD, C.; SAES, M. S. M.; SILVA, V. L. S.; RAYNAUD, E. Economia das organizações: formas plurais e desafios. São Paulo: Atlas, 2014.

MOLINA-AZORÍN, J. F. Microfoundations of strategic management: toward micromacro research in the resource-based theory. Business Research Quarterly, v. 17, n. 2, p. 102-114, 2014.

MONDELLI, M.; ZYLBERSZTAJN, D. Determinantes dos arranjos contratuais: o caso da transação produtor-processador de carne bovina no Uruguai. RESR, v. 46, n. 3, p.831868, 2008. 
MONTEVERDE, K.; TEECE, D. J. Supplier switching costs and vertical integration in the automobile industry. The Bell Journal of Economics. v. 13, n. 1, p. 206-213, spring, 1982.

MORITA, H.; SERVÁTKA, M. Group identity and relation-specific investment: an experimental investigation. European Economic Review, v. 58, p. 95-109, 2013.

MOVIMENTO DOS TRABALHADORES RURAIS SEM TERRA - MST. Nossos frutos: nossa produção. 2014. Disponível em: 〈http://www.mst.org.br/nossa-producao/>. Acesso em: 19 abr. 2016.

NELSON, R. R. Institutions, "social technologies", and economic progress. Globelics Working Paper Series, N 2007-03, 2007.

NELSON, R. R.; SAMPAT, B. N. Making sense of institutions as a factor shaping economic performance. Journal of Economic Behavior and Organization, v. 44, p. 31$54,2001$.

NORTH, D. Institutions, Institutional change and economic performance. Cambridge: Cambridge University Press, 1990. Institutions. The Journal of Economic Perspectives, v. 5, n. 1, p. 97-112, 1991.

The contribution of the New Institutional Economics to an understand of the transition problem. In: WIDER ANNUAL LECTURES, 1997, Helsinki. Anais... Helsinki: UNU World Institute for Development Economics Research, 1997.

OIJEN, A. A. V.; HENDRIKSE, G. W. Governance structure, product diversification, and performance. ERIM Report Series Research in Management. 2002.

OMTA, S. W. F.; TRIENEKENS, J. H.; BEERS, G. Chain and network science: a research framework. Journal on Chain and Network Science, v. 1, n. 1, p. 1-6, 2001

PARMIGIANI, A. Why do firms both make and buy? An investigation of concurrent sourcing. Strategic Management Journal, v. 28, p. 285-311, 2007.

PHUA, F. T. T. The antecedents of co-operative behavior among project team members: an alternative perspective on an old issue. Construction Management and Economics, v. 22, p. 1033-1045, 2004. 
PIMENTEL, A. E. B.; EID, F. As cooperativas de Reforma Agrária como alternativa para a geração de trabalho e renda. In: SIMPÓSIO DE ENGENHARIA DE PRODUÇÃO, 7., 2000. Bauru. Anais... Bauru, 2000.

RAYNAUD, E.; SAUVEE, L.; VALCESCHINI, E. Alignment between quality enforcement devices and governance structures in the agri-food vertical chains. Journal of Management and Governance, v. 9, p. 47-77, 2005.

RODRIGUES, A.; PAULO, E. Introdução à análise multivariada. In: CORRAR, L. J.; PAULO, E.; DIAS FILHO, J. M. Análise multivariada: para os cursos de administração, ciências contábeis e economia. São Paulo: Atlas, 2007.

RUESTER, S. Recent Developments in Transaction Cost Economics. SSRN Working Paper Series, n. January, 2010.

SAMMARRA, A.; BIGGIERO, L. Identity and identification in industrial districts. Journal of Management and Governance, v. 5, p. 61-82, 2001.

SANTOS, F. M.; EISENHARDT, K. M. Organizational boundaries and theory of organization. Organization Science, v. 16, n. 5, p. 491-508, 2005.

SCOPINHO, R. A.; MARTINS, A. F. G. Desenvolvimento organizacional e interpessoal em cooperativas de produção agropecuária: reflexão sobre o método. Psicologia e Sociedade, v. 15, n. 2, p. 124-143, 2003.

SHI, W.; TANG, Y. Cultural similarity as in-group favoritism: the impact of religious and ethnic similarities on alliance formation and announcement returns. Journal of Corporate Finance, v. 34, p. 32-46, 2015.

SILVA, L. H. Os assentamentos de reforma agrária nos anos 2000: o caso dos assentados da Fazenda Pirituba. In: SIMPÓSIO INTERNACIONAL LUTAS SOCIAIS NA AMÉRICA LATINA, 5., 2013, Londrina. Anais... Londrina, 2013. p. 172-187.

SILVA, V. L. S.; AZEVEDO, P. F. Formas plurais no franchising de alimentos: evidências de estudos de caso na França e no Brasil. RAC, $1^{\text {a }}$ ed. Especial, p. 129-152, 2007.

SIMON, H. A. Comportamento administrativo. 2. ed. Rio de Janeiro: Fundação Getúlio Vargas, 1971. 
SOUZA, C. R. A cooperação como estratégia organizacional do movimento dos trabalhadores rurais sem terra no Paraná: o caso da cooperativa de produção e serviços de Pitanga. 2001. 141 f. Dissertação (Mestrado em Sociologia) Universidade Federal do Paraná, Curitiba, 2001.

TAJFEL, H. La catégorisation sociale. In : MOSCOVICI, S. Introduction à la pscychologie sociale. Paris: Librairie Larousse, 1972.

Social psychology of intergroup relations. Annual Review of Psychology, v. 33, p. 1-39, 1982.

TAJFEL, H.; TURNER, J. C. The social identity theory of intergroup behavior. In: WORCHEL, S.; AUSTIN, G. Psychology of intergroup relations. Chicago: NelsonHall, 1986.

UZZI, B. Social structure and competition in interfirms networks: the paradox of embeddedness. Administrative Science Quarterly, v. 42, n. 1, p. 35-67, 1997.

VAN DE VEN, A. H.; LUFSCHITZ, A. Rational and reasonable microfoundations of markets and institutions. The Academy of Management Perspectives, v. 27, n. 2, p. 156-172, 2013.

VENÂNCIO, F. B.; SUZUKI, J. C. A criação do Assentamento Pirituba II nos municípios de Itapeva/Itaberá - SP e a participação dos movimentos sociais no campo. In: ENCONTRO NACIONAL DE GEOGRAFIA AGRÁRIA, 19., 2009, São Paulo. Anais... São Paulo, 2009. p. 1-19.

VERGARA, S. C. Projetos e relatórios de pesquisa em administração. 4. ed. São Paulo: Atlas, 2003.

VILPOUX, O. F. Agrarian reform and cooperation between settlers in the Midwest of Brazil: an institutional approach. Land Use Policy, v. 39, p. 65-77, 2014.

WACHELKE, J. F. R. Identificação com o grupo: adaptação e validação de uma medida geral para o contexto brasileiro. Psicologia e Saber Social, v. 1, n. 2, p. 187-200, 2012.

WANG, N. Measuring transaction costs: diverging approaches, contending practices.

Division of Labour \& Transaction Costs, v. 2, n. 2, p. 111-146, 2007. 
WHITE, H. D.; GRIFFITH, B. C. Author cocitation: a literature measure of intellectual structure. Journal of the American Society for Information Science, v. 32, n. 3, p. 163-171, 1981.

WILLIAMS, J. R. Strategy and the search for rents: the evolution of diversity among firms. In: RUMELT, R. P.; SCHENDEL, D. E.; TEECE, D. J. Fundamental issues in strategy. Boston: Harvard Business School Press, 1994.

WILLIAMSON, O. E. Transaction-cost economics: the governance of contractual relations. Journal of Law and Economics, v. 22, n. 2, p. 233-261, out. 1979.

. The economic institutions of capitalism: firms, markets, relational contracting. The free press. 1985.

Comparative economic organization: the analysis of discrete structural alternatives. Administrative Science Quarterly, S.L., v. 36, n. 2, p. 269-296, jun., 1991.

Transaction Cost Economics and Organization Theory. Journal of Industrial and Corporate Change, p. 107-156, 1993.

The mechanisms of governance. Nova York: Oxford University Press, 1996.

The new institutional economics: taking stock, looking ahead. Journal of Economic Literature, v. XXXVIII, p. 595-613, set. 2000.

WOOLDRIDGE, J. Introductory econometrics: a modern approach. Australia: SouthWestern Cengage Learning, 2009.

ZYLBERSZTAJN, D. Estruturas de governança e coordenação do agribusiness: uma aplicação da Nova Economia das Instituições. 1995. 239 f. Tese (Livre Docência) Universidade de São Paulo, 1995.

. Economia das organizações. In: ZYLBERSZTAJN, D (org.).; NEVES, M. F (org.). Economia e gestão dos negócios agroalimentares. São Paulo: Pioneira, 2000. 
Quatro estratégias fundamentais para cooperativas agrícolas. Working Paper $\mathrm{N}^{\mathrm{o}} 02 / 017.2002$. 


\section{APÊNDICE A - QUESTIONÁRIO}

Nome do entrevistado:

Nome do entrevistador:

Nome do assentamento:

Agrovila $n^{\circ}$ :

$\mathrm{N}^{\circ}$ do lote:

Município:

Estado:

Data da entrevista:

O(a) senhor(a) trabalha diretamente com produção agrícola?

$01 \mathrm{Sim}$

$\square 02$

Não

(encerrar)

Seção 1 - Dados sociodemográficos - Caracterização do produtor e da unidade familiar

1 - Qual a sua idade:

$\operatorname{anos}$

$2-\operatorname{Sexo}$

01 - Masculino

$02-$ Feminino

3 - Local de nascimento (cidade):

4 - É descendente de quilombola, imigrante ou indígena?

$$
01-\operatorname{Sim}
$$$$
02 \text { - Não }
$$

4.1. Se sim, de qual?

\section{5 - Participa de alguma comunidade religiosa?}

01 - Sim. Qual?

02 - Não (vá para a questão $0 \overline{6 \text { ) }}$

5.1 - Com que frequência você vai às reuniões de sua comunidade religiosa?

01 - Uma vez por semana

02 - Duas vezes por semana

03 - Mais de duas vezes por semana 
04 - De vez em quando

5.2 - Os seus principais amigos são da mesma religião que o(a) sr.(a).?
$01-\mathrm{Sim}$
$02-$ Não

6 - Em que cidade morava antes de vir para o assentamento?

7 - Há quanto tempo está neste assentamento?

8 - Há quanto tempo trabalha com produção agrícola?

9 - Participou do processo de ocupação do assentamento?

$$
01-\mathrm{Sim} \quad \square 2-\text { Não }
$$

10 - Qual a experiência anterior que o(a) senhor(a) teve no campo?

01 - Produtor por conta própria

02 - Trabalhador temporário

03 - Trabalhador permanente

04 - Meeiro

05 - Caseiro

06 - Outra, qual?

07 - Não tive experiência anterior

11 - O(a) senhor(a) usa os serviços de alguma Cooperativa (de produção, crédito, consumo, mista) ou de alguma Associação de Produtores?

01 - Sim. Quais? (escreva os nomes)

02 - Não

12 - O(a) senhor(a) faz parte de alguma Cooperativa (de produção, crédito, consumo, mista) ou de alguma Associação de Produtores?

01 - Sim (vá para a questão 12.1).

02 - Não sou cooperado ou associado (vá para a questão 16)

\begin{tabular}{|c|c|c|c|c|}
\hline $\begin{array}{c}\text { 12.1. Nome da } \\
\text { cooperativa }\end{array}$ & $\begin{array}{c}\text { Tipo da } \\
\text { cooperativa } \\
\text { (produção, } \\
\text { crédito etc.) }\end{array}$ & $\begin{array}{c}\text { A produção é } \\
\text { realizada } \\
\text { coletivamente } \\
\text { (0) Não } \\
\text { (1) Sim }\end{array}$ & $\begin{array}{c}\text { Qual a sua } \\
\text { função nessa } \\
\text { cooperativa? }\end{array}$ & $\begin{array}{c}\text { É a principal da } \\
\text { qual faz parte } \\
\text { (0) Não } \\
\text { (1) Sim }\end{array}$ \\
\hline 1 & & & & \\
\hline
\end{tabular}




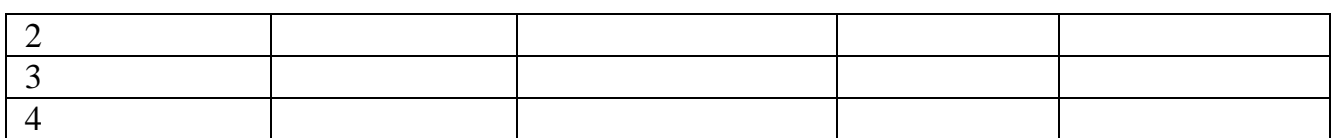

13 - Nessa Cooperativa/Associação principal, são realizadas coletivamente:

01 - gestão

02 - produção

03 - comercialização

14 - Considerando a Cooperativa/Associação principal, o(a) senhor(a) participa das reuniões da cooperativa/associação?

01 - Não frequenta

02 - Participa às vezes

03 - Participa de quase todas

04 - Participa de todas

15 - Vou fazer uma afirmação e gostaria que você me respondesse: “A participação nas reuniões contribui para as minhas decisões de produção e comercialização": 01 - Nunca contribui $\square 02$ - Poucas vezes $\square 03$ - Muitas vezes $\square 04$ - Sempre. Em que? 
16 - Com relação ao(a) senhor(a) e às pessoas que moram com o(a) senhor(a):

\begin{tabular}{|c|c|c|c|c|c|c|c|}
\hline \multirow[t]{2}{*}{ Pessoa } & \multicolumn{2}{|c|}{$\begin{array}{c}\text { Qual o maior nível de } \\
\text { escolaridade (siga a tabela } \\
\text { abaixo, para numerar). } \\
\text { Escreva ao lado qual o curso, } \\
\text { no caso de resposta no nível } \\
05 \text { (se profissionalizante), } 07 \\
\text { ou } 09\end{array}$} & \multirow[t]{2}{*}{$\begin{array}{l}\text { Qual é a } \\
\text { ocupação } \\
\text { principal? (siga a } \\
\text { tabela abaixo } \\
\text { sobre ocupação } \\
\text { principal) }\end{array}$} & \multirow[t]{2}{*}{$\begin{array}{l}\text { Essa ocupação } \\
\text { principal é: } \\
\text { (1) Dentro da } \\
\text { propriedade } \\
\text { (2) Fora da } \\
\text { propriedade }\end{array}$} & \multirow[t]{2}{*}{$\begin{array}{l}\text { A atividade } \\
\text { exercida é: } \\
\text { (1) Remunerada } \\
\text { (2) Não } \\
\text { remunerada }\end{array}$} & \multirow[t]{2}{*}{$\begin{array}{c}\text { Tem outra renda além da } \\
\text { atividade agrícola? (Siga a } \\
\text { tabela abaixo sobre outras } \\
\text { rendas) }\end{array}$} & \multirow[t]{2}{*}{$\begin{array}{l}\text { Da renda da família, } \\
\text { qual a contribuição da } \\
\text { atividade agrícola (por } \\
\text { exemplo: contribui } \\
\text { com metade, com } 1 / 4 \\
\text { etc.). }\end{array}$} \\
\hline & Nível & Curso & & & & & \\
\hline \multicolumn{8}{|l|}{ 1. Entrevistado } \\
\hline \multicolumn{8}{|l|}{2.} \\
\hline \multicolumn{8}{|l|}{3.} \\
\hline \multicolumn{8}{|l|}{4.} \\
\hline \multicolumn{8}{|l|}{5.} \\
\hline \multicolumn{8}{|l|}{6.} \\
\hline \multicolumn{8}{|l|}{7.} \\
\hline \multicolumn{8}{|l|}{8.} \\
\hline \multicolumn{8}{|l|}{9.} \\
\hline 10. & & & & & & & \\
\hline
\end{tabular}

\section{Tabela de nível de escolaridade}

\begin{tabular}{|l|l|}
\hline 01 & Nunca estudou \\
\hline 02 & Ensino Fundamental incompleto \\
\hline 03 & Ensino Fundamental completo \\
\hline 04 & Ensino Médio incompleto \\
\hline 05 & Ensino Médio completo. Se profissionalizante, qual curso? \\
\hline 06 & Ensino Superior incompleto \\
\hline 07 & Ensino Superior completo. Qual curso? \\
\hline 08 & Pós-graduação incompleto \\
\hline 09 & Pós-graduação completo. Qual curso? \\
\hline 10 & Outro: ex curso de curta duração \\
\hline
\end{tabular}

\section{Tabela sobre o curso}

\begin{tabular}{|l|l|}
\hline 01 & Direito \\
\hline 02 & Agronomia \\
\hline 03 & Pedagogia \\
\hline 04 & Administração \\
\hline 05 & Letras \\
\hline 06 & Outro, qual? \\
\hline
\end{tabular}

\section{Tabela sobre ocupação principal}

01 Agropecuária (produtor)

02 Ocupações especializadas agropecuária (tratorista, motorista etc.)

03 Indústria, construção civil

04 Diarista

05 Comércio e serviços em geral

06 Outra, qual?

Tabela sobre outras rendas

\begin{tabular}{|l|l|}
\hline 01 & Não possui \\
\hline 02 & Aposentadoria \\
\hline 03 & Bolsa Família \\
\hline 04 & Outra, qual? \\
\hline
\end{tabular}


17 - Vou citar algumas frases sobre Educação e gostaria que o(a) senhor(a) me dissesse qual o grau de concordância que tem com cada uma delas. Essas afirmações foram elaboradas para que possa saber o que o(a) $\operatorname{sr}($ a) pensa sobre $o$ assunto.

\begin{tabular}{|c|c|c|c|c|c|}
\hline & $\begin{array}{c}\text { Discordo } \\
\text { totalmente }\end{array}$ & Discordo & \begin{tabular}{|c|} 
Não \\
concordo/nem \\
discordo
\end{tabular} & Concordo & $\begin{array}{c}\text { Concordo } \\
\text { totalmente }\end{array}$ \\
\hline 17.1. A formação em escolas do campo é mais adequada para quem vai trabalhar no campo. & 01 & 02 & 03 & 04 & 05 \\
\hline $\begin{array}{l}\text { 17.2. Meu rendimento financeiro melhorou após eu ou alguém de minha família ter concluído a } \\
\text { faculdade/universidade. }\end{array}$ & 01 & 02 & 03 & 04 & 05 \\
\hline 17.3. Gostaria de ter feito uma faculdade/universidade para poder trabalhar no campo. & 01 & 02 & 03 & 04 & 05 \\
\hline 17.4. Quem faz faculdade deve sair do campo para trabalhar na cidade. & 01 & 02 & 03 & 04 & 05 \\
\hline $\begin{array}{l}\text { 17.5. Pude aplicar o que foi estudado por mim ou por alguém da minha família na escola ou } \\
\text { faculdade/universidade em minha atividade produtiva. }\end{array}$ & 01 & 02 & 03 & 04 & 05 \\
\hline $\begin{array}{l}\text { 17.6. Os filhos devem estudar em escolas ou faculdades/universidades para que melhore a minha } \\
\text { produção no campo. }\end{array}$ & 01 & 02 & 03 & 04 & 05 \\
\hline 17.7. A educação na faculdade/universidade traz melhorias para a produção no campo. & 01 & 02 & 03 & 04 & 05 \\
\hline $\begin{array}{l}\text { 17.8. Deveria haver faculdade/universidade dentro do assentamento para aprender algo que pudesse ser } \\
\text { aplicado no campo. }\end{array}$ & 01 & 02 & 03 & 04 & 05 \\
\hline 17.9. É preciso formação em faculdade/universidade para poder trabalhar em produção rural. & 01 & 02 & 03 & 04 & 05 \\
\hline $\begin{array}{l}\text { 17.10. Deveria haver um programa do governo para enviar as pessoas que trabalham no campo para as } \\
\text { faculdades/universidades. }\end{array}$ & 01 & 02 & 03 & 04 & 05 \\
\hline
\end{tabular}

\section{Seção 2 - Créditos e subsídios para a produção}

\section{8 - O(A) senhor(a) fez empréstimos para a produção agrícola?}

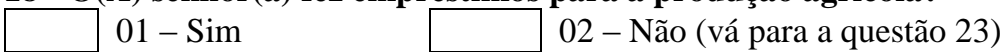

19 - Em caso afirmativo, quando (em que ano)?

20 - Para quê?

$\square 01$ - Investimento $\square 2$ - Custeio 
21 - Qual o valor do último empréstimo que fez? Investimento:

(ano:

) e Custeio:

(ano:

\section{2 - O empréstimo está inserido dentro de algum programa governamental? (Pronaf ou outro)}

01 - Sim. Qual?

02 - Não

Seção 3 - Uso da Terra

23 - Em relação ao uso da terra, qual a área sob sua gestão no ano safra 2014/2015? (verificar qual a unidade de medida utilizada pelo produtor: alqueire (especificar - paulista, mineiro, goiano etc.), hectares).

\begin{tabular}{|ll|}
\hline Área sob sua gestão & Medida: \\
\hline Total da área sob sua gestão & {[} \\
A - Área própria no quintal & {[} \\
B - Área própria individual & {[} \\
C - Área na produção coletiva & {[} \\
D - Área de terceiro arrendada pelo(a) senhor(a) & {[} \\
\hline
\end{tabular}

24 - Você arrenda ou empresta parte do seu lote a terceiros?

01 - Sim, arrendo. Por que?

$01-$ Sim, empresto. Por que?

02 - Não (vá para a questão 26)

25 - Em caso afirmativo, qual a medida? (especificar se alqueire - qual e se hectare etc.)

Seção 4 - Caracterização da atividade

\section{6 - Quanto à sua produção (própria ou coletiva), considerando a safra 2014/2015:}

\begin{tabular}{|c|c|c|c|c|c|c|}
\hline $\begin{array}{l}\text { Você produz... } \\
\text { (assinale os produtos } \\
\text { que o entrevistado } \\
\text { informa produzir) }\end{array}$ & $\begin{array}{c}\text { Qual a quantidade } \\
\text { produzida na safra } \\
\text { 2014/2015? (especificar } \\
\text { a unidade - Quilos / } \\
\text { toneladas / caixas / } \\
\text { litro) }\end{array}$ & $\begin{array}{c}\text { Percentual produzido } \\
\text { individual e } \\
\text { coletivamente }^{16}\end{array}$ & $\begin{array}{l}\text { Quantidade vendida } \\
\text { (especificar unidade - } \\
\text { quilos / toneladas / } \\
\text { caixas / litros) }\end{array}$ & $\begin{array}{c}\text { Esse } \\
\text { produto é } \\
\text { produzido } \\
\text { em seu } \\
\text { quintal } \\
\text { para seu } \\
\text { consumo? }\end{array}$ & $\begin{array}{l}\text { Esse } \\
\text { produto } \\
\text { também } \\
\text { é para } \\
\text { venda? } \\
\text { (0) Não } \\
\text { (1) Sim }\end{array}$ & $\begin{array}{l}\text { Esse produto é } \\
\text { seu principal } \\
\text { produto de venda } \\
\text { em termos de } \\
\text { quantidade } \\
\text { (0) Não } \\
\text { (1) Sim }\end{array}$ \\
\hline
\end{tabular}

${ }^{16}$ Perguntar essa questão caso o produtor não saiba especificar a quantidade. 


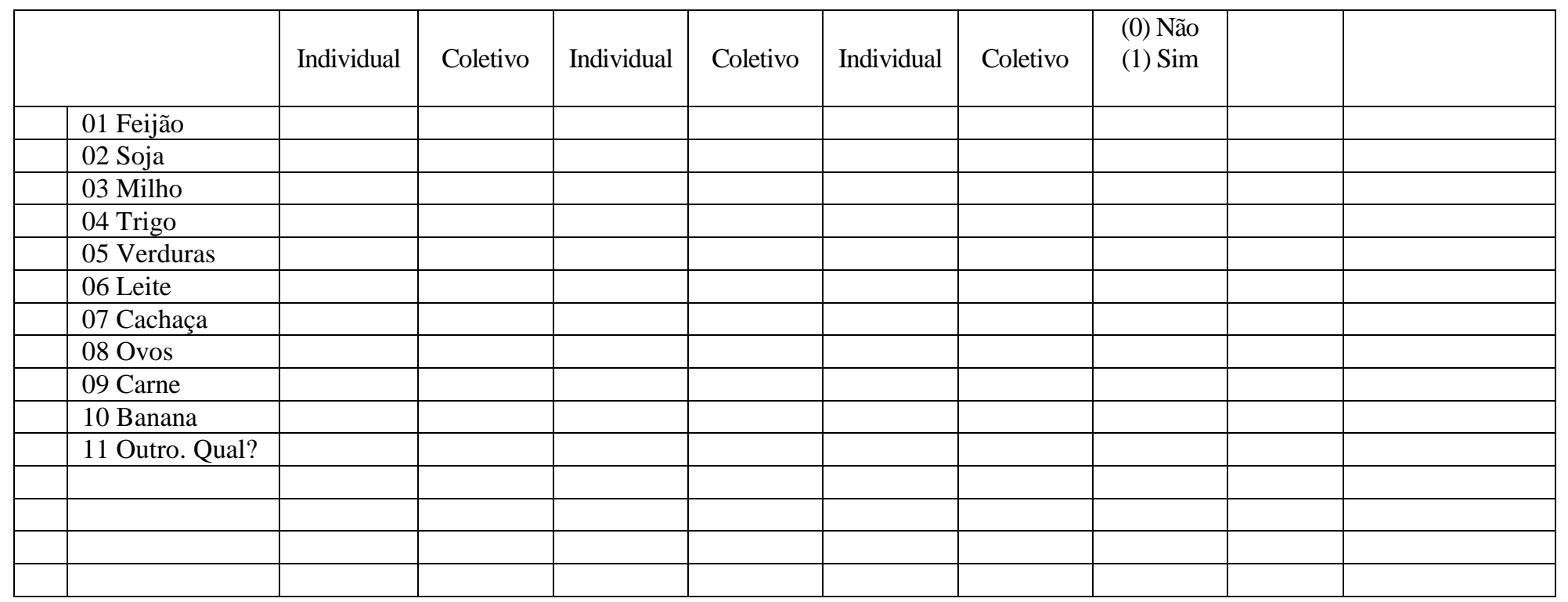

27 - A sua principal preocupação ao produzir é:
\begin{tabular}{|l|l}
01 - aumentar a sua produção \\
02 - o prazer de trabalhar com agricultura \\
03 - participar da comunidade produtiva
\end{tabular}
04 - investir na educação dos filhos

28 - Uso de mão de obra na produção agropecuária no ano safra 2014/2015

\begin{tabular}{|l|c|}
\hline \multicolumn{2}{|c|}{ Morador } \\
\hline $\begin{array}{c}\text { Grau de parentesco } \\
\text { (membro da família, } \\
\text { outros...) }\end{array}$ & $\begin{array}{c}\text { Horas de trabalho por } \\
\text { semana }\end{array}$ \\
\hline 1. Entrevistado & \\
\hline 2. & \\
\hline 3. & \\
\hline 4. & \\
\hline & \\
\hline
\end{tabular}

Não Morador (fora do lote): plantio, capina, roçada, colheita, etc

\begin{tabular}{|l|c|c|}
\hline \multicolumn{3}{|c|}{ Não Morador (fora do lote): plantio, capina, roçada, colheita, etc } \\
\hline Trabalhadores & $\begin{array}{c}\text { Horas de trabalho anual (se } \\
\text { não souber pode } \\
\text { dia/semana, mas veja se é o } \\
\text { ano todo ou só alguns } \\
\text { meses) }\end{array}$ & $\begin{array}{c}\text { Paga em: } \\
\text { (1) dinheiro } \\
\text { (2) espécie } \\
\text { (3) favor }\end{array}$ \\
\hline 1 & & \\
\hline 2 & & \\
\hline 3 & & \\
\hline 4 & & \\
\hline Total gasto (ano) & & \\
\hline
\end{tabular}


28.1 Você participa de mutirão?
01 - Não, (vá para
02 - Construção de casa de vizinho

29)

03 - Construção armazém /outro na cooperativa

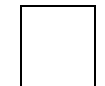

28.2 Qual foi a última vez que participou?

Por que? (participa / ou não):

28.3 Existe uma regra (não escrita) na prática de mutirão?

28.4 Se você cooperava e não coopera mais, diga porque:

Consumo de fertilizantes na producão agropecuária no ano safra 2014/2015:

29 - Utiliza adubos?

\begin{tabular}{|c|c|c|}
\hline & \multicolumn{2}{|c|}{$02-$ Não (vá para a questão 30) } \\
\hline & 01 Sim & \multicolumn{2}{|c|}{} \\
\hline Uso de adubos & $\begin{array}{c}\text { Quantidade utilizada na safra } \\
\mathbf{2 0 1 4 / 2 0 1 5}\end{array}$ & $\begin{array}{c}\text { Valor gasto na safra } \\
\mathbf{2 0 1 4 / 2 0 1 5}\end{array}$ \\
\hline Químico & & \\
\hline Orgânico & & \\
\hline
\end{tabular}

30 - Utiliza agrotóxico (veneno)?
$\square 01-\mathrm{Sim}$
02 - Não (vá para a questão 32)

31 - Em caso afirmativo: Valor gasto na safra 2014/2015:

Quantidade utilizada na safra 2014/2015:

Em relacão ao seu maquinário/implementos agrícolas (arado, grade, semeadeira, colheitadeira):

32 - Você utiliza trator na produç̃o agrícola?

$\square 01-\operatorname{Sim} \quad 02$ - Não (vá para a questão 33)

\begin{tabular}{|l|l|l|l|}
\hline Relação de máquinas e implementos & $\begin{array}{l}\text { (0) individual } \\
\text { (1) coletivo } \\
\text { (2) empréstimo de terceiros }\end{array}$ & Anos de uso & Horas de utilização anual \\
\hline 1. & & & \\
\hline 2. & & & \\
\hline 3. & & & \\
\hline 4. & & & \\
\hline 5. & & & \\
\hline
\end{tabular}

33 - Detalhe, por favor, os implementos utilizados na produção agrícola. 


\begin{tabular}{|l|l|l|}
\hline $\begin{array}{l}\text { Implementos (arado, grade, semeadeira, } \\
\text { colheitadeira etc): }\end{array}$ & $\begin{array}{l}\text { (0) individual } \\
\text { (1) coletivo } \\
\text { (2) empréstimo de terceiros }\end{array}$ & Horas de utilização anual \\
\hline 1. & & \\
\hline 2. & & \\
\hline 3. & & \\
\hline 4. & & \\
\hline 5. & & \\
\hline
\end{tabular}

\section{4 - Quanto aos seus custos:}

\begin{tabular}{|l|l|}
\hline Gasto total na safra 2014-2015 & Gasto total $(\mathbf{R} \$)$ \\
\hline 1. Óleo Diesel (l) & \\
\hline 2. Energia elétrica $(\mathrm{kW})$ & \\
\hline 3. Água para irrigação $(\mathrm{l})$ & \\
\hline 4. Outros (especificar) & \\
\hline
\end{tabular}

35 - O senhor(a) empresta para seu vizinho implementos/maquinário agrícolas?
01 - Sim, para todos
02 - Sim, só para alguns
$03-$ Não

36 - Principal motivo de emprestar ou não:

36.1 O senhor(a) troca informação da sua produção? (pode preencher mais de uma opção e colocar em ordem de importância)

$01-$ Sim, com vizinhos

$02-$ Sim, com compradores

03 - Sim, com amigos da igreja

04 - Sim, com parente

05 - Não divido informação (vá para a questão 36.3)

36.2 Se sim, que tipo de informação?

(sobre técnica de produção, preço, sobre o que plantar, para quem vender)

36.3 Os demais produtores dividem informação de produção/comércio com você?

$$
\begin{aligned}
& 01 \text { - Sim, meus vizinhos } \\
& 02 \text { - Sim, compradores } \\
& 03 \text { - Sim, amigos da igreja } \\
& 04 \text { - Sim, parente } \\
& 05 \text { - Não dividem informação comigo (vá para a questão 37) }
\end{aligned}
$$

36.4 Se sim, que tipo de informação? 
36.5 Com quem você conversa para obter informações sobre a produção, mercado? Nome:

O que ele é seu:

(vizinho, amigo da igreja, comprador, diretor da cooperativa, técnico do ITSP)?

Seção 5 - Comercialização

37 - Quais são os seus três principais produtos de venda, (considerando a produção individual e coletiva), em termos de:

\begin{tabular}{|l|l|}
\hline Produtos & Quantidade \\
\hline $\mathbf{1}^{\mathbf{o}}$ principal produto de venda & \\
\hline $\mathbf{2}^{\mathbf{0}}$ principal produto de venda & \\
\hline $\mathbf{3}^{\mathbf{0}}$ principal produto de venda & \\
\hline
\end{tabular}

38 - Considerando os seus três principais produtos de venda, em termos de quantidade, produzidos individual ou coletivamente, para quem são entregues, em média? Indicar o percentual (\%) e de que forma a venda é realizada (pensando na relação produtor - comprador, mesmo que seja com a cooperativa). Para preencher a forma de venda, siga a seguinte codificação:

01 Contrato formal (escrito e assinado)

02 Contrato informal (compromisso verbal, acordo)

03 Mercado (você não desenvolve nenhuma relação com o comprador, sem contrato, ex: feiras)

\begin{tabular}{|c|c|c|c|c|c|c|c|c|c|c|c|c|c|c|c|c|c|}
\hline \multirow[t]{2}{*}{ Produto } & \multirow[t]{2}{*}{$\begin{array}{c}\text { Tipo de } \\
\text { produção }\end{array}$} & \multicolumn{2}{|c|}{$\begin{array}{l}\text { 01. Diretamente } \\
\text { para o Governo } \\
\text { (PAA - } \\
\text { Programa de } \\
\text { Aquisição de } \\
\text { Alimentos) } \\
\end{array}$} & \multicolumn{2}{|c|}{$\begin{array}{l}\text { 02. Diretamente } \\
\text { para o Governo } \\
\text { (PNAE - } \\
\text { Programa de } \\
\text { Alimentação } \\
\text { Escolar) } \\
\end{array}$} & \multicolumn{2}{|c|}{$\begin{array}{c}03 . \\
\text { Cooperativa } \\
\text { coletiva }\end{array}$} & \multicolumn{2}{|c|}{$\begin{array}{c}04 . \\
\text { Cooperativa } \\
\text { regional }\end{array}$} & \multicolumn{2}{|c|}{$\begin{array}{c}05 . \\
\text { Atravessador }\end{array}$} & \multicolumn{2}{|c|}{$\begin{array}{c}\text { 06. } \\
\text { Consumidor } \\
\text { final (feiras) }\end{array}$} & \multicolumn{2}{|c|}{$\begin{array}{c}\text { 07. } \\
\text { Vizinhos }\end{array}$} & \multicolumn{2}{|c|}{$\begin{array}{l}\text { 08. Outro. } \\
\text { Especificar: }\end{array}$} \\
\hline & & $\%$ & $\begin{array}{c}\text { Forma de } \\
\text { venda }\end{array}$ & $\%$ & $\begin{array}{c}\text { Forma de } \\
\text { venda }\end{array}$ & $\%$ & $\begin{array}{c}\text { Forma } \\
\text { de } \\
\text { venda }\end{array}$ & $\%$ & $\begin{array}{c}\begin{array}{c}\text { Forma } \\
\text { de } \\
\text { venda }\end{array} \\
\end{array}$ & $\%$ & $\begin{array}{c}\text { Forma } \\
\text { de } \\
\text { venda }\end{array}$ & $\%$ & $\begin{array}{c}\begin{array}{c}\text { Forma } \\
\text { de } \\
\text { venda }\end{array} \\
\end{array}$ & $\%$ & $\begin{array}{c}\text { Forma } \\
\text { de } \\
\text { venda }\end{array}$ & $\%$ & $\begin{array}{c}\text { Forma de } \\
\text { venda }\end{array}$ \\
\hline \multirow{2}{*}{$\begin{array}{c}1^{\circ} \\
\text { principal } \\
\text { produto } \\
\text { de venda } \\
\end{array}$} & $\begin{array}{l}\text { Produção } \\
\text { individual }\end{array}$ & & & & & & & & & & & & & & & & \\
\hline & $\begin{array}{c}\text { Produção } \\
\text { coletiva }\end{array}$ & & & & & & & & & & & & & & & & \\
\hline \multirow{2}{*}{$\begin{array}{c}2^{\circ} \\
\text { principal } \\
\text { produto } \\
\text { de venda } \\
\end{array}$} & $\begin{array}{l}\text { Produção } \\
\text { individual }\end{array}$ & & & & & & & & & & & & & & & & \\
\hline & $\begin{array}{c}\text { Produção } \\
\text { coletiva }\end{array}$ & & & & & & & & & & & & & & & & \\
\hline $\begin{array}{c}\mathbf{3}^{\mathbf{0}} \\
\text { principal }\end{array}$ & $\begin{array}{l}\text { Produção } \\
\text { individual }\end{array}$ & & & & & & & & & & & & & & & & \\
\hline
\end{tabular}




\begin{tabular}{|c|c|l|l|l|l|l|l|l|l|l|l|l|l|l|l|l|l|l|}
\hline $\begin{array}{c}\text { produto } \\
\text { de venda }\end{array}$ & $\begin{array}{c}\text { Produção } \\
\text { coletiva }\end{array}$ & & & & & & & & & & & & & & & & & \\
\hline
\end{tabular}

39 - Qual o motivo de o(a) senhor(a) escolher essas formas de venda (esse arranjo) para seu principal produto?

40 - Teria dificuldade de vender a sua produção para outros compradores (não habituais)?
$01-\operatorname{Sim}$
02 - Não.

41 - O(a) senhor(a) deixaria de vender para outro comprador para vender para a cooperativa do assentamento (coletiva ou regional)?

$01-$ Sim. Por que?

02 - Não. Por que

\begin{tabular}{|c|c|c|c|c|c|}
\hline $\begin{array}{l}\text { Vou citar algumas frases sobre cooperação e gostaria que o(a) senhor(a) me } \\
\text { respondesse qual o seu grau de concordância: }\end{array}$ & $\begin{array}{l}\text { Discordo } \\
\text { totalmente }\end{array}$ & Discordo & $\begin{array}{c}\text { Não } \\
\text { concordo/ } \\
\text { nem discordo }\end{array}$ & Concordo & $\begin{array}{l}\text { Concordo } \\
\text { totalmente }\end{array}$ \\
\hline 42 - Se você vender para a cooperativa, seus companheiros irão lhe aceitar mais & 01 & 02 & 03 & 04 & 05 \\
\hline $\begin{array}{l}43 \text { - Você fica menos satisfeito se vender para outro comprador que não seja a cooperativa, } \\
\text { ou seja, se vender fora da cooperativa }\end{array}$ & 01 & 02 & 03 & 04 & 05 \\
\hline 44 - Vendo fora da cooperativa se me pagarem um preço melhor & 01 & 02 & 03 & 04 & 05 \\
\hline 45 - A cooperativa precisa do meu produto para agroindústria (ensacar feijão, laticínio) & 01 & 02 & 03 & 04 & 05 \\
\hline
\end{tabular}

46 - Você já procurou informação para se cadastrar para se tornar fornecedor de PAA e PNAE?

01 - Sim

$\square 02$ - Não

46.1. Você teve dificuldade? Se sim, quais? 


\section{7 - Em relação à sua participação no PAA (Programa de Aquisição de Alimentos) e no PNAE (Programa Nacional de Alimentação Escolar):}

$\square 01$ - Participo do programa PAA $\square 02$ - Participo do programa PNAE PAA $\square 03$ - Não participo diretamente, mas participo via cooperativa

04 - Não participo diretamente, mas participo via atravessador

05 - Não participo dos programas (ir para a questão 48)

\section{1 - Quanto ao PAA:}

1 - Desde quando participa?

2 - $\%$ vendido pelo PAA:

3 - Houve aumento de renda após a participação?

4 - O preço pelo PAA normalmente é maior que o preço do mercado?

5 - A sua renda se tornou mais estável após o programa?

6 - O(A) sr(a). mudou a produção para poder participar do programa?

7 - $\mathrm{O}(\mathrm{A}) \mathrm{sr}(\mathrm{a})$. investiu no processo sabendo que vai ter venda garantida?

8 - O(A) sr(a). aumentou o volume de produção desde o início da participação no programa?

9 - $\mathrm{O}(\mathrm{A})$ sr(a). vende seus produtos pela cooperativa para participar do programa?

10 - As vendas aumentaram devido ao programa?
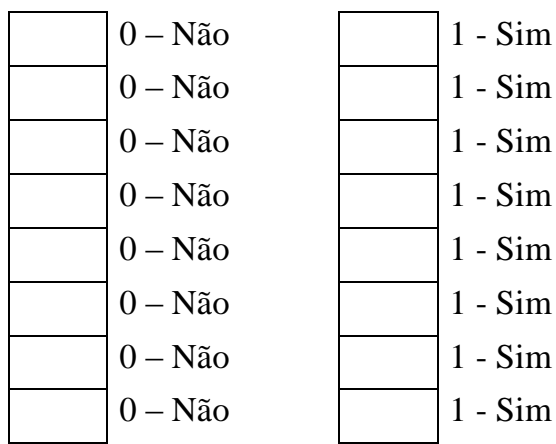

11 - Quais os produtos mais vendidos pelo programa?

\section{2 - Quanto ao PNAE:}

1 - Desde quando participa?

2 - \% vendido pelo PNAE

3 - Houve aumento de renda após a participação?

4 - O preço pelo PNAE normalmente é maior que o preço do mercado?

5 - A sua renda se tornou mais estável após o programa?

6 - O(A) sr(a). mudou a produção para poder participar do programa?

7 - O(A) sr(a). investiu no processo sabendo que vai ter venda garantida?

8 - O(A) sr(a). aumentou o volume de produção desde o início da participação no programa?

9 - O(A) sr(a). vende seus produtos pela cooperativa para participar do programa?

10 - As vendas aumentaram devido ao programa?
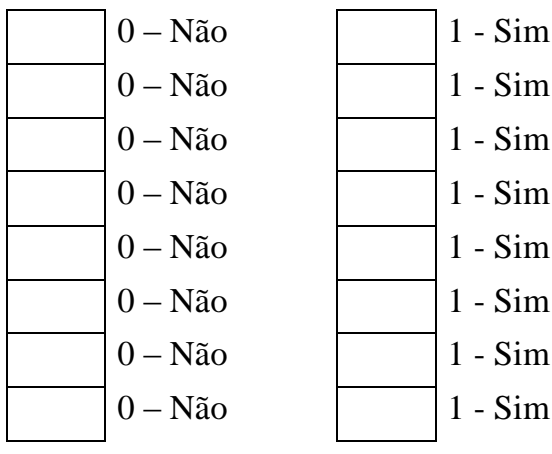

11 - Quais os produtos mais vendidos pelo programa? 


\section{3 - Quanto aos dois programas (PAA/PNAE):}

1 - $\mathrm{O}(\mathrm{A})$ sr(a) acha que a venda pelos programas vai continuar como está (não será afetada por fatores externos como política)?

2 - O sr. passou a vender menos para outros porque começou a vender pelos programas?

3 - A participação nos programas possibilitou a abertura de novos canais de venda?
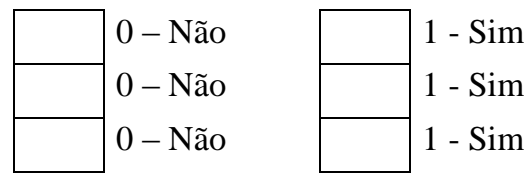

\section{Seção 6 - Caracterização das transaç̃̃es}

48- Seu principal produto de venda, em termos de quantidade (questão 37), possui alguma característica que o diferencia dos demais produtores?

$\square 01$ Não possui

02 Possui qualidade diferenciada. Explique:

03 Orgânico certificado

04 Orgânico sem certificação

05 Outra, qual?

49 - Com que frequência é realizada a venda desse seu principal produto (tanto para cooperativa quanto para os demais compradores)?

$\square 01$ Diariamente

$\square 02$ Semanalmente

$\square 03$ Quinzenalmente

$\square 04$ Mensalmente

$\square 05$ Uma vez por semestre

$\square 06$ Uma vez por ano

$\square 07$ Outra

50 - Você estoca o seu principal produto

$\square$ 01 Sim

\begin{tabular}{|c|c|c|c|c|c|}
\hline $\begin{array}{l}\text { Vou citar algumas frases sobre a entrega de seu principal produto de venda e } \\
\text { gostaria que você me dissesse qual o grau de concordância com cada uma delas: }\end{array}$ & $\begin{array}{l}\text { Discordo } \\
\text { totalmente }\end{array}$ & Discordo & $\begin{array}{c}\text { Não } \\
\text { concordo/nem } \\
\text { discordo }\end{array}$ & Concordo & $\begin{array}{l}\text { Concordo } \\
\text { totalmente }\end{array}$ \\
\hline $\begin{array}{l}51 \text { - Se um comprador quebrar o acordo ou desistir de comprar, é fácil vender esse } \\
\text { produto para outro comprador, sem ter prejuízo. }\end{array}$ & 01 & 02 & 03 & 04 & 05 \\
\hline 52 - Você tem certeza que esse produto sempre terá comprador. & 01 & 02 & 03 & 04 & 05 \\
\hline 53 - Na maioria das vezes planto e sei que vou conseguir vender. & 01 & 02 & 03 & 04 & 05 \\
\hline
\end{tabular}




\section{Secão 7 - Microfundamentos e identidade}

54- Em termos de movimentos sociais, eu me considero membro de:

\begin{tabular}{|c|c|c|c|c|c|}
\hline $\begin{array}{l}\text { Vou fazer algumas afirmações e gostaria que você me dissesse qual o grau de concordância } \\
\text { com cada uma delas. }\end{array}$ & $\begin{array}{l}\text { Discordo } \\
\text { totalmente }\end{array}$ & Discordo & $\begin{array}{c}\text { Não } \\
\text { concordo/ } \\
\text { nem } \\
\text { discordo }\end{array}$ & Concordo & $\begin{array}{l}\text { Concordo } \\
\text { totalmente }\end{array}$ \\
\hline 55 - A agricultura familiar é importante para o Brasil & 01 & 02 & 03 & 04 & 05 \\
\hline 56 - Sou a favor da agricultura familiar & 01 & 02 & 03 & 04 & 05 \\
\hline 57 - Sou a favor do agronegócio (grandes empresas envolvidas) & 01 & 02 & 03 & 04 & 05 \\
\hline 58 - Sou a favor da agroecologia & 01 & 02 & 03 & 04 & 05 \\
\hline 59 - Sou a favor do uso de defensivos & 01 & 02 & 03 & 04 & 05 \\
\hline 60 - Prefiro a garantia de alimento para todos os brasileiros em vez de exportação & 01 & 02 & 03 & 04 & 05 \\
\hline $\begin{array}{l}61 \text { - Os outros produtores do assentamento a que você pertence se esforçam tanto quanto você } \\
\text { na produção agrícola }\end{array}$ & 01 & 02 & 03 & 04 & 05 \\
\hline 62 - Eu busco mais aumentar minha inclusão no grupo do que melhorar o meu desempenho & 01 & 02 & 03 & 04 & 05 \\
\hline 63 - Gostaria que meus filhos continuassem trabalhando no assentamento & 01 & 02 & 03 & 04 & 05 \\
\hline
\end{tabular}

\begin{tabular}{|c|c|c|}
\hline $\begin{array}{l}\text { Vou citar algumas frases sobre o MST e sobre o assentamento e gostaria que você desse uma nota de } 0 \text { a } 10 \text {, de acordo com } 0 \\
\text { seu nível de concordância (sendo } 0 \text { - não, nem um pouco e } 10 \text { - sim, muito). Marcar apenas números inteiros. } \\
\text { Não existe resposta certa, queremos apenas que expresse sua opinião }\end{array}$ & $\begin{array}{c}\text { Nota para o } \\
\text { MST }\end{array}$ & $\begin{array}{c}\text { Nota para o } \\
\text { Assentamento }\end{array}$ \\
\hline \multicolumn{3}{|l|}{64 - Eu me vejo como um membro do grupo } \\
\hline \multicolumn{3}{|l|}{65 - Eu geralmente sinto que sou um membro útil para o grupo } \\
\hline \multicolumn{3}{|l|}{66 - Tenho muito em comum com os membros desse grupo (tenho muitas características parecidas) } \\
\hline \multicolumn{3}{|l|}{67 - No geral, o grupo é considerado bom pelas pessoas de fora } \\
\hline \multicolumn{3}{|l|}{68 - As pessoas do grupo têm muito em comum umas com as outras } \\
\hline \multicolumn{3}{|l|}{69 - Sinto que tenho uma ligação com o grupo } \\
\hline \multicolumn{3}{|l|}{70 - Me sinto comprometido com o grupo } \\
\hline \multicolumn{3}{|l|}{71 - Sou feliz por participar desse grupo } \\
\hline \multicolumn{3}{|l|}{72 - As pessoas desse grupo tem muito do que se orgulhar } \\
\hline \multicolumn{3}{|l|}{73 - Me sinto bem por participar desse grupo } \\
\hline \multicolumn{3}{|l|}{74 - O fato de ser membro desse grupo é parte importante de quem eu sou } \\
\hline 75 - Penso com frequência sobre o grupo & & \\
\hline
\end{tabular}


76- Se a liderança decide sobre uma questão eu tenho que obedecer

77- Eu sinto os problemas do grupo como se fossem meus

\section{Secão 8 - Sobre suas preferências e forma de agir}

\begin{tabular}{|l|c|c|c|}
\hline Quanto ao seu relacionamento com os seus vizinhos: & Nunca & Poucas vezes & Sempre \\
\hline 78 - Você já ajudou o seu vizinho & 01 & 02 & 03 \\
\hline 79 - Você já foi ajudado por seu vizinho & 01 & 02 & 03 \\
\hline
\end{tabular}

\begin{tabular}{|c|c|c|c|c|c|}
\hline $\begin{array}{l}\text { Vou fazer algumas afirmações e gostaria que você me dissesse qual o grau de concordância } \\
\text { com cada uma delas. }\end{array}$ & $\begin{array}{l}\text { Discordo } \\
\text { totalmente }\end{array}$ & Discordo & $\begin{array}{c}\text { Não } \\
\text { concordo/ } \\
\text { nem } \\
\text { discordo }\end{array}$ & Concordo & $\begin{array}{l}\text { Concordo } \\
\text { totalmente }\end{array}$ \\
\hline $80-$ Eu gosto de tentar coisas novas no meu lote & 01 & 02 & 03 & 04 & 05 \\
\hline 81 - Quando se trata de negócios, eu prefiro a opção mais segura & 01 & 02 & 03 & 04 & 05 \\
\hline 82 - Sempre que possível, eu cubro os riscos da produção fazendo seguros & 01 & 02 & 03 & 04 & 05 \\
\hline $\begin{array}{l}83 \text { - Quando eu tenho que tomar decisões importantes, eu busco todas as informações para estar } \\
\text { completamente inteirado do assunto }\end{array}$ & 01 & 02 & 03 & 04 & 05 \\
\hline $\begin{array}{l}84 \text { - Considero minha capacidade de gestão da atividade agropecuária superior a média dos } \\
\text { produtores rurais }\end{array}$ & 01 & 02 & 03 & 04 & 05 \\
\hline 85 - A maioria das pessoas tenta ser útil & 01 & 02 & 03 & 04 & 05 \\
\hline $86-$ A maioria das pessoas apenas olha para si mesma & 01 & 02 & 03 & 04 & 05 \\
\hline 87 - A maioria das pessoas tentaria tirar vantagem de mim se tivesse chance & 01 & 02 & 03 & 04 & 05 \\
\hline $88-$ A maioria das pessoas seria justa comigo & 01 & 02 & 03 & 04 & 05 \\
\hline 89 - Pode-se confiar nas pessoas, em geral & 01 & 02 & 03 & 04 & 05 \\
\hline 90 - Eu ajudo as pessoas em geral sem esperar contribuição & 01 & 02 & 03 & 04 & 05 \\
\hline 91 - Eu ajudo principalmente as pessoas que me ajudam em outras ocasiões & 01 & 02 & 03 & 04 & 05 \\
\hline
\end{tabular}

92- Se você ganhasse 30 mil reais, hoje, o que você faria? 
APÊNDICE B - TESTES DA REGRESSÃO LOGÍSTICA

\section{REGRESSÃO LOGÍSTICA 1}

Testes de coeficientes de modelo Omnibus

\begin{tabular}{|c|c|c|c|c|}
\hline & & Qui-quadrado & $\mathrm{df}$ & Sig. \\
\hline \multirow{3}{*}{ Etapa 1} & Etapa & 51,977 & 28 & ,004 \\
\hline & Bloco & 51,977 & 28 & ,004 \\
\hline & Modelo & 51,977 & 28 & ,004 \\
\hline \multirow{3}{*}{ Etapa $2^{a}$} & Etapa &, 000 & 5 & 1,000 \\
\hline & Bloco & 51,977 & 23 & 001 \\
\hline & Modelo & 51,977 & 23 &, 001 \\
\hline \multirow{3}{*}{ Etapa $3^{a}$} & Etapa & ,000 & 5 & 1,000 \\
\hline & Bloco & 51,977 & 18 & ,000 \\
\hline & Modelo & 51,977 & 18 &, 000 \\
\hline \multirow{3}{*}{ Etapa $4^{a}$} & Etapa & $-26,099$ & 5 &, 000 \\
\hline & Bloco & 25,878 & 13 & ,018 \\
\hline & Modelo & 25,878 & 13 & ,018 \\
\hline \multirow{3}{*}{ Etapa $5^{a}$} & Etapa &,- 109 & 3 & ,991 \\
\hline & Bloco & 25,769 & 10 & ,004 \\
\hline & Modelo & 25,769 & 10 & ,004 \\
\hline \multirow{3}{*}{ Etapa $6^{a}$} & Etapa &,- 475 & 1 & ,491 \\
\hline & Bloco & 25,294 & 9 & ,003 \\
\hline & Modelo & 25,294 & 9 & ,003 \\
\hline \multirow{3}{*}{ Etapa $7^{a}$} & Etapa & $-4,174$ & 3 & ,243 \\
\hline & Bloco & 21,120 & 6 & ,002 \\
\hline & Modelo & 21,120 & 6 &, 002 \\
\hline \multirow{3}{*}{ Etapa $8^{a}$} & Etapa &,- 021 & 1 & ,886 \\
\hline & Bloco & 21,099 & 5 & ,001 \\
\hline & Modelo & 21,099 & 5 &, 001 \\
\hline
\end{tabular}

Resumo do modelo

\begin{tabular}{|l|r|r|r|}
\hline Etapa & $\begin{array}{r}\text { Verossimilhanç } \\
\text { a de log }-2\end{array}$ & $\begin{array}{r}\text { R quadrado Cox } \\
\text { \& Snell }\end{array}$ & $\begin{array}{r}\text { R quadrado } \\
\text { Nagelkerke }\end{array}$ \\
\hline 1 &, $000^{\mathrm{a}}$ &, 379 & 1,000 \\
2 &, $000^{\mathrm{a}}$ &, 379 & 1,000 \\
3 &, $000^{\mathrm{a}}$ &, 379 & 1,000 \\
4 & $26,099^{\mathrm{a}}$ &, 211 &, 557 \\
5 & $26,208^{\mathrm{a}}$ &, 211 &, 555 \\
6 & $26,683^{\mathrm{a}}$ &, 207 &, 546 \\
7 & $30,857^{\mathrm{b}}$ &, 176 &, 464 \\
8 & $30,878^{\mathrm{b}}$ &, 176 &, 464 \\
\hline
\end{tabular}


Teste de Hosmer e Lemeshow

\begin{tabular}{|l|r|r|r|}
\hline Etapa & Qui-quadrado & df & Sig. \\
\hline 1 &, 000 & 8 & 1,000 \\
2 &, 000 & 8 & 1,000 \\
3 &, 000 & 8 & 1,000 \\
4 & 2,240 & 8 &, 973 \\
5 & 2,383 & 8 &, 967 \\
6 & 1,905 & 8 &, 984 \\
7 & 4,695 & 8 &, 790 \\
8 & 4,735 & 8 &, 786 \\
\hline
\end{tabular}

Tabela de classificação ${ }^{a}$

\begin{tabular}{|c|c|c|c|c|c|}
\hline \multirow{2}{*}{\multicolumn{3}{|c|}{ Observado }} & \multicolumn{3}{|c|}{ Previsto } \\
\hline & & & \multicolumn{2}{|c|}{ Mec_gov } & \multirow{2}{*}{$\begin{array}{l}\text { Porcentagem } \\
\text { correta }\end{array}$} \\
\hline & & & 0 & 1 & \\
\hline \multirow{3}{*}{ Etapa 1} & \multirow{2}{*}{ Mec_gov } & 0 & 102 & 0 & 100,0 \\
\hline & & 1 & 0 & 7 & 100,0 \\
\hline & \multicolumn{2}{|c|}{ Porcentagem global } & & & 100,0 \\
\hline \multirow{3}{*}{ Etapa 2} & \multirow{2}{*}{ Mec_gov } & 0 & 102 & 0 & 100,0 \\
\hline & & 1 & 0 & 7 & 100,0 \\
\hline & \multicolumn{2}{|c|}{ Porcentagem global } & & & 100,0 \\
\hline \multirow{3}{*}{ Etapa 3} & \multirow{2}{*}{ Mec_gov } & 0 & 102 & 0 & 100,0 \\
\hline & & 1 & 0 & 7 & 100,0 \\
\hline & \multicolumn{2}{|c|}{ Porcentagem global } & & & 100,0 \\
\hline \multirow{3}{*}{ Etapa 4} & \multirow{2}{*}{ Mec_gov } & 0 & 100 & 2 & 98,0 \\
\hline & & 1 & 6 & 1 & 14,3 \\
\hline & \multicolumn{2}{|c|}{ Porcentagem global } & & & 92,7 \\
\hline \multirow{3}{*}{ Etapa 5} & \multirow{2}{*}{ Mec_gov } & 0 & 99 & 3 & 97,1 \\
\hline & & 1 & 6 & 1 & 14,3 \\
\hline & \multicolumn{2}{|c|}{ Porcentagem global } & & & 91,7 \\
\hline \multirow{3}{*}{ Etapa 6} & \multirow{2}{*}{ Mec_gov } & 0 & 100 & 2 & 98,0 \\
\hline & & 1 & 6 & 1 & 14,3 \\
\hline & \multicolumn{2}{|c|}{ Porcentagem global } & & & 92,7 \\
\hline \multirow{3}{*}{ Etapa 7} & \multirow{2}{*}{ Mec_gov } & 0 & 100 & 2 & 98,0 \\
\hline & & 1 & 6 & 1 & 14,3 \\
\hline & \multicolumn{2}{|c|}{ Porcentagem global } & & & 92,7 \\
\hline \multirow{3}{*}{ Etapa 8} & \multirow{2}{*}{ Mec_gov } & 0 & 100 & 2 & 98,0 \\
\hline & & 1 & 6 & 1 & 14,3 \\
\hline & \multicolumn{2}{|c|}{ Porcentagem global } & & & 92,7 \\
\hline
\end{tabular}




\section{REGRESSÃO LOGÍSTICA 2}

Testes de coeficientes de modelo Omnibus

\begin{tabular}{|c|c|c|c|c|}
\hline & & Qui-quadrado & $\mathrm{df}$ & Sig. \\
\hline \multirow{3}{*}{ Etapa 1} & Etapa & 45,686 & 17 & ,000 \\
\hline & Bloco & 45,686 & 17 & ,000 \\
\hline & Modelo & 45,686 & 17 &, 000 \\
\hline \multirow{3}{*}{ Etapa $2^{\mathrm{a}}$} & Etapa & $-1,231$ & 3 & ,746 \\
\hline & Bloco & 44,455 & 14 & ,000 \\
\hline & Modelo & 44,455 & 14 &, 000 \\
\hline \multirow{3}{*}{ Etapa $3^{a}$} & Etapa & $-6,530$ & 5 & ,258 \\
\hline & Bloco & 37,925 & 9 & ,000 \\
\hline & Modelo & 37,925 & 9 & ,000 \\
\hline \multirow{3}{*}{ Etapa $4^{a}$} & Etapa & $-1,404$ & 1 & ,236 \\
\hline & Bloco & 36,521 & 8 &, 000 \\
\hline & Modelo & 36,521 & 8 &, 000 \\
\hline \multirow{3}{*}{ Etapa $5^{a}$} & Etapa & $-2,022$ & 1 & , 155 \\
\hline & Bloco & 34,499 & 7 & ,000 \\
\hline & Modelo & 34,499 & 7 & ,000 \\
\hline \multirow{3}{*}{ Etapa $6^{a}$} & Etapa & $-14,482$ & 5 & ,013 \\
\hline & Bloco & 20,017 & 2 & ,000 \\
\hline & Modelo & 20,017 & 2 & ,000 \\
\hline
\end{tabular}

Resumo do modelo

\begin{tabular}{|l|r|r|r|}
\hline Etapa & $\begin{array}{r}\text { Verossimilhanç } \\
\text { a de log }-2\end{array}$ & $\begin{array}{r}\text { R quadrado Cox } \\
\text { \& Snell }\end{array}$ & $\begin{array}{l}\text { R quadrado } \\
\text { Nagelkerke }\end{array}$ \\
\hline 1 & $86,275^{\mathrm{a}}$ &, 342 &, 488 \\
2 & $87,506^{\mathrm{a}}$ &, 335 &, 477 \\
3 & $94,036^{\mathrm{a}}$ &, 294 &, 419 \\
4 & $95,439^{\mathrm{a}}$ &, 285 &, 406 \\
5 & $97,461^{\mathrm{a}}$ &, 271 &, 386 \\
6 & $111,944^{\mathrm{b}}$ &, 168 &, 239 \\
\hline
\end{tabular}

Tabela de classificação

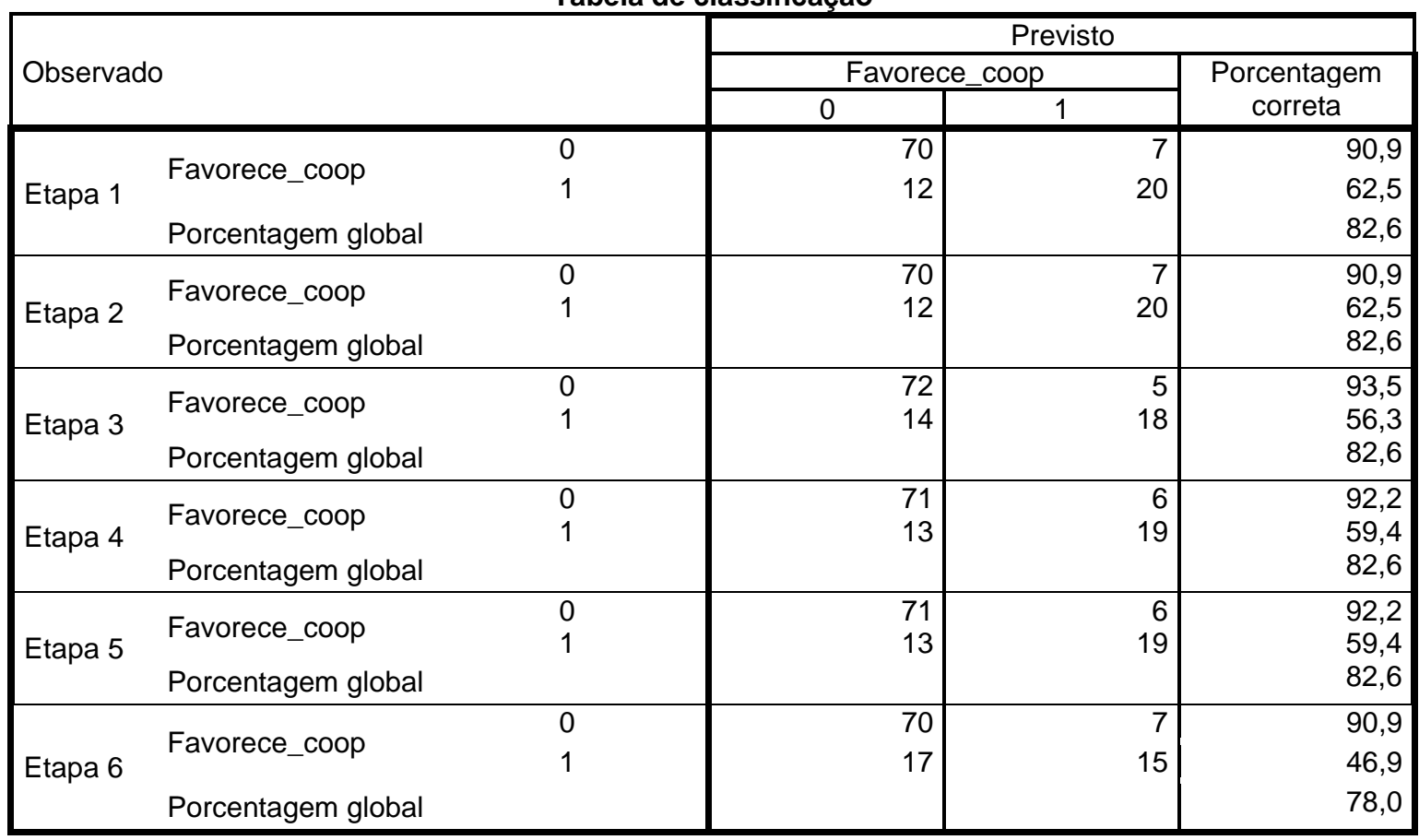




\section{APÊNDICE C - DECLARAÇÃo DE AUTORIZAÇÃO DE PESQUISA}

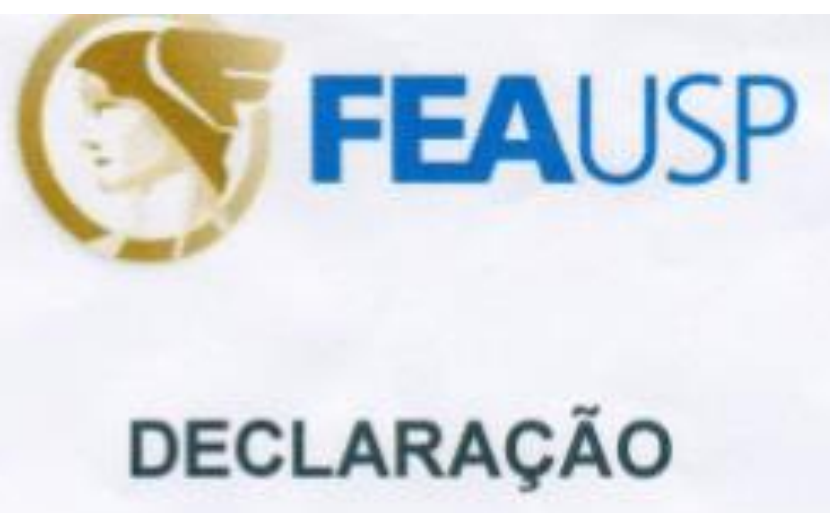

Eu, SEBASTIÃO ARANHA, declaro que autorizo o uso das informaçø̄es obtidas dos produtores do Assentamento Pirituba II, em trabalhos, assim como teses, artigos e livros, provenientes do estudo intitulado "A LOGICA NAS ESCOLHAS DOS MECANISMOS DE GOVERNANÇA: A INFLUÊNCIA DA IDENTIDADE SOCIAL: A pesquisadora responsável pelo estudo é a aluna de doutorado CAROLINE FOSCACHES DE OLIVEIRA QUEVEDO, do Programa de PósGraduação em Administração (PPGA) da Universidade de São Paulo, $n^{\circ}$ USP: 8240799, que pode ser contatada pelo e-mail carolinefoscaches@usp.br. A pesquisa é realizada sob a orientação e responsabilidade da Professora $\mathrm{Dr}^{*}$ MARIA SYLVIA MACCHIONE SAES, também da Faculdade de Economia, Administração e Contabilidade da Universidade de São Paulo. As responsáveis pela pesquisa assumem o compromisso de compartilhar o material produzido antes de sua publicaçăo e de não divulgar informaçōes que năo estejam de acordo com a politica de privacidade do assentamento.

Săo Paulo, 23 de julho de 2015.

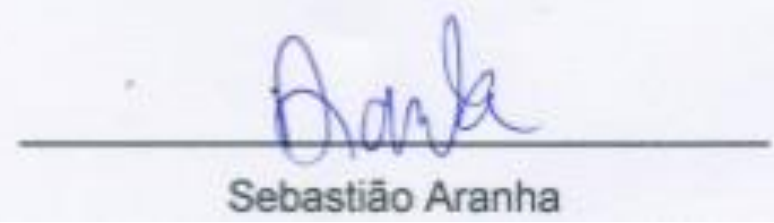

